THE UNIVERSITY OF MANITOBA

Effects of Oxygen Tension on the Lipid

Composition of Azotobacter chroococcum

by

EDWARD B. RECZER

A Thesis

Submitted to the Faculty of Graduate Studies

In Partial Fulfilment of the Requirements

For the Degree of Master of Science

\author{
Department of Microbiology \\ Winnipeg, Manitoba \\ October, 1977.
}

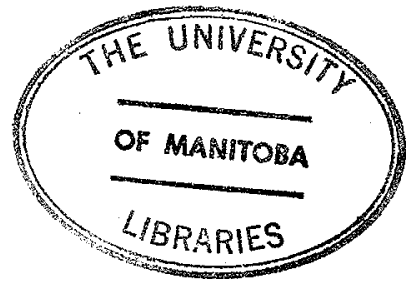




\section{EFFECTS OF OXYGEN TENSION ON THE LIPID \\ COMPOSITION OF AZOTOBACTER CHROOCOCCUM}

BY

EDWARD B. RECZEK

A dissertation submitted to the Faculty of Graduate Studies of the University of Manitoba in partial fulfillment of the requirements of the degree of

MASTER OF SCIENCE

(C). 1977

Permission has been granted to the LIBRARY OF TIIL UNIVERSITY OF MANITOBA to lend or sell copies of this dissertation, to the NATIONAL LIBRARY OF CANADA to microfilm this dissertation and to lend or sell copies of the film, and UNIVERSITY MICROFILMS to publish an abstract of this dissertation.

The author reserves other publication rights, and neither the dissertation nor extensive extracts from it may be printed or otherwise reproduced without the author's written permission. 
To my wife Sharon and my. parents. 


\section{ACKNOWLEDGEMENTS}

The author wishes to express his sincere appreciation to Dr. D.N. Burton for his advice and criticism which helped to make these studies successful ard rewarding. The author also wishes to thank $\mathrm{Dr}$. H. Lees for assistance with the continuous culture and Mrs. R. Gillespie for the electron microscopy.

Special thanks are also extended to the staff and graduate students of the Department of Microbiology, especially to A. Tsim, D. Dawson, S. Byrne and P. Hine for their helpful assistance. 
ABSTRACT

Azotobacter chroococcum ATCC 7493 was grown in continuous cultures at vortex agitation rate (1750 r.p.m.), under $\mathrm{N}_{2}$-fixing conditions and in the presence of various concentrations of oxygen in the incoming air supply. The cultures were allowed to reach a steadystate (stabilized condition) for three days and the lipid composition and uptake of $\mathrm{U}^{14} \mathrm{C}$-acetate were studied. Cell yield was found to vary widely with changing oxygen tension as was the amount of extracellular polysaccharide and cellular debris harvested with the pellet of whole cells. Total lipid averaged $8.9 \%$ of the dry weight of the cells and remained quite constant with varying oxygen tension. The composition of the total lipid fraction was found to vary depending on the oxygen tension - at oxygen tensions greater than $20 \% 0_{2}$, the amount of phospholipid decreased and the amount of neutral lipid increased. Examination of individual lipid classes indicated a phospholipid fraction consisting solely of phosphatidylethanolamine and a neutral lipid fraction which contained free fatty acids plus two unidentified components. Fatty acids detected were $C_{16: 0}, C_{16: 1}$ and $C_{18: 1}$, together with other minor components. Higher oxygen tensions favored the replacement of $C_{16: 1}$ with increasing amounts of $C_{18: 1}$, most notably in the free fatty acid fraction. This may indicate an attempt to regulate the fluidity of the membrane. Incorporation experiments carried out with $\mathrm{U}^{14} \mathrm{C}$-acetate indicate a precursor-product relationship 
may exist between the free fatty acids of the neutral lipid fraction and the phospholipid fraction. Possible implications of the changes in the composition of total lipids with varying oxygen tension and respiratory protection are discussed. 
TABLE OF CONTENTS

PAGE

ACKNOWLEDGEMENTS. . . . . . . . . . . . . . . . . . iii

Abstract ......................... . iv

TABLE OF CONTENTS ........................ . . vi

List of tables . . . . . . . . . . . . . . . . ix

List of figures. . . . . . . . . . . . . . . . . x INTRODUCTION. . . . . . . . . . . . . . . . . . 1

Models of Membrane Structure . . . . . . . . . . 4

Structure of Nitrogenase................ . 7

Reactions Catalyzed by Nitrogenase . . . . . . . . 9

Control of Enzyme Biosynthesis . . . . . . . . . . 13

Control of Nitrogenase Activity. . . . . . . . . 16

Effect of Oxygen on Nitrogenase. . . . . . . . . . 17

Theory of Continuous Culture . . . . . . . . . . 19

Membranous vesicles of Azotobacter . . . . . . . . 23

Introduction to Work in this Thesis. . . . . . . . . 29

MATERIALS AND METHODS . . . . . . . . . . . . . . . . 31

Materials................... 32

Organism . . . . . . . . . . . . . . . . 32

Chemicals and Radiochemicals . . . . . . . . . . 32

Continuous Culture Apparatus . . . . . . . . . . . 32 
Sampling Procedure. ................ 33

Preparation of Lyophilized Bacteria . . . . . . . . . 33

Extraction of Total Lipids. . . . . . . . . . . . 34

Column Chromatography of Total Lipid Extract. . . . . . . 35

Extraction of Free Fatty Acids from Neutral Lipid

Fractions . . . . . . . . . . . . . 36

Incorporation of $\mathrm{U}-{ }^{14} \mathrm{C}$-Acetate Into Azotobacter 1ipid . . . 36

Scintillation counting. . . . . . . . . . . . 38

Thin Layer Chromatography . . . . . . . . . . . 38

Solvent Systems for Thin Layer Chromatography . . . . . . 38

Preparation of Thin Layer Plates. . . . . . . . . . . 38

Sample Application. . . . . . . . . . . . . 39

Development . . . . . . . . . . . . . . 39

Separation of Phospholipid Components . . . . . . . . 40

Gas Chromatography of Fatty Acids . . . . . . . . . . 40

Preparation of Fatty Acid Methyl Esters . . . . . . . . 41

RESULTS. . . . . . . . . . . . . . . . 43

Changes in Cell Yield During Growth at Different

Oxygen Tensions . . . . . . . . . . . . . . . 44

Changes in Total Lipid During Changes in Oxygen

Tension . . . . . . . . . . . . . . . 47 
Table of Contents Cont'd...

PAGE

Changes in Composition of Total Lipid During

Changes in Oxygen Tension. . . . . . . . . . . . 47

Detailed Chromatographic Analysis of Azotobacter 1ipids. . . 50

Thin Layer Chromatography of ${ }^{14} \mathrm{C}$ Labelled Lipids . . . . . . 56

Fatty Acid Composition of Azotobacter lipids . . . . . . 59

Incorporation of $1-{ }^{14} \mathrm{C}$-Acetate into Lipid by

A. Chroococcum During Growth Under Different Oxygen

Tensions . . . . . . . . . . . . . . 72

DISCUSSION. . . . . . . . . . . . . . . . . 77

REFERENCES. . . . . . . . . . . . . . . . . 87 
LIST OF TABLES

PAGE

Table I. Changes in cell yield with increasing oxygen tension. . . . . . . . . . . 45

Table II. Fatty acid composition of lipid classes obtained from A. chroococcum during growth under different oxygen tensions... . . . . 65

Table III. Fatty acid composition of lipid classes obtained from A. chroococcum during growth under different oxygen tensions. . . . . 66 
LIST OF FIGURES

PAGE

Figure 1. Reaction scheme for Nitrogenase. . . . . . . . 11

Figure 2. Influence of dilution rate on the steady state concentration of organisms in a chemostat culture. . . . . . . . . 24

Figure 3. Electron micrography (8000x) of gummy polysaccharide layer containing cells, cellular debris and polysaccaride . . . . . . . . 46

Figure 4. Changes in lipid content of Azotobacter

chroococcum during changes in oxygen tension . . . 48

Figure 5. Influence of oxygen tension on the composition of total lipids of A. chroococcum. . . . . . .

Figure 6. Typical thin layer chromatogram of silicic acid column fractions of $\underline{A}$. chroococcum total lipids............... 51

Figure 7. Thin layer chromatogram of A. chroococcum neutral lipids from cells grown under different oxygen tensions. . . . . . . . . . . 53 
Figure 8. Thin layer chromatogram of phospholipid fractions obtained from A. chroococcum grown under different oxygen tensions. . . . . 54

Figure 9. Thin layer chromatogram of phospholipid fraction of $\mathrm{A}$. chroococcum lipid . . . . . . . 55

Figure 10. Thin layer chromatogram of neutral lipid minus free fatty acid (NLMF) fractions obtained from A. chroococcum cells grown under varying oxygen tensions. . . . . . . 57

Figure 11. Thin layer chromatogram of sodium carbonate extract of neutral lipids of $\underline{A}$. chroococcum cells grown under different oxygen tensions. . . 58 .

Figure 12. Autoradiogram of thin layer chromatogram of neutral lipid fraction extracted from cells grown in $\mathrm{J}^{14} \mathrm{C}$-acetate ........... 60

Figure 13. Autoradiogram of thin layer chromatogram of phospholipid fraction extracted from cells grown in $\mathrm{U}^{14} \mathrm{C}$-acetate ............ 61 
Figure 14. Plot of $10 \mathrm{~g}$ of relative retention time for various fatty acid methyl esters versus chain length. . . . . . . . . . . . 63

Figure 15. Gas chromatographic identification of total fatty acids obtained from total lipid fraction extracted from cells grown under $40 \%$ oxygen. . . . . . . . . . . . . . 64

Figure 16. Changes in major constituents of free fatty acid fraction during growth under different oxygen tensions . . . . . . . . . . . . 68

Figure 17. Changes in major constituents of neutral lipid minus free fatty acid fraction during growth under different oxygen tensions ......... 69

Figure 18. Changes in major constituents of phospholipid fraction during growth under different oxygen tensions. . . . . . . . . . . . . . . 70

Figure 19. Changes in major constituents of total lipid extract obtained from A. chroococcum during growth under different oxygen tensions . . 71 
Figure 20. Uptake of $\mathrm{U}-{ }^{14} \mathrm{C}$-acetate into total lipid

fraction of $\underline{A}$. chroococcum grown under

varying oxygen tensions. ......... 73

Figure 21. Uptake of $\mathrm{U}^{14} \mathrm{C}$-acetate into individual

lipid classes of $\underline{A}$. chroococcum during

growth under $20 \% \mathrm{o}_{2} \ldots \ldots \ldots$

Figure 22. Uptake of $\mathrm{U}^{14} \mathrm{C}$-acetate into individual lipid

classes of $\underline{A}$. chroococcum during growth

under $20 \% \mathrm{o}_{2} \ldots \ldots \ldots . \ldots . \ldots 75$ 
INTRODUCTION 
INTRODUCTION

Today, one does not question the existence of membranes but rather accepts their existence as fact. Yet it was not until the late 1950s that the plasma membrane was accepted as a structural entity and the older idea that the boundary between the outside environment and the cell was merely an interphase between two continuous phases was found untenable. Biological membranes have been isolated in a purified form, weighed, fractionated, analyzed, photographed and studied by an almost infinite number of techniques.

The fact that membranes contain large amounts of lipid distinguishes them from most other cellular structures. The study of membranes has concentrated on the study of their lipid components, since they seemed most involved in restricting the passage of water soluble materials. Yet lipids are rather difficult to handle; they are water insoluble and at times, even today, remain difficult to obtain in a high degree of purity. The emergence in the 1950s and 1960s of powerful and yet simple tools to investigate the physical and biochemical properties of these molecules was an equally important reason for concentrating study on membrane lipids. The refinement of column chromatographic techniques using silicic acid and other support materials in the mid 1950s permitted the isolation of comparatively large amounts of pure lipids, and the use of thin-layer chromatography allowed their rapid and accurate identification. Gas chromatography of lipids was developed in the same period thus permitting the identification and quantitation of 
fatty acid and other hydrocarbon components of membrane lipids. Also, about this time, lipid chemists developed techniques for the synthesis of phospholipids (Van Deenen and de Haas, 1964). The revolution in the techniques of lipid chemistry and the availability of natural and synthetic lipids of suitable purity made possible an accurate survey of lipid composition and structure in various organs and tissues and in a wide variety of microorganisms. Of late, studies of membrane structure have been attempted using associations between various membrane components (Bangham, 1972, Razin, 1972, Vail et al., 1974, Segrest, 1974, Gulik-Krzywicki, 1975, Eytan et al., 1976 and Tyrrel1, 1976). However, in spite of the massive amounts of data which have been accumulated regarding membrane structure and function, it is still quite difficult to give a simple definition of a biological membrane. However, the following definition may be widely agreed upon:

Biological membranes are continuous structures which serve to separate two aqueous phases. They are relatively impermeable to water soluble compounds, contain large amounts of lipids and proteins and show a characteristic three-layered appearance when fixed sections are examined by electron microscopy.

No longer may we think of membranes as being simple structures. They have been found to vary in composition, structure and function from one species to another, from cell to cell and from organelle to organelle within a cell. To attempt to describe membrane anatomy with simple molecular models would be naive indeed. Nevertheless, 
models do provide a foundation upon which we can shape and reshape further thoughts on the subject. It is now thought that, excepting some highly specialized parts of membranes such as cell and synaptic junctions, most biological membranes may be visualized as a twodimensional viscous liquid (Gulik-Krzywicki, 1975). They are very thin objects, about $100 \AA$ thick, essentially composed of lipids and proteins. Under those conditions found in the cell, most, if not all membrane lipids diffuse fairly freely in the plane of the membrane (Linden et al., 1973, Shimshick and McConne11, 1973, Wunderlick, 1973, Torres-Pereira et al., 1974 and $\mathrm{Li}$ and Fox, 1975) but extremely slowly from one side of the membrane to the other, a property which presumably maintains the asymmetry of the membrane. A great deal of work has been done in investigating the physiological consequences to the different components of the membrane of manipulating membrane 1ipids (Cronan and Vagelos, 1972, Linden et al., 1973, Overath and Trauble, 1973, 1973 Morrisett et al., 1975 and Birchmeier et al., 1976).

Models of Membrane Structure

There have been many models of membrane structure proposed through the years (Gorter and Grendel, 1925, Danielli and Davson, 1935, Robertson, 1959, Cook, 1971, Singer, 1971 and Finean, 1972). The model of membrane structure which is currently "in vogue" may be called the fluid mosaic model of alternating globular protein and phospholipid bilayer proposed simultaneously by Lenard and Singer and by Wallach 
and Zahler in 1966. The phospholipids are arranged as a discontinuous bilayer with their ionic and polar heads in contact with the bulk aqueous phase and with their non-polar side chains separated from the aqueous phase. Some membrane proteins are superficially bound to the membrane surface (peripheral membrane proteins), while others (integral membrane proteins) are embedded in the lipid matrix and can even span the whole membrane (Singer and Nicolson, 1972).

In addition to thermodynamic considerations, this model is consistent with data obtained experimentally. For example, the proposal of the fluid mosaic model that an integral protein is a globular molecule embedded in the membrane is supported by freeze-etching studies that show a smooth surface interrupted by a large number of particles (Bayer and Remsen, 1970). Numerous other virtues of this model have been extolled in various articles and reviews on membrane structure (Singer, 1971, Singer and Nicolson, 1972, Singer, 1974, Quinn, 1976 and Salton and Owen, 1976).

It would be an understatement to say that today, membranes have been implicated in a wide variety of cellular processes. In addition to being responsible for maintaining cell integrity, the outer surface of the membrane may serve as a repository for the various molecular species the cell requires to receive and respond to external stimuli. An obvious example would be the receptor sites for hormones and their action through the membrane bound enzyme adenyl cyclase. Some evidence that lipids of the membrane are involved in modulating catalytic 
activity by hormone binding has been obtained (Puchwein et al., 1974). In eukaryotic cells, subcellular compartments and the membranous structures of which they are made are also concerned with the regulation of metabolic reactions. Examples of the relationship between different metabolic compartments and substrate pools in the liver cell have been reviewed (Gumaa et al., 1974). 'In prokaryotes, such cellular compartmentalization is lacking. Thus, all functions which in plant and animal cells are distributed among specialized membrane structures are connected in bacteria with the cytoplasmic membrane and systems of internal membranes such as the mesosomes. Taking place in the membrane of bacteria are such processes as electron transfer in the respiratory chain, the transformation of energy during photosynthesis, the transport of ions and metabolites into and/or out of the cell and the synthesis of phospholipids, cell wall components and other substances. The bacteria membrane is also concerned with such complicated processes as division, sporulation and cyst formation (Gronan and Gelman, 1975 and Gel'man et al., 1975).

In view of the complex functions carried out by membrane components, it should not be surprising to find a requirement for certain lipids in the activity of many membrane bound enzymes. It is now known that generally, enzyme activity is lost when lipid is removed from an enzyme system and is restored when lipid is added back. An example of this is the dependence of membrane transport enzymes on the condition of the lipids comprising the membrane. For instance, it was found that the rate-temperature profile of lactose transport could be altered 
by supplementing unsaturated fatty acid auxotrophs of E. coli with various unsaturated fatty acids (Wilson et al., 1970).

In another example, an oxygen insensitive nitrogenase preparation of Azotobacter vinelandii was obtained from cells which had been disrupted by a French pressure cell (Bulen, Burns and LeComte, 1964 and Hardy and Knight, 1966). This extract was sedimentable by centrifugation which suggested that it was particulate. Further purification of crude nitrogenase conferred upon it sensitivity to oxygen, which necessitated the maintenance of anaerobic conditions during purification (Bulen and LeComte, 1966).

\section{Structure of Nitrogenase}

Work on nitrogen fixation was restricted to whole cells until 1960 when suitably supplemented extracts of Clostridium pasteurianum were made to fix nitrogen (Carnahan et al., 1960). Today, after a decade or more of work during which great amounts of biological and biochemical data were compiled, the trend in nitrogenase research is towards biophysical methods. X-ray diffraction studies will be possible once larger crystals are obtained than have been at present (Burns, Holsten and Hardy, 1970). The presence of transition metals in nitrogenase makes electron paramagnetic resonance spectroscopy a useful technique. Mössbauer spectroscopy has been used in the study of isotope-enriched ${ }^{57}$ Fe samples (Münck et al., 1975).

Although nitrogenases have now been obtained from a wide variety of organisms, they are all quite similar (but not necessarily identical) 
in structure. However, components of nitrogenase from one organism will quite often cross-react with components from others to yield a functional enzyme (Eady and Postgate, 1974). Nitrogenase is a multi-subunit ironsulfur and molybdenum-containing protein. Both a molybdenum-iron protein, containing acid-labile sulfur (molybdoferredoxin, component or fraction I, Kpl or azofermo) and an iron protein, containing labile sulfur (azoferredoxin, component or fraction II, Kp2 or azofer) are required for the reduction of nitrogen.

The molybdoferredoxin of Klebsiella and Clostridium is a tetrameric complex consisting of two molecules of each of two types of subunits of 50,000 and 60,000 MW (Eady et al., 1972, Huang et al., 1973 and Tso, 1974). Klebsiella molybdoferrodixin contains $17 \mathrm{Fe}$ atoms, 17 atoms of sulfur and about 1.2 Mo atoms per 218,000 MW (Eady et al., 1972). Clostridial molybdoferredoxin contains 12-18 atoms of $\mathrm{Fe}, 8-15$ atoms of acid labile sulfur and 2 Mo atoms per molecule of 210,000 MW (Tso, 1974). Molybdoferredoxin from Azotobacter vinelandii was reported to contain two types of subunits (Shah and Brill, 1973), but more recent work indicates that all of the subunits are of the same size (Kleiner and Chen, 1974 and Yates and Planque, 1975). Molybdoferredoxin from Azotobacter chroococcum contains one subunit type (Yates and Planqué, 1975) of $60,000 \mathrm{MW}$ and yielded 23 atoms of Fe, 20 atoms of acid-1abile sulfur and 1.9 atoms of Mo per molecule. Chen et al., (1973) showed that the amino acid compositions of molybdoferredoxin proteins of Azotobacter, Klebsiella and Clostridium to be very similar, except for the tryptophan content of Clostridium which is much less than that of the others. 
On the other hand, azoferredoxins of $\underline{\mathrm{c}}$. pasteurianum and $\underline{\mathrm{K}}$. pneumoniae exist as dimers with identical subunits and differ only in their molecular weights; $56,000 \mathrm{MW}$ for the former, 66,800 MW in the case of the latter (Tso, 1974 and Eady et al., 1972). The azoferridoxin of A. chroococcum also consists of two identical subunits of 30,800 MW each (Yates and P1anque, 1975). An interesting feature of the amino acid compositions of the azoferredoxins is that they all lack trypotophan (Eady et al., 1972, Kleiner and Chen, 1974 and Yates and Planqué, 1975). Otherwise, the contents of the other amino acids are quite similar. The azoferredoxins of both Klebsiella and Clostridium contain 4 iron atoms and 4 acid-labile sulfur atoms (Eady et al., 1972), as do those of Azotobacter chroococcum (Yates and Planque, 1975). Most work with nitrogenase has been done with components of the complex. It would be advantageous - to work with an intact nitrogenase complex, as did Bulen and LeComte (1972). One would then be able to compare data obtained from such a complex with that obtained from reconstituted enzyme systems.

\section{Reactions Catalyzed by Nitrogenase}

Nitrogenase preparations, when provided with ATP, are not monospecific but will reduce a wide range of substrates under anaerobic conditions. Most are structurally related to nitrogen in that they have a pair of triply bonded atoms situated terminally on the molecule. Some of these substrates may be gaseous $\left(\mathrm{N}_{2} \mathrm{O}\right.$ and acetylene), some are organic molecules (nitriles, isonitriles and substituted acetylenes) and some are anions 
$\left(\mathrm{CN}^{-}, \mathrm{N}_{3}^{-}\right)$. In the absence of any of these $\mathrm{H}_{2} \mathrm{O}\left(\mathrm{H}^{+}\right)$serves as the substrate. $\mathrm{H}_{2}$ and $\mathrm{CO}$ both inhibit the action of nitrogenase (Zumft and Mortenson, 1975). Both molybdoferredoxin and azoferredoxin must be present in the correct ratios and enzyme activity will be seen to rise with increasing molybdoferredoxin concentration followed by a slow decrease at low ratios of azoferredoxin to molybdoferredoxin (Bui and Mortenson, 1969, Vandecastelle and Burris, 1970 and Eady et al., 1972). In addition, magnesium, ATP and a reductant are al1 required. In vitro, ferredoxins or the flavodoxin of Azotobacter or artificial electron donors such as sodium dithionite (Watt and Burns, 1977) may serve as the reductant. The energy requirement of the reaction is met by hydrolysis of ATP to ADP and inorganic phosphate. Since ADP is inhibitory to nitrogenase and $\mathrm{ADP}$ and inorganic phosphate are the products of ATP utilization by nitrogenase, an ATP generating system should be included in the assay mix (Dalton and Mortenson, 1972).

The reactions taking place as nitrogenase catalyzes the reduction of substrates are summarized in Figure 1. Electrons are first donated from ferredoxin to oxidized azoferredoxin to yield reduced azoferredoxin. MgATP $^{-2}$ may bind to the reduced azoferredoxin:

$$
\begin{aligned}
& \mathrm{Fe}_{2}{ }^{\mathrm{R}}+2 \mathrm{MgATP}^{-2} \longrightarrow \mathrm{Fe}_{2}{ }^{\mathrm{R}} \cdot \text {.MgATP } \\
& \left(\mathrm{Fe}_{2}{ }^{\mathrm{R}} \text { denotes reduced state of azoferredoxin }\right)
\end{aligned}
$$

ATP is not hydrolyzed until the reduced azoferredoxin $\mathrm{MgATP}^{-2}$ complex 


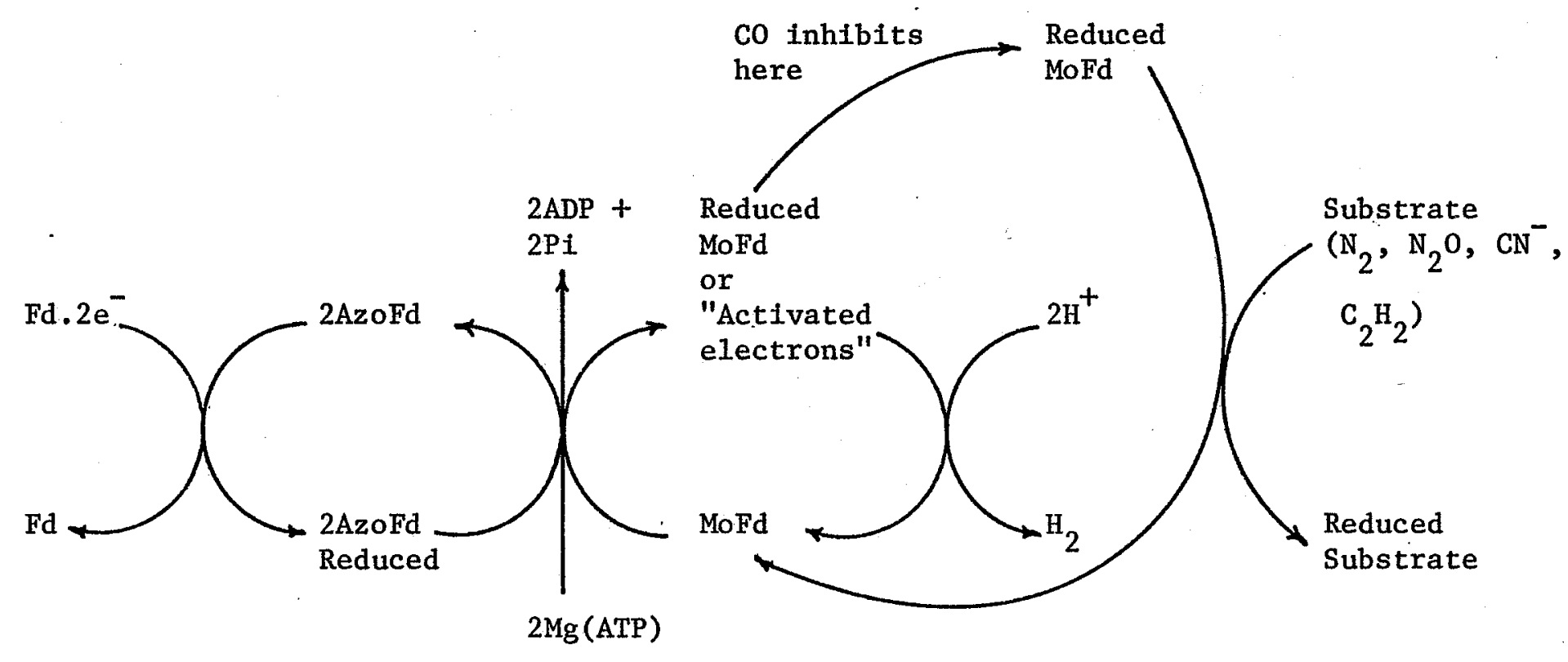

Figure 1. Reaction Scheme for Nitrogenase

$$
\begin{aligned}
\text { Fd } & =\text { Ferredoxin } \\
\text { AzoFd } & =\text { Azoferredoxin } \\
\text { MoFd } & =\text { Molybdoferredoxin }
\end{aligned}
$$


combines with molybdoferredoxin:

$$
\begin{aligned}
& {\mathrm{Mo}-\mathrm{Fe}_{2}}_{2}+\mathrm{Fe}_{2}{ }^{\mathrm{R}} \cdot 2 \mathrm{MgATP} \longrightarrow \mathrm{Mo}_{2} \mathrm{Fe}_{2} \mathrm{IFe}_{2}{ }^{\mathrm{R}} \cdot 2 \mathrm{MgATP}
\end{aligned}
$$

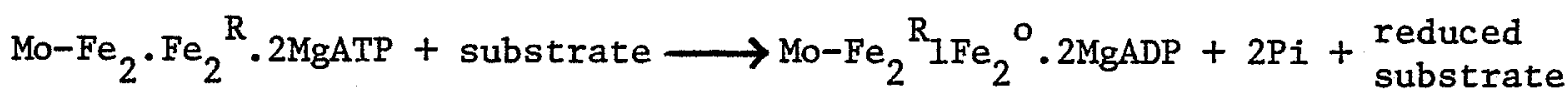

Electrons are also transferred to molybdoferredoxin from azoferredoxin. The fully reduced molybdoferredoxin is now capable of reducing substrates, but not without the presence of azoferredoxin (Zumft and Mortenson, 1975). Electrons flow from substrate oxidation through ferredoxin to azoferredoxin, to molybdoferredoxin then to the substrate undergoing reduction. However, few details concerning the specific steps in the reaction are available. The reaction has never been reversed. No enzyme - free intermediate such as diazine or hydrazine has been found; added in situ they are not reduced (Hardy et al., 1975). Also $\mathrm{H}^{+}$is a competitive inhibitor of the nitrogenase reaction (Zumft et al., 1975).

A major problem in performing kinetic studies on the nitrogenase is the fact that one reducible substrate, $\mathrm{H}^{+}$, is always present. Kinetic studies of all substrates other than $\mathrm{H}^{+}$must take into account the fact that $\mathrm{H}^{+}$may be reduced to $\mathrm{H}_{2}$. Hadfield and Bulen (1969) found the ratio of $\mathrm{H}_{2}$ produced to $\mathrm{N}_{2}$ reduced increased from 1.46 at $100 \% \mathrm{~N}_{2}$ to 17.7 at $25 \% \mathrm{~N}_{2}-75 \% \mathrm{H}_{2}$. If a substrate is not available, nitrogenase will reduce $\mathrm{H}^{+}$in the presence of ATP to form hydrogen gas. This ATP dependent hydrogen evolution was earlier used as an assay for 
nitrogenase activity; it was absent from bacteria which had been grown in media containing fixed nitrogen. The reduction of acetylene by nitrogenase was discovered by Dilworth (1966) and by Schö11horn and Burris (1967). More recently, it is this reduction of acetylene to ethylene which has been used to determine nitrogenase activity. This reaction is a specific property of nitrogenase - no other known biological system performs this reaction.

Despite the fact that, theoretically, nitrogen fixation should be exothermic, ATP is required for the reaction. Hadfield and Bulen (1969) showed that 15 ATP were hydrolyzed per electron pair transferred to the substrate of the nitrogenase, measured between $\mathrm{pH} 7$ and 8 and at a temperature of $30^{\circ} \mathrm{C}$. The stoichiometry of the reaction was shown to be $\mathrm{pH}$ sensitive (Bui and Mortenson, 1969) and temperature sensitive (Hadfield and Bulen, 1969), but was independent of the substrate type or concentration (Hadfield and Bulen, 1969). The reason why ATP is required is not clear. ATP may induce a conformational change in azoferredoxin, creating a species able to reduce the substrate (Zumft et al., 1973). Alternately, ATP may act as an "activator" of the electrons involved in the $\mathrm{N}_{2}$-fixing reaction (Hardy and Burns, 1968).

Control of Enzyme Biosynthesis

At first glance the possibility that $\mathrm{N}_{2}$ may act as an inducer for nitrogenase may appear a somewhat attractive idea. However, if grown

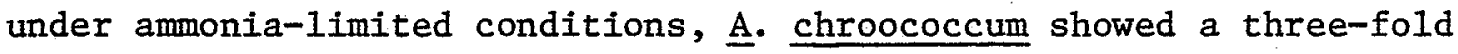
increase in $\mathrm{N}_{2}$-fixing activity when the atmosphere of a chemostat culture 
was changed from air to a mixture containing $20 \%$ oxygen and $80 \%$ argon (Dalton and Postgate, 1969 a). Dalton and Mortenson (1973) considered it unlikely that the nitrogen content of the gases used (approximately $10^{-7} \mathrm{M}$ ) would be sufficient to act as an inducer for nitrogenase, particularly as no such situation is likely in nature and hence there would be no selective pressure for a mechanism to act in such a manner. Further, nitrogen is very unreactive and hence would be unable to associate readily with a repressor molecule. Alternately, since $\mathrm{N}_{2}$ complexes are stable, it is also unlikely that the repressor $-\mathrm{N}_{2}$ complex, once formed, could dissociate. Such a mechanism of induction would not be favored.

Alternately, ammonia may act as a corepressor. Thus under ammonia limited conditions, $\mathrm{N}_{2}$-fixing activity is present in cells. When ammonia is added to a medium containing cells which are actively fixing nitrogen, the synthesis of nitrogenase should stop. However, nitrogenase which is present already does not stop functioning, but is lost by an unknown mechanism during growth with no additional nitrogenase synthesis (Shah et a1., 1972 and Tubb and Postgate, 1973). Another way in which nitrogenase is lost was shown by Tubb and Postgate (1973). Klebsiella nitrogenase showed a shorter half-life after addition of ammonia (195 min) than the theoretical half-life of washing out (288 min). Addition of chloramphenicol increased the half-life to $240 \mathrm{~min}$ which suggested some protein, necessary for the inactivation of nitrogenase, was being synthesized. During the first hour after addition of ammonia, the Azotobacter nitrogenase seems to decrease by dilution. Such is also 
the case if the amount of enzyme present is measured immunologically. However, when nitrogenase activity was measured by dithionite oxidation, acetylene reduction, $\mathrm{N}_{2}$ reduction or loss of EPR signal, it was found to decrease much more rapidly, approximately one hour after addition of ammonia (Shah, Davis and Bri11, 1972). It was suggested that the loss of activity, but not protein, resulted from destruction of ironsulfur centres following loss of protection from $\mathrm{O}_{2}$, the protein being broken down later and reutilized. Strandberg and Wilson (1968) and Drozd et al. (1972) also observed a more rapid decrease in nitrogenase activity than if the enzyme were simply being diluted out as growth occurred.

It has been found there is a lag between the exhaustion of ammonia and the onset of nitrogen fixation (Shah, Davis and Brill, 1972). In $\underline{A}$. vinelandii both nitrogenase components appeared together in about $15 \mathrm{~min}$ at $32^{\circ} \mathrm{C}$. Work using rifampicin (inhibits transcription) and chloramphenicol (inhibits translation) showed that Klebsiella required 40 min to reach maximum nitrogenase synthesis after exhaustion of ammonium in the medium (Tubb and Postgate, 1973). It is interesting to note that while A. vinelandii showed coordinate synthesis of the two nitrogenase components, molybdoferredoxin appeared to be synthesized 10-15 min before azoferredoxin in C. pasteurianum (Seto and Mortenson, 1974).

It was genetic studies which initially implicated glutamine synthetase in the control of nitrogenase (Streicher et al., 1975). Strains of $\underline{\mathrm{K}}$. pneumoniae which lacked glutamine synthetase (glnphenotype) were not able to fix nitrogen. When a P1 lysate of a 
strain of $\underline{\mathrm{K}}$. aerogenes which was without nitrogenase (nif-phenotype) and was glutamine synthetase constitutive ( $\mathrm{g} \ln \mathrm{C}^{-}$phenotype) was crossed with a strain of $\underline{K}$. pneumoniae $\left(\mathrm{nif}^{+}, \mathrm{gln} \mathrm{n}^{-}\right.$), a new strain of $\underline{\mathrm{K}}$. pneumoniae emerged in which nitrogenase activity was not repressed by concentrations of ammonia which completely repressed the wild type. It was suggested that the deadenylylated glutamine synthetase acts on the nitrogenase gene activator to allow transcription of nitrogenase. That glutamine synthetase does dontrol biosynthesis of nitrogenase was proven by Tubb (1974). The nitrogenase genes of $\underline{\mathrm{K}}$. pneumoniae were transferred to a strain of $\underline{\mathrm{K}}$. aerogenes (nif $\mathrm{f}^{-}, \mathrm{gln} \mathrm{C}^{-}$) via an F factor. The new strain produced synthésized high levels of nitrogenase in the presence of ammonia. Glutamine synthetase was proved to have a regulatory effect on nitrogenase.

\section{Control of Nitrogenase Activity}

The activity of nitrogenase is regulated by $0_{2}$, by $A D P$ concentration and also by theintracellular carbamyl phosphate concentration. Oxygen effects, termed "switching on and switching off" of nitrogenase, will be discussed in the section "Effect of Oxygen".

It was stated earlier that in vitro, an ATP generating system should be used when assaying nitrogenase activity, as ADP is inhibitory. ADP binding inhibits all reactions of nitrogenase. ADP prevents MgATP ${ }^{-2}$ from binding azoferredoxin to form the azoferredoxin -2MgATP complex required for nitrogen fixation (Bui and Mortenson, 1968). It is likely that ADP binds to azoferredoxin at two sites, one site, which can also bind $\mathrm{MgATP}^{-2}$ has a dissociation constant for $\mathrm{ADP}$ of $5 \mu \mathrm{M}$ and $\mathrm{a}$ dissociation constant for ATP of about $17 \mu \mathrm{M}$ (Tso and Burris, 1973), and 
another site where ADP has a considerably higher dissociation constant (Zumft and Mortenson and Palmer, 1974).

Carbamyl phosphate, a product of ammonia incorporation, inhibits the reduction of acetylene and nitrogen-fixing activities in vitro and in vivo (Seto and Mortenson, 1973 and 1974) but has no effect on the evolution of hydrogen nor upon the hydrolysis of ATP. Each tetramer of molybdoferredoxin strongly binds two carbamyl phosphate groups, but only when the system is intact and operating (Seto and Moretenson, 1974).

\section{Effect of Oxygen on Nitrogenase}

The sensitivity of nitrogenase to inhibition by oxygen is well known and can be seen to vary with the degree of purity of the nitrogenase (Yates and Daniel, 1970) and with the method of extraction of the nitrogenase from the cell. Lysis of the organism by osmotic shock gave enzyme which was soluble and oxygen intolerant (Oppenheim et al., 1970). Dalton and Postgate (1969 a) suggested that the oxygen tolerant nitrogenase enzyme represented a model of the "conformationally protected" enzyme - one in which a reversible conformational change has taken place in the enzyme complex so that the oxygen sensitive sites are accessible to oxygen, but simultaneously, the complex became unable to fix nitrogen. Further, it was proposed that internal membranes surround the soluble nitrogen-fixing enzyme system and the respiratory enzymes contained therein maintain conditions which are conductive to nitrogen fixation. However, conformational protection is not the only mechanism which is thought ta act in scavenging oxygen from the nitrogen fixing site. This other mechanism was termed "respiratory 
protection" (Dalton and Postgate, 1969 a).

The toxicity of oxygen in Azotobacteraceae is well documented (Meyerhoff and Burke, 1928, Tschapek and Grambiagi, 1955 and SchmidtLorenz and Rippe1-Baldes, 1957) and the members of this genus are among the most intensely respiring aerobes (Wyss et al., 1961). Phillips and Johnson (1961) proposed that respiration is used to scavenge oxygen from the neighborhood of the nitrogen fixing site since they observed that, given excess oxygen, A. vinelandii consumed sugar at a rate greater than that necessary to provide the cell's energy requirements. In early experiments with batch culture, Dalton and Postgate (1969 a,b) repeated the observation that nitrogenase activity was lost in the presence of oxygen. They then showed that $\mathrm{N}_{2}$-fixing cultures exhibited sensitivity to oxygen whereas cultures growing on media containing fixed nitrogen showed no unusuál sensitivity towards oxygen. Furthermore, carbon and phosphate limited continuous cultures exhibited even more sensitivity to oxygen when fixing nitrogen but none when growing on $\mathrm{NH}_{4}^{+}$. They also took their results as evidence that this second form of protective mechanism operates in the living organism. Respiratory protection serves to protect the active nitrogenase. Inactive nitrogenase was a result of conformational protection. In support of these views are the work of Yates (1970) and Drozd and Postgate (1970) who used the acetylene test to assay for functional nitrogenase.

Thus, under a wide range of oxygen tensions, respiratory protection 
serves to provide long term protection from oxygen damage for the nitrogenase enzyme of nitrogen fixing cells. Although the $\mathrm{QO}_{2}$ increases greatly in $\mathrm{N}_{2}$-fixing cells which are challenged with $\mathrm{O}_{2}$, the intracellular concentration of ATP does not increase but rather decreases (Jones et al., 1973). Ackrell and Jones (1971 a) showed this was due to the uncoupling of energy production, to varying extents, at two coupling sites. This might cause a lowering of the ATP/ $\mathrm{ADP}$ ratio with the concomitant loss of respiratory control and an increase in the rates of respiration and substrate catabolism. The amounts of different cytochromes in the cells varies with growth conditions (Ackrell and Jones, 1971 b) and thus the previous history of a population of cells will influence its response to oxygen challenge. Cultures grown at low $\mathrm{PO}_{2}$ values will experience a "switching off" of nitrogenase activity upon being shaken. Respiratory protection is no longer adequate so a reversible, rapid conformational change within the nitrogenase complex takes place causing the oxygen sensitive sites to become inaccessible to oxygen and the nitrogenase to become inactive $1 . e$. conformational protection is in effect. Cellular respiration is now enhanced. Once a tolerable oxygen concentration is attained, the conformational change is reversed, nitrogenase activity is "switched on" and assimilation of nitrogen from the atmosphere begins again.

\section{Theory of Continuous Culture}

Investigations concerned with the physiology of A. chroococcum have used organisms obtained by both batch and by continuous culture. 
A batch culture has four definate stages in its growth cycle: the lag, exponential, stationary and death phases. The freshly innoculated chemostat begins life as a batch culture. After innoculation, the organisms remain in the lag phase until the cells can begin dividing and proceed into the exponential phase. Now the population may be kept in a steady state condition of exponeritial growth by controlling the rate of addition of fresh medium into the vessel. From this culture one may now obtain cells of a constant composition and in a predetermined physiological state suitable for experimental use. The theory of the chemostat has been given by Herbert, Elsworth and Telling (1956) and by Tempest (1970). Only a few points will be discussed here.

The exponential growth phase may be expressed as:

$$
\mu=\frac{1}{x} \cdot \frac{d x}{d t}=\frac{d(\ln x)}{d t}=\frac{(\ln 2)}{t d} \quad \text { (Tempest, 1970, }
$$

where $(\mu)$ is the specific growth rate constant in $h^{-1},(x)$ is the initial concentration of organisms in $\mathrm{mg} / \mathrm{ml}$, and ( $t d$ ) is the generation time of the culture. As stated by Herbert (1958), "The key to the mode of action of the chemostat lies in the way in which the specific growth rate $(\mu)$ depends on the concentration of a limited growth substance (s) in the culture medium." This dependence is empirically described by the equation:

$$
\mu=\mu_{\max } \frac{\mathrm{s}}{\mathrm{Ks}+\mathrm{s}} \quad \text { (Monod, 1950), }
$$

where $\left(\mu_{\max }\right)$ is the maximum specific growth rate, and (Ks) is a saturation constant numerically equal to the substrate concentration 
at which $\mu=\frac{1}{2} \mu_{\max }$. It is therefore of paramount importance when growing aerobic organisms that the culture is adequately aerated so there is no unexpected oxygen limitation (Herbert, Elsworth and Telling, 1956).

When a chemostat is innoculated with a pure culture and the dilution rate (D) is fixed (the dilution rate may be expressed as $\mathrm{w} / \mathrm{v}$; where $(\mathrm{w})$ is the influx rate in $\mathrm{ml} / \mathrm{hr}$ and $(\mathrm{v})$ is the volume of the culture in $\mathrm{ml.}$ ), the substrate concentration (s) automatically reaches a steady-state level at which $\mu=D$. This holds for all dilution rates below a certain critical one, above which complete wash-out occurs. We therefore have:

$$
\frac{\mathrm{dx}}{\mathrm{dt}}=\mu \mathrm{x} \text {, representing the instantaneous growth rate of the }
$$
population and,

$$
\frac{d x}{d t}=-D x \text {, the rate of loss of cells by washing out. It }
$$

follows that,

$$
\frac{d x}{d t}=\mu x-D x=(\mu-D) x \text {, represents the actual rate at which }
$$

the population within the culture vessel will change. It follows from this that a dilution rate exceeding $\mu_{\max }$ will result in the washout of the culture. A submaximal value of (D) will ensure that, all other things being equal, $\frac{d x}{d t}$ will be positive and the size of the population will increase. The steady state $\frac{d x}{d t}=0$ concentration of the growth limiting substance (s) in the chemostat depends on the dilution rate (D) according to the equation: 


$$
\begin{aligned}
& \mathrm{D}=\mu=\mu_{\max } \frac{\mathrm{s}}{\mathrm{Ks}+\mathrm{s}} \text { or rearranging we have; } \\
& \bar{s}=\mathrm{Ks} \frac{\mathrm{D}}{\mu_{\max }-\mathrm{D}} \quad \text { (Herbert et al., 1956) where }(\overline{\mathrm{s}}) \text { is }
\end{aligned}
$$

defined as the steady state value of the growth limiting nutrient. At this point, the growth rate is equal to the dilution rate.

During the exponential growth phase, we would expect the efficiency of production of cell material to remain constant. Thus we may define the yield factor ( $Y$ ) where:

$$
Y=\frac{\text { weight of organisms produced }}{\text { weight of substrate consumed }}
$$

The relation between the growth rate and the rate of substrate consumption is constant (Monod, 1942).

$$
\left.\frac{d x}{d t}=-Y \frac{d s}{d t} \quad \text { (Herbert et } \underline{a l} ., 1956\right)
$$

We may supply the culture with substrate at a concentration (Sr). This will be reduced by the organisms to the concentration $(\bar{s})$. The concentration of organisms $(\bar{x})$ will be given by:

$$
(\bar{x})=Y(S r-s)=Y\left(S r-K s \frac{D}{\left.\mu_{\max }^{-D}\right)} \quad\right. \text { (Herbert et al., 1956). }
$$

We may assume $\left(\mu_{\max }\right),(\mathrm{Ks})$ and $(Y)$ are all constant over a wide range of dilution rates. The main effect of varying the dilution rate then, will be to vary $(\bar{s})$, the growth-limiting substrate concentration within the culture and therefore, since each of $(\bar{s})$ and $(\mu)$ is proportional to the other, it is the specific growth rate of the organism 
which will be affected by (D) (Tempest, 1970). When (Ks) is smal1 compared with (Sr), we obtain steady-state curves of the type in A, whereas curves of type B are obtained when (Ks) is large as compared with (Sr) (Fig. 2).

\section{Membranous Vesicles of Azotobacter}

In Bergey's manual (8th edition) cells of Azotobacteracege are described as aerobic, gram-negative, "bluntly rod-shaped to oval in appearance...not producing endospores...normally fixing at least $10 \mathrm{mg}$ of atmospheric nitrogen per gram of carbohydrate consumed". Although $\underline{A}$. chroococcum is considered to be the genus type species, most of the research on this genus has been undertaken on $\underline{A}$. vinelandii. The cells have a definate life cycle (Sadoff, 1975) and have the ability to become metabolically dormant cysts which are morphologically distinct. Under suitable conditions these cysts can germinate to regenerate the type of cell from which they arose. Encystment in Azotobacter may be initiated by the addition of $\beta$-hydroxybutyrate (BHB) to exponentially growing cells and it appears that the cell membrane is the target organelle. Furthermore, BHB was found to exert an effect on nitrogen fixation which is carried out by a membrane bound complex (Lin and Sadoff, 1968). For this reason, membrane modifications were first examined as early events in encystment, and changes in lipid composition were determined as they related to the encystment process (Sadoff, et al. and Sadoff, 1975).

It was in an electron microscopic study of encysting and germinating 


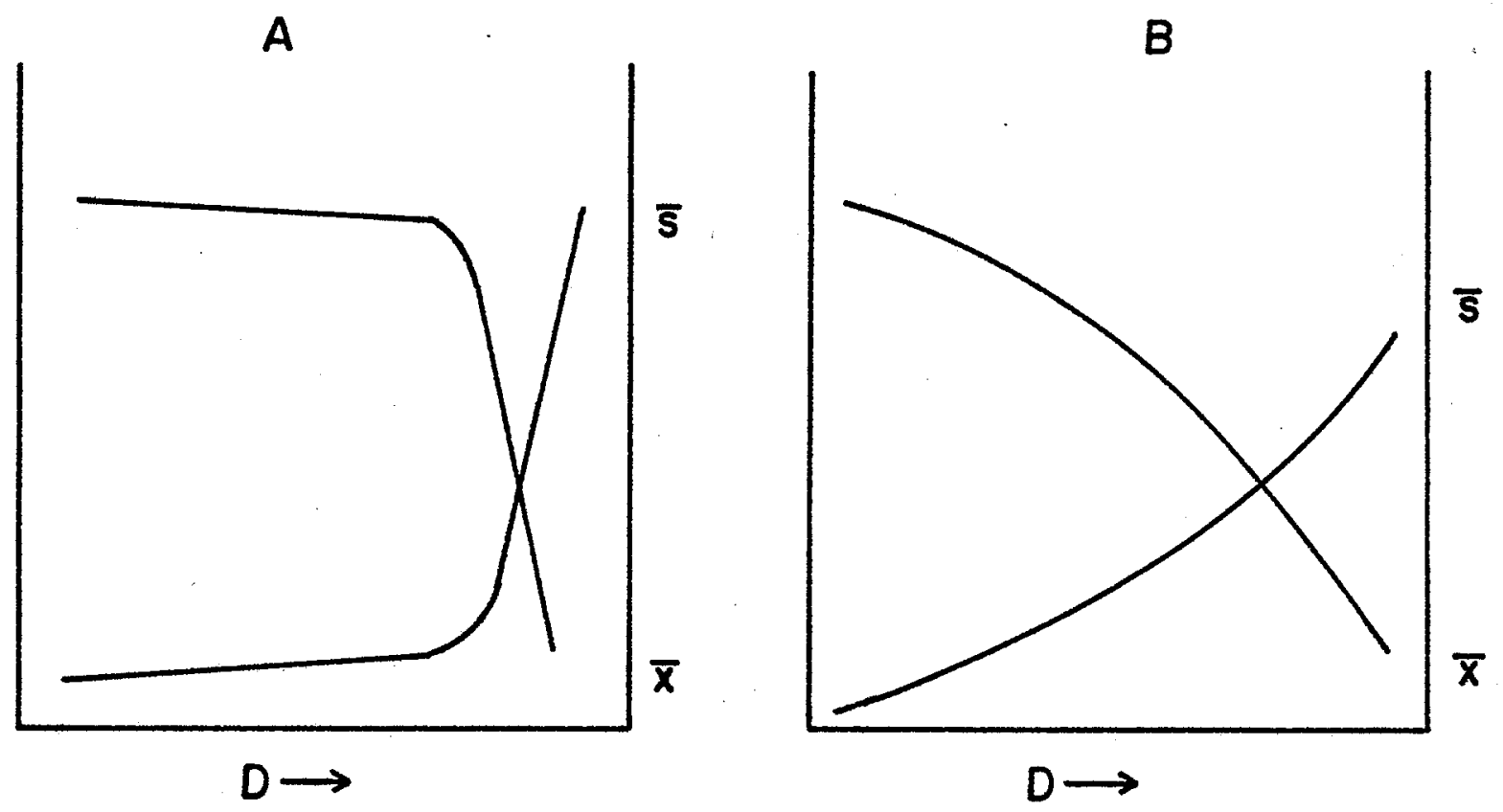

Figure 2. Influence of dilution rate on the steady-state concentration of organisms in a chemostat culture, (A) when $\mathrm{Ks}$ is small relative to $\mathrm{Sr}$ and, (B) when $\mathrm{Ks}$ is large relative to $\mathrm{Sr}$.

$\overline{\mathrm{x}}=$ concentration of organisms at the steady state.

$\mathrm{D}=$ dilution rates $\mathrm{hr}^{-1}$.

$\bar{s}=$ steady state concentration of the substrate. 
cells that Wyss et al. (1961) described peripheral bodies in the vegative cells of $\underline{A}$. vinelandii grown in air $\left(\mathrm{N}_{2}\right)$. They concluded that these represented a network of small tubules or invaginations of the cell membrane which disappear upon cyst formation and reappear upon germination. Pangborn et al. (1962) presented further evidence that the membranes are either attached to or are extensions of the peripheral membrane and also that the internal membranes are most likely a locus of respiratory enzymes in thecells. In aerobes, the extent of development of bacterial membrane systems can be seen to vary from species to species. For example, bacteria of the enteric group (Escherichia coli and Aerobacter aerogenes) have a rather poorly developed system of internal membranes. The $\mathrm{Q}_{\mathrm{O}_{2}}$ values of $\underline{E}$. $\underline{\text { coli }}$ range from 200 to 300 , compared to the extremely high values ranging from 10,000 to 2,000 for Azotobacter (Wyss et a1., 1961). The peripheral bodies were thought to offer a way for the cell to increase the surface area available to the respiratory enzymes, enabling the cell to maintain its extremely high rate of respiration.

Considering the predominance of nitrogen fixation in the physiology of Azotobacter and hence the importance of the membrane-bound nitrogenase enzyme, it would seem probable that factors which influence nitrogenase would also tend to exert an influence on the composition and morphology of the bacterial membrane systems. Oppenheim and Marcus (1970) detailed the effect of nitrogen source on the production of the internal membranous network. Azotobacter grown in batch culture was found to synthesize an extensive internal membranous network when grown in air (nitrogen fixing conditions). However, when provided with fixed nitrogen in the 
form of ammonia and amino acids, the cells contained only small amounts of internal membranes which were concentrated about the cell periphery. In addition, Marcus and Kaneshiro (1972) compared the lipid composition of A. vinelandii grown in batch culture, under conditions in which the internal membranes were induced or repressed. Variations were noted in phospholipid content (which increased by $30 \%$ under induced conditions), neutral 1ipid content ( $80 \%$ reduction under induced conditions) and anionic phospholipid such as phosphatidylglycerol (50\% reduction under induced conditions).

Then in 1972, Hill et al. used continuous culture to study growth of Azotobacter chroococcum in the presence of $\mathrm{N}_{2}$ or fixed nitrogen. Although cultures of high and low $\mathrm{O}_{2}, \mathrm{~N}_{2}$-fixing chemostat populations each showed essentially the same membrane contents, phospholipid analyses on $\mathrm{NH}_{4}^{+}$assimilating populations indicated the $\mathrm{N}_{2}$-fixing organisms contained $70 \%$ more phospholipid than did $\mathrm{NH}_{4}^{+}$grown ones (Hill, Drozd and Postgate, 1972). This however, was later attributed to experimental error (Drozd, Tubb and Postgate, 1972). They found that the phospholipid content of cells grown in $\mathrm{N}_{2}$ and those assimilating $\mathrm{NH}_{4}^{+}$were similar. Again, the network of internal membranes was much more extensive in $\mathrm{N}_{2}$-fixing cultures than in those assimilating $\mathrm{NH}_{4}^{+}$, and the internal membrane content was thought to be correlated to the nitrogenase content, not to the respiratory activity. Results conflicting with these were reported by Pate et al. (1973). Cells of A. vinelandii which were grown in batch culture on $\mathrm{N}_{2}$, ammonium acetate, $\mathrm{NH}_{4} \mathrm{Cl}$ and $\mathrm{NaNO}_{3}$ all showed evidence of an internal network of membranes. It seemed that the cell population and rate of agitation 
of the culture, irrespective of the nitrogen source, influenced the amount of internal membrane. Cells in late exponential growth contained more internal membranes than cells from flasks with baffles (Pate et al., 1973). It was concluded that it was $O_{2}$ that had the major role in regulating the amount of internal membrane. Cells of Azotobacter respond to dissolved $\mathrm{O}_{2}$ concentration by synthesizing more membrane material when $\mathrm{O}_{2}$ is limiting. This it was felt, would permit the cell to increase the surface area enabling it to sequester enough oxygen to remain in the exponential growth phase. It was concluded that differences in cytochrome pattern and membrane content are a consequence of differences in the amount of $\mathrm{O}_{2}$ available to the organisms, rather than the presence or absence of fixed nitrogen (Shah et al., 1973). The controversy over the formation of the internal membranes and their function in the cell has yet to be resolved. Reed, Toia and Raveed (1974) reported the purification of vesicular nitrogenase containing membranes from $\underline{A}$. vinelandii which they termed "azotophores". It was found that these azotophores could be released by osmotic lysis under conditions where the respiratory cytochromes remained associated with the bacterial ghost. This suggested that the nitrogenase containing azotophores could exist in the cell separate from the respiratory membrane. This type of internal organization may be important in the respiratory protection of the nitrogenase from oxygen inactivation. More concrete attempts have been made to determine the cellular localization of nitrogenase enzymes (Stasny, Burns and Hardy, 1973). Ferritin-conjugated anti- 
molybdoferredoxin IgG, which attaches to the molybdoferredoxin protein antigen, was applied to the surface of thin-sections of $\mathrm{N}_{2}-$ fixing Azotobacter cells. Eighty percent of the ferritin-conjugated antibody was seen to bind at the cell periphery while $20 \%$ was seen to bind in an organized manner in the internal cytoplasm, whereas controls with ferritin or other ferritin-conjugated antibodies showed no binding. Similar studies were carried out using antibody to the iron molybdenum protein of nitrogenase which was conjugated to ferritin (Reed et al., 1973). These studies indicated that the nitrogenase is localized on the inner surface of the intracellular membrane in Azotobacter vinelandii. Further studies are needed before the intracellular location of nitrogenase can be demonstrated conclusively. Another area which remains obscure at this time is the precise role the vesicles play in nitrogen fixation.

In a culture stirred at a conventional rate $(400-1000 \mathrm{rpm})$ using a magnetic stirrer, aerobic bacteria are surrounded by a sheath of water molecules through which oxygen must diffuse before it can enter the cell (Aiba, Humphrey and Mi11s, 1973). This water layer may then be capable of limiting the rate of respiraton of the aerobe as a result of its inhibiting the transfer of oxygen from the media to the cell. It was in order to minimize the effects of this water sheath that $\underline{A}$. chroococcum was grown in an intensely agitated continuous culture at a vortex rate of stirring $(1750 \mathrm{rpm})$. At this intense rate of stirring, the water barrier would be almost totally removed and measurements of oxygen tension in the culture would be much nearer to the 
actual $\mathrm{O}_{2}$ tension at the surface of the cell (Hine, 1975 and Hine and Lees, 1976).

Introduction to Work Done in this Thesis

The possibility of oxygen limitation, as well as the nature of the nitrogen source, are factors to be considered in defining the nutritional conditions under which growth occurs. Previous studies have been confined to following changes in lipid composition during encystment (Sadoff, Page and Reusch, 1975); to tracing changes in general lipid classes in batch culture when the internal membrane system was induced or repressed (Marcus and Kaneshiro, 1972), and to comparisons of phospholipid content under induced or repressed conditions in chemostats (Hi11, Drozd and Postgate, 1972 and Drozd, Tubb and Postgate, 1972). It therefore remained to do a more definative study under a more controlled set of conditions i.e. - in a chemostat under conditions which preclude the possibility of oxygen limitation. Hine (1975) described a method whereby Azotobacter chroococcum may be grown to high cell densities without becoming oxygen limited. Since systematic studies of the effects of varying concentrations of $\mathrm{NH}_{4}^{+}$in the medium and various concentrations of oxygen in the gas phase (Tsim, 1976) on the enzyme pattern of $\underline{A}$. chroococcum were undertaken and also changes in the morphology under different growth conditions at vortex stirring rates were determined (Dawson, 1977), it remained to attempt a detailed study of the lipid composition of $\underline{A}$. chroococcum under different conditions of growth. Specifically, the oxygen concentration in the incoming air 
supply was varied while $\underline{A}$. chroococcum was being grown at vortex stirring rates. Lipid was extracted and fractionated by column chromatography and gas-liquid and thin-layer chromatography were used to analyze the fractions. measurements of the rates of lipid synthesis were undertaken using $\mathrm{U}^{14} \mathrm{C}$-acetate. These experiments would give insight into what changes, if any, occur in the lipid composition as a result of changes in the oxygen tension. Attempts were to be made at ascertaining levels of tetraphosphoguanosine (ppGpp) in the cells as a relationship between these and the rates of membrane phospholipid synthesis have been shown (Nunn and Cronan, 1976). However, as will be seen, levels of phospholipid were relatively constant over a wide range of oxygen tensions and thus ppGpp levels would be expected to remain constant also. 
MATERIALS AND METHODS 
MATERIALS AND METHODS

\section{Materials}

\section{Organism}

Azotobacter chroococcum ATCC 7493 was used throughout the course of this study.

Chemicals and Radiochemicals

Reagent grade chemicals were used in all media. All solvents used for lipid isolation or separation were freshly distilled in glass. Safety-Kotes self-charring chromatographic plates were obtained from Applied Science Laboratories, Inc. Silicic acid used for column chromatography was Bio-Sil A (100-200 mesh) from Bio-Rad Laboratories. Lipid standards for gas chromatographic analysis were obtained from Applied Science Laboratories, Inc. MNNG (N-methy1- $\left.\underline{N}^{\prime}-n i t r o-N-n i t r o s o g u a n i d i n e\right)$ for preparation of diazomethane was obtained from Aldrich Chemical Company, Inc. U.S.A. and a diazometharie generator (Fales et al., 1973) was obtained from Kontes Glass Co., Vineland, N.J. U- ${ }^{14}$ C-acetate was obtained from Amersham-Searle, Ltd.

\section{Continuous Culture Apparatus}

Azotobacter was grown on modified Burke's nitrogen-free media (mannitol $\mathrm{B}_{6}$ ) described by Dalton and Postgate (1969 a,b) with the exception that organisms grown at greater concentrations of oxygen than $30 \% \mathrm{O}_{2}$ were grown on $2 \%$ mannitol. The continuous culture apparatus used was based on that which was described by Baker (1968) and modified 
by Hine (1975) and Tsim (1976). Hardware for measuring dissolved oxygen was described by Dawson (1977). Cultures were maintained at $27^{\circ} \mathrm{C}$ and aerated with a suitable gas mixture supplied at the rate of $150 \mathrm{ml} / \mathrm{min}$. Final dilution rate was kept at 0.2 throughout the course of the experiment.

Inoculum (about $50 \mathrm{~m} 1$ ) was aseptically added to a sterilized continuous culture vessel which contained 150 to $200 \mathrm{ml}$ of medium maintained at $30^{\circ} \mathrm{C}$. Gentle, overnight stirring allowed the organism to grow. The next day, the stirring rate was increased to $1750 \mathrm{rpm}$ (vortex) and enough nitrogen gas was added to the incoming air to maintain a negligible $(0-3 \mu \mathrm{M})$ dissolved oxygen tension within the medium. The culture was allowed to adjust to the increased oxygen before more oxygen was added to the incoming air, again so that the dissolved oxygen did not increase over $10 \mu \mathrm{M}$. Oxygen was added in this stepwise fashion until the required oxygen tension was reached in the incoming air. The dilution rate was graudally increased to the desired value. The culture was allowed to stabilize for 3 days before it was sampled.

\section{Sampling Procedure}

Samples which were to be used for lipid analysis were collected overnight in a receiver vessel set in ice.

\section{Preparation of Lyophilized Bacteria}

Samples collected on ice were centrifuged and the cells were washed three times with distilled water. At the last washing, a sticky coating which consisted largely of extracellular polysaccharide and cellular debris 
was washed off. Cells were now weighed to determine wet weight where required. Pellets were then scraped from the centrifuge tubes and frozen overnight at $-20^{\circ} \mathrm{C}$ in a beaker before being lyophilized. After freeze-drying, the cultures were collected from the beakers and ground gently into a powder using a mortar and pestle before being placed in teflon-sealed screw-cap tubes where they were stored at $-20^{\circ} \mathrm{C}$ until weighed for lipid extractions.

\section{Extraction of Total Lipids}

A modified Bligh and Dyer (1959) procedure was used to extract the lipids of $\underline{A}$. chroococcum. Generally, to $100 \mathrm{mg}$ of freeze-dried cells was added $2 \mathrm{ml}$ of water and the wet cells were agitated until all particles of cells were broken-and dissolved. $7.50 \mathrm{ml}$ of methanolchloroform $(2: 1 \mathrm{v} / \mathrm{v})$ mixture was then added and each vial was shaken repeatedly throughout the hour-1ong extraction period which followed. Each sample was then centrifuged and the supernatant was saved. To the pellet obtained from the first centrifugation, a further $9.0 \mathrm{ml}$ of methanol-chloroform-water $(2: 1: 0.8 \mathrm{v} / \mathrm{v})$ was added. These were again shaken vigorously at intervals during the next hour. After a second centrifugation, the supernatant was combined with the first. To these combined supernatants was added $10 \mathrm{ml}$ of $\operatorname{chloroform-water~}(1: 1 \mathrm{v} / \mathrm{v})$. The phases were allowed to separate for $10 \mathrm{~min}$ before the lower chloroform phase was withdrawn with a Pasteur pipette. To aid in removal of traces of water, benzene was added to the chloroform phase before it 
was brought to dryness in a rotary evaporator. Lipid was then resuspended in $5 \mathrm{ml}$ of chloroform, transferred quantitatively to tared vials and evaporated to dryness. After removal of the solvent, vials were maintained under a stream of nitrogen for an additional 8 hours before the weight of lipid was determined. This method resulted in more complete drying and better reproducibility than did the standard method of drying in a vacuum over calcium sulfate (Heefner and claus, 1976). Following weight determination, lipid residues were dissolved in a suitable solvent and stored under an atmosphere of nitrogen at $-20^{\circ} \mathrm{C}$ in screw-capped vials sealed with teflon septums.

\section{Column Chromatography of Total Lipid Extract}

of the several adsorbents which have been used in the column chromatography of lipids the most effective is silicic acid. Its use was outlined by Rouser, Kritchevsky and Yamamoto in 1967. The silicic acid was activated for 2 hours at $120^{\circ} \mathrm{C}$ before use. The chromatography tube was $2.0 \mathrm{~cm}$ (inside diameter) by $40 \mathrm{~cm}$ long, equipped with a coarse sintered glass filter and teflon stopcock at the bottom and a 24/40 female ground glass joint at the top. The bottom of a $250 \mathrm{~m} 1$ separatory funnel with a teflon stopcock was fitted with a male 24/40 ground glass joint in order that it should serve as a solvent reservoir (Kates, 1972). A slurry of $15 \mathrm{~g}$ of activated silicic acid was made with about $30-50$ $\mathrm{ml}$ of chloroform and poured into the chromatography tube. After tapping the column gently to allow removal of air bubbles and to aid in settling " the silicic acid, the solvent level was allowed to drop to the level of the bed and the column was washed with about 2 column volumes of distilled chloroform. Then with the solvent level just at the top of 
the column, the lipid sample was introduced quantitatively with a Pasteur pipette allowing the chloroform washings to drain into the bed of the column between each successive addition. Elution of the column was then carried out at a flow rate of about $3 \mathrm{ml} / \mathrm{min}$ with 10 column volumes of chloroform, 40 column volumes of acetone and 10 column volumes of methanol. The total volumes of each fraction were collected in round bottom flasks and reduced in volume on a Bucchi Rotavapor until the volume was sufficiently small to be placed into a tared teflon-capped tube. Samples were then treated as outlined in the extraction of total lipids.

\section{Extraction of Free Fatty Acids from Neutral Lipid Fractions}

The solvent extraction outlined by Dittmer and We1ls (1969) was used. The dried lipid sample was dissolved in $3 \mathrm{ml}$ of petroleum ether. This was extracted four times with $1 \mathrm{ml}$ of $4 \%$ aqueous sodium carbonate. The combined sodium carbonate extracts were washed twice with $2 \mathrm{ml}$ of ether. These ether washes were then combined with the original ether solution. This is the neutral lipid fraction minus the free fatty acids (NLMF). The sodium carbonate solution was acidified with sulfuric acid and extracted once with $2 \mathrm{ml}$ and twice with $1 \mathrm{ml}$ of petroleum ether. This solution containing the free fatty acids was then concentrated to a desirable volume.

Incorporation of $\mathrm{U}-{ }^{14} \mathrm{C}$-Acetate into Azotobacter Lipid

A $50 \mathrm{ml}$ sample of culture was withdrawn into a $250 \mathrm{ml}$ collection flask in which the air had been previously purged with the air supply 
being fed to the chemostat at the time. A magnetic stirring bar stirred the culture at a vortex rate continuously throughout the experiment. At zero time, $25 \mu \mathrm{Ci} \mathrm{U}-{ }^{14} \mathrm{C}$-acetate $(5.8 \mathrm{mCi} / \mathrm{mmole})$ was added and $10 \mathrm{ml}$ samples were withdrawn by pipette and immediately transferred to flasks which had previously been immersed in a dry-ice acetone bath. At the conclusion of the experiment, samples were allowed to thaw in the fridge, then were spun down immediately, washed once with distilled water and once with $1 \%$ acetic acid. Lipid was then extracted by, the modified Bligh and Dyer method described previously. Lipid residues were dried, dissolved in $1 \mathrm{ml}$ of ether, and a $100 \mu 1$ aliquot of this was counted for determination of radioactivity. The rest of the extracted lipid was loaded onto a silicic acid column and separated into chloroform, acetone and methanol fractions. Radioactivity was determined in aliquots of each of three fractions.

Neutral 1ipid fractions were then spotted onto a pre-washed thinlayer plate and developed using a solvent for general lipid class separation. Similarly, selected phospholipid fractions were spotted onto pre-washed plates and run in solvent for polar lipid separation. Autoradiograms were obtained by laying Kodak RP Royal X-Omat Medical $\mathrm{X}$-Ray Film on the chromatograms and allowing exposure to take place over a five-day period. Autoradiograms were then developed. Thin layer plates were charred at $180^{\circ} \mathrm{C}$ for one hour. Results were recorded photographically using Polaroid film. 


\section{Scintillation Counting}

Radioactivity in the incorporation experiments was measured by liquid scintillation counting in a Beckman model LS-230 liquid scintillation counter. Aliquots of extracted lipid were placed into counting vials, the chloroform or ether in which they were dissolved was evaporated and the samples were dissolved in $10 \mathrm{ml}$ Bray's solution (Bray, 1960) which contained: napthalene $60 \mathrm{~g}$, PPO $4.0 \mathrm{~g}$, POPOP $0.2 \mathrm{~g}$, methanol $100 \mathrm{ml}$, ethylene glycol $20 \mathrm{ml}$ and dioxane to a final volume of one litre. A quench curve was used to determine true disintegrations per minute.

Thin-Layer Chromatography

The methodology used for thin layer chromatography was described by Skipsky and Barclay (1969).

\section{Solvent Systems for Thin-Layer Chromatography}
A) Pre-washing solvent chloroform-methanol $2: 1 \mathrm{v} / \mathrm{v}$
B) Solvent for general lipid class separation petroleum ether-diethylether-acetic acid 90:10:1 v/v
C) Solvent for polar lipid separation chloroform-methanol-water $65: 25: 4 \mathrm{v} / \mathrm{v}$

\section{Preparation of Thin-Layer Plates}

In all cases, Safety-Kotes, self-charring plates were used for thin-1ayer chromatography. These plates do not need to be activated at $110^{\circ} \mathrm{C}$ for $60 \mathrm{~min}$ as does silica gel $\mathrm{G}$, but rather are ready for use 
immediately. To prevent solvent drag, the plates were edged with a fingernail before use. In order to remove any contaminating neutral lipids, all plates were first run in the pre-washing solvent until the solvent was within one centimeter of the top of the plate (Skipsky and Barclay, 1969).

\section{Sample App1ication}

Lipid samples were applied as $1 \%$ solutions in ether using either a flat-tipped Hamilton syringe or disposable micro-pipettes. Spots were placed regularly through the use of a template; they were placed $2 \mathrm{~cm}$ from the developing solvent and $2 \mathrm{~cm}$ from the edge of the plate.

\section{Development}

A11 chromatograms were developed in the ascending direction in jars lined with filter paper wetted with the developing solvent. The plates were run until the developing solvent was 2-3 cm from the uppermost edge of the plate. After developing, the plates were removed and left to dry in a fume hood before staining or charring spots was attempted in the following ways:

\section{A) Safety-Kotes Self-Charring Plates}

In a11 those cases which required a permanent record to be made, chromatograms were run on Safety-Kotes self-charring plates. After development and a short period of drying, the plates were placed in an oven at $180^{\circ} \mathrm{C}$ for one hour. Lipids then appeared as brown spots and could be photographed for a permanent record of the results. 
B) Iodination

A small beaker containing iodine was placed in one corner of the developing tank and plates were allowed to remain inside until the desired degree of staining was attained. A permanent record was obtained by the use of tracing papers or photography with a red filter. C) UV lamp

A small hand-held UV lamp made possible a quick determination of lipid classes present. When it was required, tracing paper was used for a permanent record.

\section{Separation of Phospholipid Components}

Phospholipid fractions were first run on Safety-Kotes using the standard polar lipid developing solvent described previously. A check of the purity of the phospholipid spot (identified as phosphatidylethanolamine) was made according to the method of Skipsky and Barclay (1969). Chromatograms were developed with a solvent mixture (chloroform-methano1-1MNH 4 OH $80: 36: 2 \mathrm{v} / \mathrm{v}$ ) known to separate phosphatidylethanolamine from any contaminating glycolipids.

\section{Gas Chromatography of Fatty Acids}

Either a Hewlett-Packard model 5720 or a Varian Aerograph series 2100 gas chromatograph was used for gas chromatographic analyses. In the case of the former, a $3 / 16^{\prime \prime} \circ . d . \times 12^{\prime}$ copper column was packed with $10 \%$ EGSS - X on Gas-Chrom Q. Column temperature was $165^{\circ} \mathrm{C}$ and flow rate of the nitrogen carrier gas was $40 \mathrm{ml} / \mathrm{min}$. This was sufficient 
to permit a qualitative estimation of the types of fatty acids present. Quantitative work was done on the Varian equipped with a glass column $\left(6^{\prime} \times 1 / 8^{\prime \prime}\right.$ id) packed with the same column packing. However, the column temperature was $180^{\circ} \mathrm{C}$ and flow rate of the nitrogen carrier gas was $40 \mathrm{ml} / \mathrm{min}$. The relative retention times of the various fatty acids, both standards and unknowns, were plotted using $C_{16: 0}$ methylester (methyl palmitate) as 1.00 . Standard curves for various lipid types were constructed by plotting the relative retention time versus the carbon number. Areas of the peaks were calculated by integration and by triangulation according to the method of Carroll (1961), and the components were identified by their relative retention times.

\section{Preparation of Fatty Acid Methyl Esters}

In all cases excepting free fatty acid fractions, methyl esters were prepared by the method of Nichols, Harris and James (1965). Lipid was dissolved in a suitable volume of methanol-benzene-sulfuric acid (150:75:5) and refluxed continuously for $1 \frac{1}{2}-2$ hours. Ether was added to extract the methyl esters, then addition of a small amount of water caused partitioning of the two phases. The aqueous phase was extracted twice more with ether, the extracts being added to the first fraction. After washing the combined extracts with water, anhydrous sodium sulfate was added and the ether extracts were dried for one hour. Following drying, the extract was filtered over a sintered glass filter and evaporated to an appropriate volume under a stream of nitrogen.

Free fatty acid fractions were methylated according to the method of Fales et al. (1973). Approximately 1 mmole (133 mg) of MNNG was 
placed in the centre tube of the Kontes apparatus together with $0.5 \mathrm{ml}$ of water to aid in cooling during the reaction. The top was sealed with a teflon septum and a screw-cap (Law, 1976). In the outer tube was placed $3 \mathrm{ml}$ of cold ether. The two parts of the tube were assembled using a spring-loaded clamp and a buty1-rubber "o-ring" and together were immersed in an ice bath. About $0.6 \mathrm{~m} 1$ of sodium hydroxide was injected through the septum using a syringe with a No. 26 gauge needle and the diazomethane so generated was allowed to collect in the cold ether for about $30 \mathrm{~min}$. Equal volumes of fatty acid solutions and diazomethane in ether were mixed, placed on ice and the excess yellow diazomethane was driven off under a stream of nitrogen gas. 


\section{RESULTS}
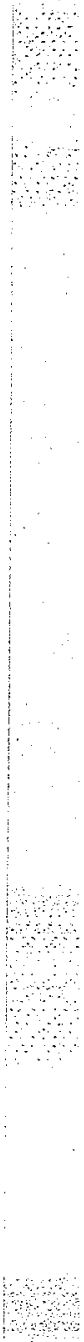
RESULTS

Changes in Cell Yield During Growth at Different Oxygen Tensions

Table I shows the changes observed in cell yield as the chemostat was subjected to increasing oxygen concentrations. It can be observed that the yield increased from 1.19 grams of wet cells per liter of culture collected to a maximum value of 3.31 grams when grown under $20 \%$ oxygen. As the oxygen tension was further increased, with the mannitol concentration being increased from $1 \%$ to $2 \%$ also, the cell yield decreased to a value of 1.90 grams of wet cells per liter of culture at $30 \%$ oxygen and then again to 0.19 grams of wet cells when grown at $40 \%$ oxygen. The rise from $1.19 \mathrm{~g}$ to $3.31 \mathrm{~g}$ represents a 2.78 fold increase while the fall in yield from $3.31 \mathrm{~g}$ to $1.90 \mathrm{~g}$ represents a 1.74 fold decrease. The fall in values from $3.31 \mathrm{~g}$ to $0.12 \mathrm{~g}$ represents a 17.4 fold decrease, certainly a dramatic decrease in cell yield.

In addition, the quantity of a thick, gummy layer of extra-cellular polysaccaride and cellular debris (Fig. 3) was seen to vary inversely with the cell yield. At $20 \%$ oxygen, there was almost no polysaccharide layer present, whereas at $40 \%$ oxygen, the layer was much more predominant than the pellet made up of whole cells. Further, at $5 \%$ oxygen and $30 \%$ oxygen, the polysaccharide layer was of intermediate size, between those seen at $40 \%$ and $20 \%$ oxygen. 
Changes in cell yield with increasing oxygen tension a

\begin{tabular}{cc}
\hline Percent $\mathrm{O}_{2}$ & $\begin{array}{c}\text { Wet Weight } \\
(\mathrm{g} / \text { Iiter })^{\mathrm{b}}\end{array}$ \\
\hline 5 & 1.19 \\
20 & 3.31 \\
30 & 1.90 \\
40 & 0.12 \\
\hline
\end{tabular}

Weight changes were determined by methods as described in the text

${ }^{b}$ Data presented here represent the average of two determinations 
Figure 3.

Electron micrograph (8000 x) of gumny polysaccharide layer containing cells, cellular debris and polysaccharide. This layer was routinely washed off pellet during preparation of the bacteria after freeze-drying. 


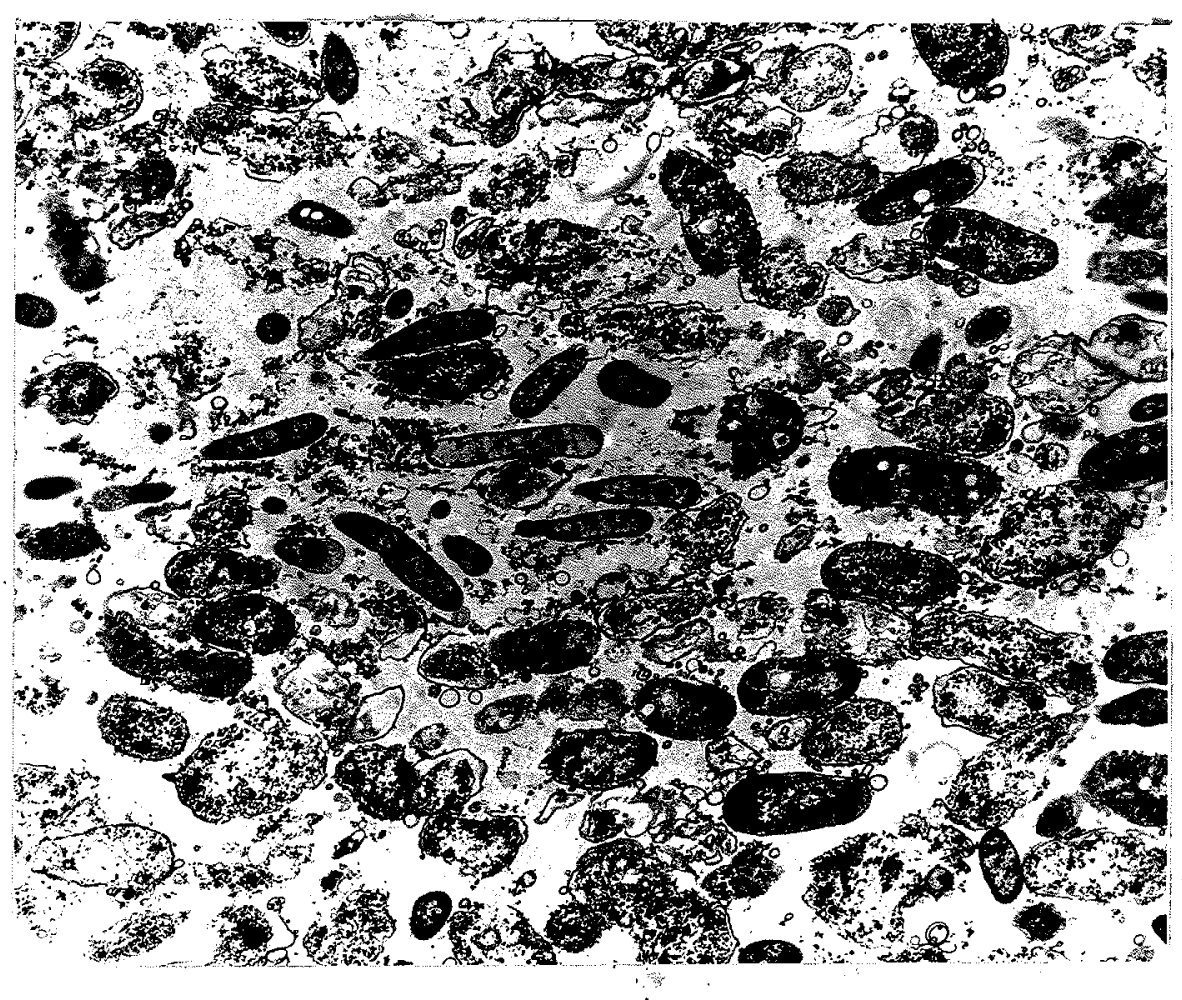


Changes in Total Lipid During Changes in Oxygen Tension

Figure 4 shows the changes in total lipid content of Azotobacter chroococcum grown at different oxygen tensions. All determinations are the result of three to four extractions performed on cells collected on different days. All values at each oxygen tension deviated less than $2 \%$ from the average values represented graphically in Figure 4. Lipid accounted for $9.2 \%$ of the dry weight of Azotobacter during growth at the lower oxygen tensions $\left(5 \%\right.$ and $\left.20 \% \mathrm{O}_{2}\right)$. The values decreased slightly at $30 \%$ and $40 \%$ oxygen. Here, total lipid represented $8.6 \%$ and $8.7 \%$ respectively, of the dry weight of Azotobacter.

Changes in Composition of Total Lipid During Changes in Oxygen Tension

The influence of oxygen tension upon the composition of total lipid of A. chroococcum can be seen in Figure 5. Total lipids were extracted from cells grown under different oxygen tensions using column chromatography as described in "Methods". Glycolipid decreased slightly from $5.1 \%$ of the total lipid at $5 \% \mathrm{O}_{2}$ to $2.5 \%$ of total 1 ipid at $20 \% \mathrm{O}_{2}$. However, further increasing the oxygen tension lead to an increase in glycolipid to $4.1 \%$ of total lipid at $30 \% \mathrm{O}_{2}$ and again to $13.5 \%$ at $40 \% \mathrm{O}_{2}$. Clearly the proportion of total lipid made up by glycolipid is relatively small regardless of oxygen tension and the significance of changes of this proportion is doubtful.

Changes in the content of phospholipid followed inversely the changes in neutral lipid content. Neutral lipid decreased from $12.7 \%$ at $5 \% \mathrm{O}_{2}$ to $5.5 \%$ at $20 \% \mathrm{O}_{2}$, which represents halving the amount of neutral 1ipid. Phospholipid, on the other hand, increased from $82.5 \%$ at $5 \% \mathrm{O}_{2}$ 
Figure 4 .

Changes in 1ipid content of Azotobacter chroococcum with changes in oxygen tension. Lipid extractions were performed as described in "Methods". Each point on the curve represents the average of three to four determinations. 
LIPID ( $\mathrm{mg} / \mathrm{g}$ dry weight cells )

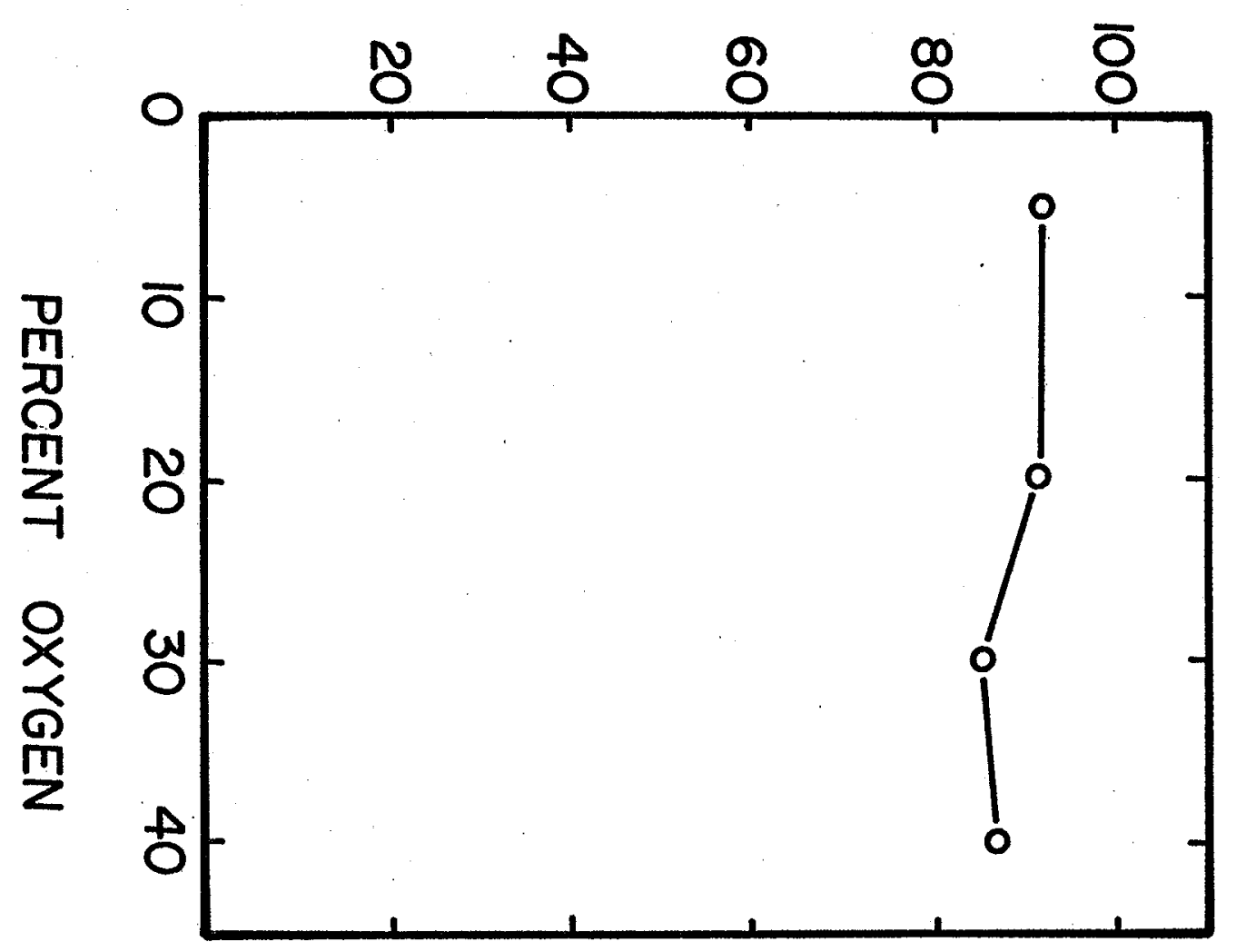


Figure 5. Influence of oxygen tension on the composition

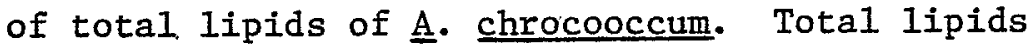
were fractionated into three lipid classes: neutral lipid, glycolipid and phospholipids as described in "Methods".

$\mathrm{x} \longrightarrow \mathrm{x}$ Neutral 1ipid

Glycolipid

$\Delta-\Delta$ Phospholipid 


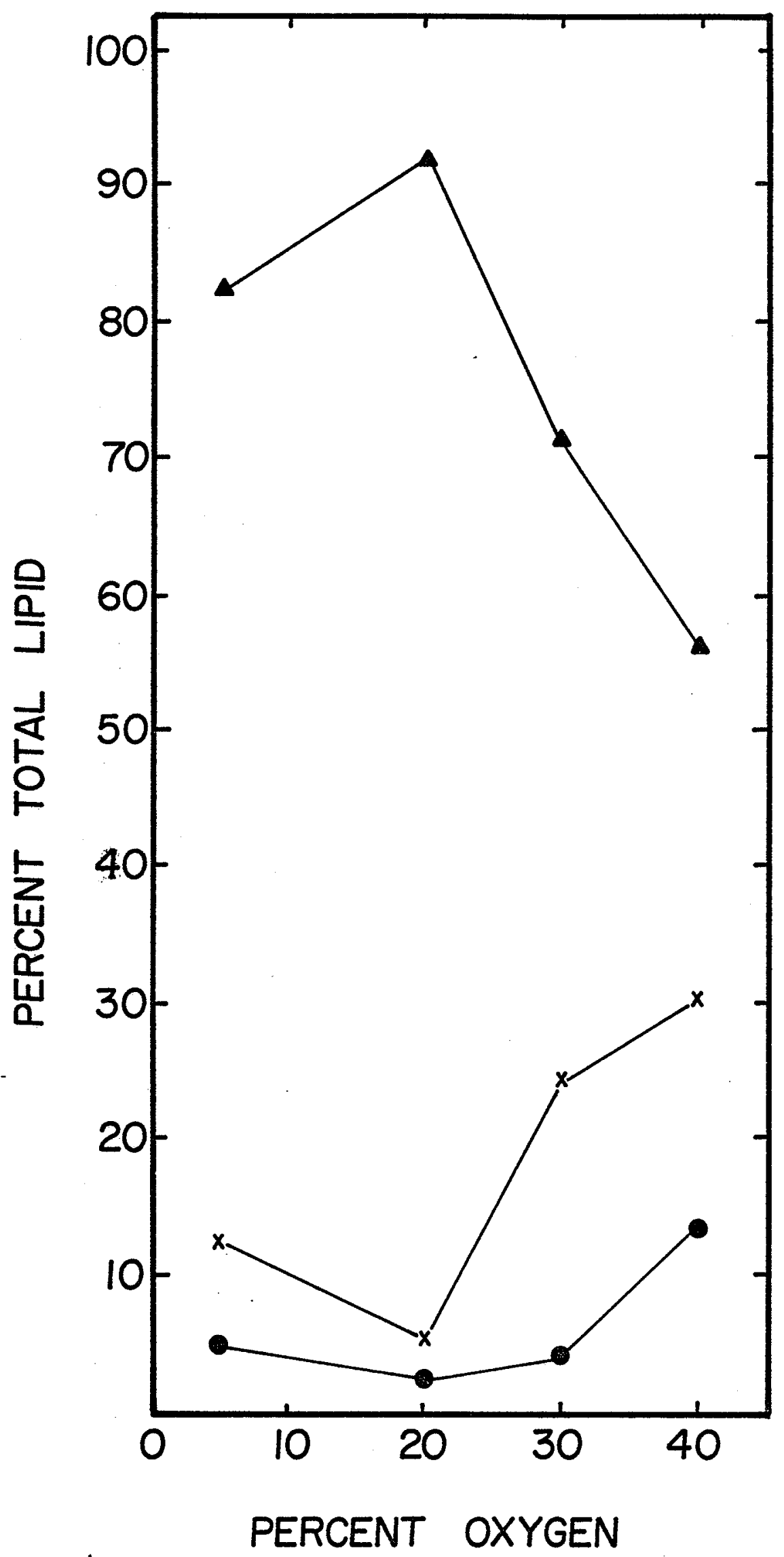


to a value of $92 \%$ at $20 \% \mathrm{O}_{2}$. Thereafter, as oxygen tension increased, phospholipid content decreased while neutral lipid content increased. From $20 \% \mathrm{O}_{2}$ to $30 \% \mathrm{O}_{2}$ there was a substantial loss of phospholipid to a value of $71.5 \%$ at $30 \% \mathrm{O}_{2}$ and an approximately four-fold increase in neutral lipid content (to a value of $24.3 \%$ at $30 \% \mathrm{O}_{2}$ ). When the oxygen tension was further increased to $40 \%$, the phospholipid content decreased further to a value of $56.3 \%$ at $40 \% \mathrm{O}_{2}$, while neutral lipid content continued to increase to a maximum of $30.2 \%$ at $40 \% \mathrm{O}_{2}$. In total, the proportion of phospholipid decreased by $35.7 \%$ between $20 \% \mathrm{O}_{2}$ and $40 \%$ $\mathrm{O}_{2}$. The total increase for neutral lipid over the same range of oxygen tensions was $24.7 \%$. Increase in glycolipid over this range of oxygen tensions was 11\%. Thus the amount of phospholipid lost in the total lipid of Azotobacter as the oxygen tension is increased from $20 \% \mathrm{O}_{2}$ to $40 \% \mathrm{O}_{2}$ is accounted for by increased amounts of neutral lipid and glycolipid.

\section{Detailed Chromatographic Analysis of Azotobacter Lipids.}

Lipids of Azotobacter chroococcum were spotted on Safety-Kotes self-charring plates and developed using the solvent systems described in "Methods". Figure (6) shows that neither the acetone fractions nor the methanol fractions were contaminated with any neutral lipids. Therefore the particular method of column chromatography chosen resulted in a clean separation of the three lipid classes. From this chromatogram the major components of the neutral lipid fraction were identified as free fatty acids, an unidentified intensely yellow pigmented component more polar than free fatty acids and another unidentified 
Figure 6. Typical thin layer chromatogram of silicic acid column fractions of $\underline{A}$. chroococcum total lipids. Total lipids were separated into chloroform fraction (neutral lipids): acetone fraction (glycolipids); and methanol fraction (phospholipids) using silicic acid column chromatography as described in "Methods". Samples used in this chromatogram were derived from cells grown under 20\% oxygen. A general 1ipid class separation solvent mixture was used (see Methods).

Column (1) $100 \mu \mathrm{g}$ : $20 \%$ oxygen chloroform fraction

(2). $50 \mu \mathrm{g} 20 \%$ oxygen chloroform fraction

(3) $100 \mu \mathrm{g}$ each of TLC standard (1) + (3)

(4) $100 \mu \mathrm{g}$ each of TLC standard (3) + (5)

(5) $100 \mu \mathrm{g} 20 \%$ oxygen acetone fraction

(6) $50 \mu g \quad 20 \%$ oxygen acetone fraction

(7) $100 \mu \mathrm{g} 20 \%$ oxygen methanol fraction

(8) $50 \mu \mathrm{g} 20 \%$ oxygen methanol fraction

Composition of Standards:

TLC \# (1) Cholesteryl oleate, methyl oleate, triolein, oleic acid

TLC \# (3) Cholesterol, phosphatidlethanolamine, lecithin, 1ysolecithin

TLC \# (5) Palmitic acid, lecithin, lysolecithin, xglycerol phosphate.

Spots: In ascending order (O) origin (A) uknown (B) cholesterol

(C) unknown (D) free fatty acid

(E) triolein (F) methyl oleate (G)

cholesteryl oleate. 


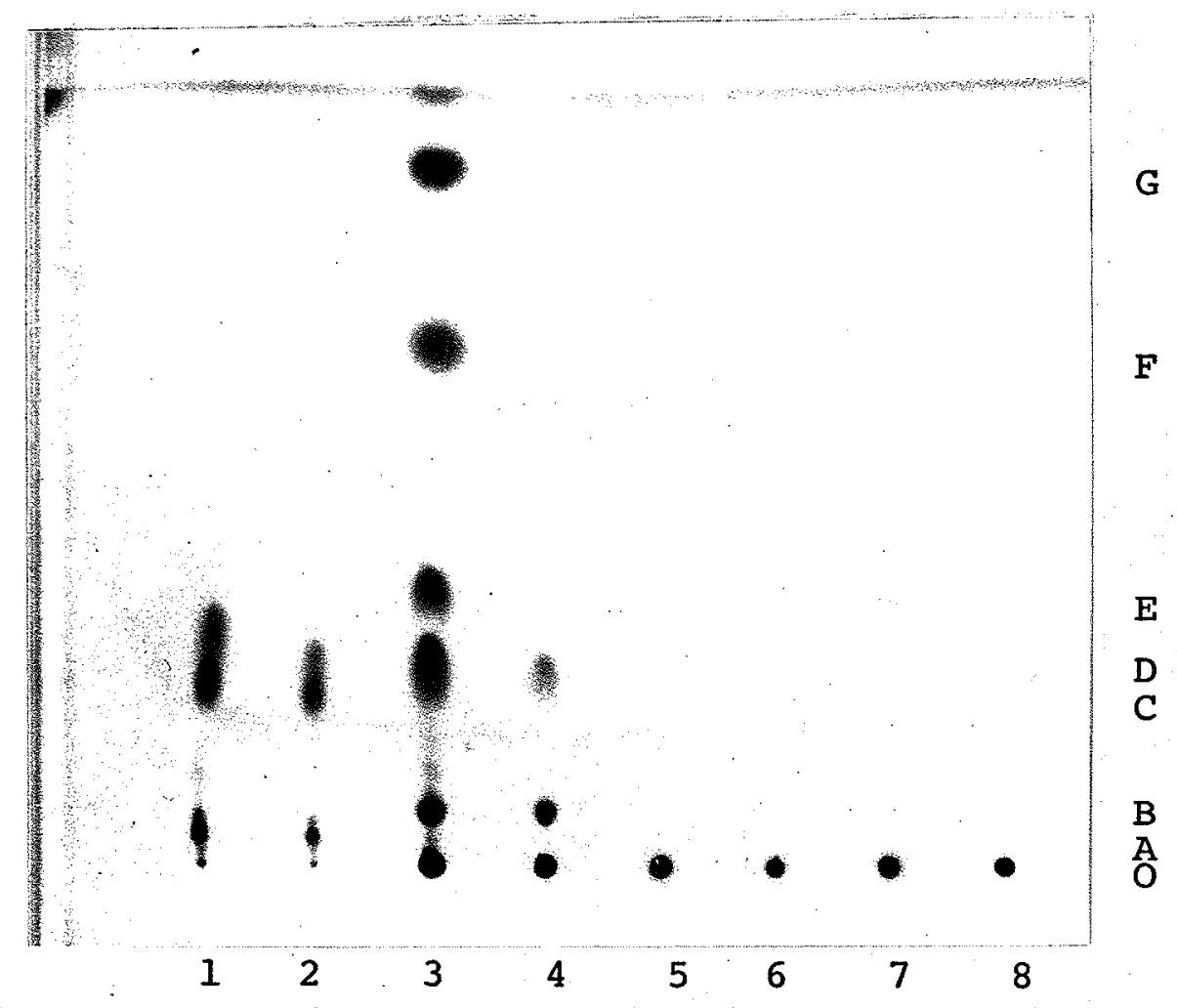


component more polar than cholesterol but less polar than phosphatidylethanolamine or other phospholipid standards. The most polar of these two unknown components may not be pure: in some chromatograms it may be seen to be just beginning to separate into two components (Figs. 6, 7, 10 and 11). The identity of these two components remains unknown. The major component of the neutral lipid fraction is slightly more polar than free fatty acids. In an attempt to further characterize this material about $10 \mathrm{mg}$. of neutral lipid was applied to a thin layer plate and the band corresponding to this component was scraped from the plate after development. Infra-red spectroscopy of this was inconclusive, but indicated the presence of some conjugation. Spectra in the visible and ultra-violet regions exhibited a strong absorbance peak at $300 \mathrm{~nm}$ on a broader absorbance peak at $425 \mathrm{~nm}$. This broad peak disappeared upon the addition of sodium borohydride, leaving only the peak at $300 \mathrm{~nm}$. This unknown also showed no staining with the application of rhodamine $6 \mathrm{G}$ to the plate.

Figure 7 shows the separation of $\underline{A}$. chroococcum neutral lipid into three components seen earlier in Figure 6 . The composition of the neutral 1ipid fraction did not change with increasing oxygen tension. Visual inspection of the chromatograms did not reveal any major change in quantity in either of the two major components of the neutral 1ipid fraction and for this reason, quantitative measurement by the use of photoreflectometry (Law, 1975) was not attempted.

Similarly, Figures 8 and 9 show the separation of A. chroococcum 
Figure 7. Thin layer chromatogram of $\mathrm{A}$. choococcum neutral lipids from cells grown under different oxygen tensions. A solvent system for general lipid class separation was used. The procedures are described in "Methods". Results show changes occurring in neutral lipid composition during changes in oxygen tension.

Column (1) neutral 1ipid $5 \% \quad \mathrm{O}_{2} 100 \mu \mathrm{g}$

(2) neutral lipid $20 \% \mathrm{O}_{2} 100 \mathrm{\mu g}$

(3) TLC standard (1) + (3) $50 \mu \mathrm{g}$ of each

(4) neutral lipid $30 \% \mathrm{o}_{2} 100 \mathrm{\mu g}$

(5) neutral lipid $40 \% \mathrm{O}_{2} 100 \mu \mathrm{g}$

Spots: in ascending order: (0) origin (A) unknown (B) cholesterol (C) unknown (D) fatty acids (E) triglyceride (F) methyl oleate (G) cholesteryl oleate. 


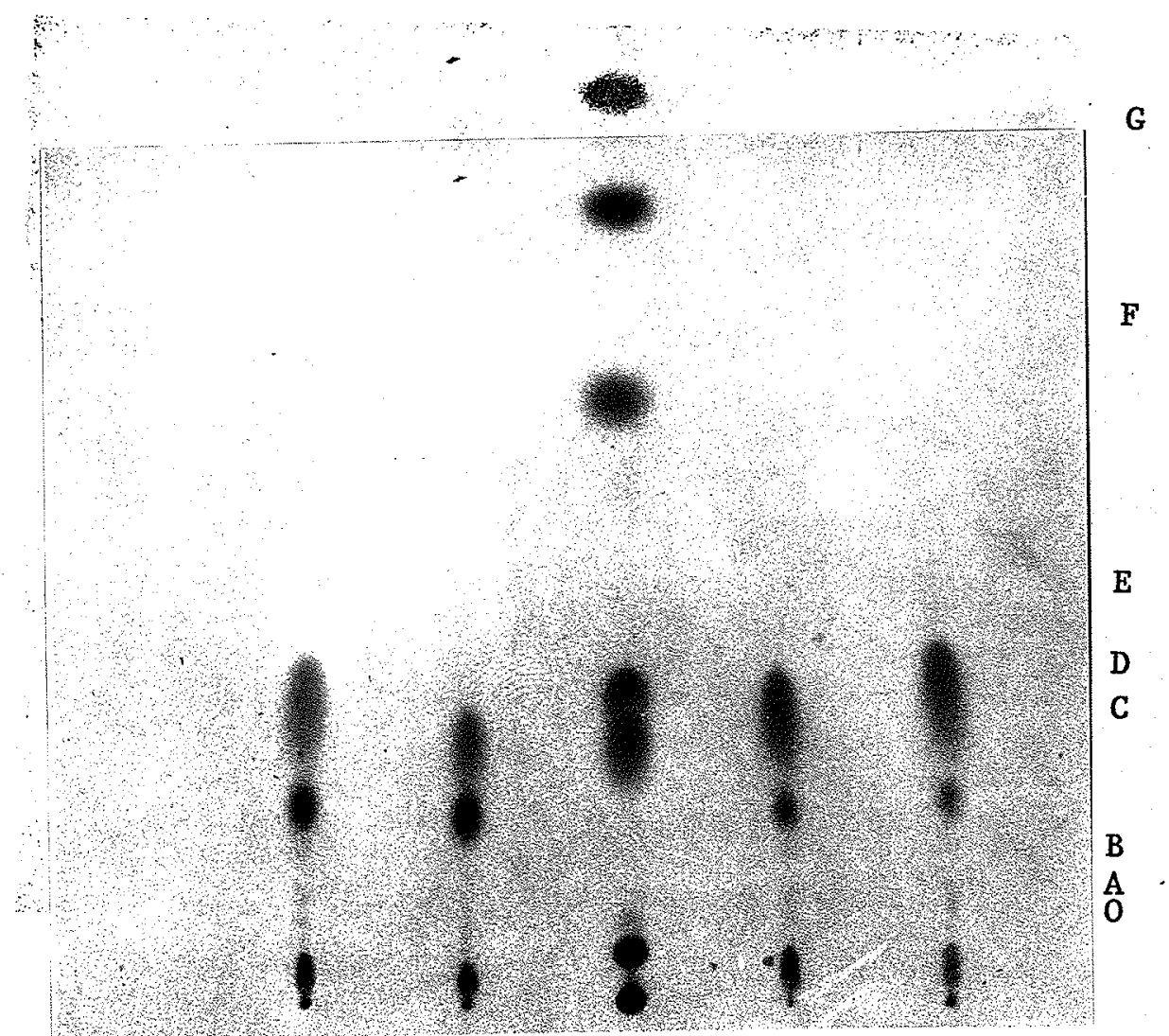


Figure 8. Thin layer chromatogram of phospholipid fractions obtained from A. chroococcum grown under different oxygen tensions. A solvent system for phospholipid separation was used. Procedures are described in "Methods".
Column (1) phospholipid fraction $5 \% \mathrm{O}_{2} \quad 100 \mathrm{\mu g}$
(2) phospholipid fraction $20 \% \mathrm{O}_{2} 100 \mathrm{\mu g}$
(3) TLC standard 非(3) $100 \mu \mathrm{g}$
(4) phospholipid fraction $30 \% \mathrm{O}_{2} 100 \mathrm{\mu g}$
(5) phospholipid fraction $40 \% \mathrm{O}_{2} 100 \mathrm{\mu g}$
Spots: in ascending order: (0) origin (A) lysolecithin (B) lecithin (C) phosphatidyl-
ethanolamine (D) cholesterol. 


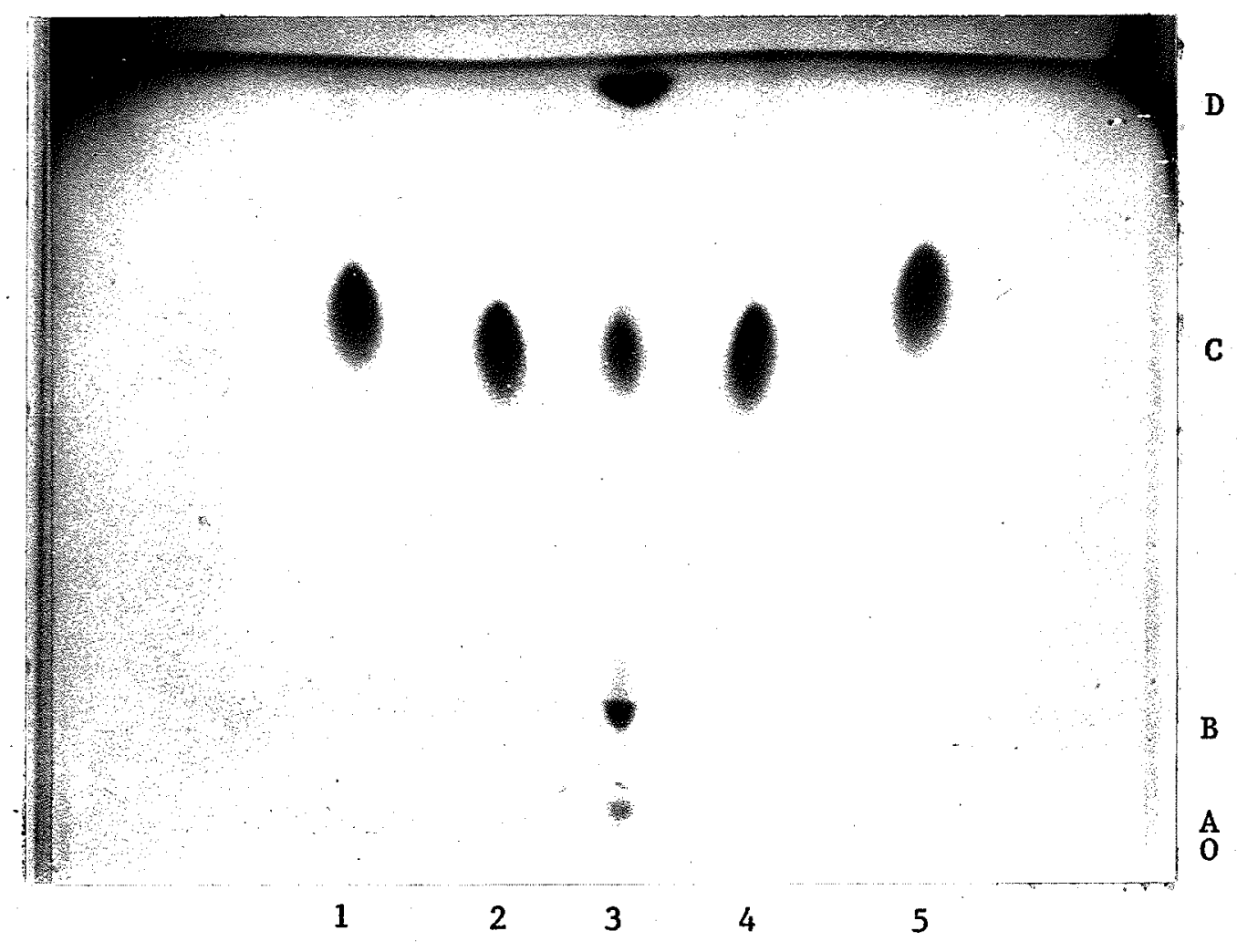


Figure 9. Thin layer chromatogram of phospholipid fraction of A. chroococcum 1ipid. A special phospholipid solvent was used which separates phosphatidy1ethanolamine in a pure form without contamination with glycolipids. Refer to "Methods" section for procedure.

Column (1) $100 \mu \mathrm{g}$ phospholipid fraction $5 \% \mathrm{O}_{2}$

(2) $100 \mu \mathrm{g}$ phospholipid fraction $20 \% \mathrm{O}_{2}$

(3) $100 \mu \mathrm{g}$ TLC standard \#(3)

(4) $100 \mu \mathrm{g}$ phospholipid fraction $30 \% \mathrm{O}_{2}$

(5) $100 \mu \mathrm{g}$ phospholipid fraction $40 \% \mathrm{O}_{2}$

Spots: in ascending order: (0) origin (A) 1ysolecithin

(B) lecithin (C) phosphatidylethanolamine

(D) cholesterol. 


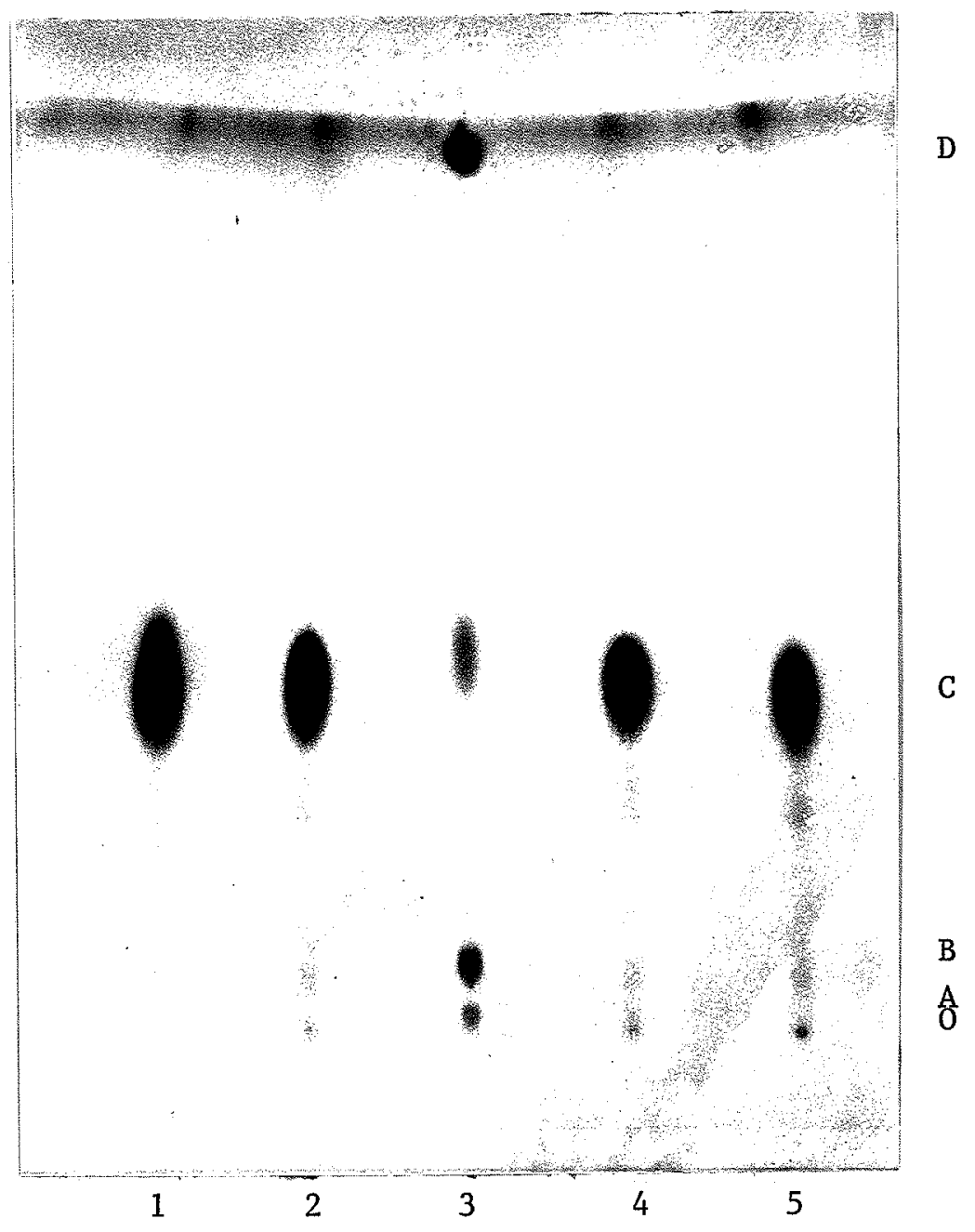


phospholipid fractions on Safety-Kotes self-charring plates. It can be seen from Figure 8 that the phospholipid fraction consists of one glycerophosphatide, namely phosphatidylethanolamine. Visual inspection did not reveal major changes in the amounts of phosphatidylethanolamine as the oxygen tension was changed and quantitative analysis was not done. In most systems designed for analysis of phospholipids, phosphatidylglycerol and phosphatidylethanolamine have similar $R_{f}$ values and there is practically no separation of glycolipids. Therefore, in order to ensure positive determination of the phospholipid fraction, chromatograms were also developed with a mixture of chloroform-methanol-1M $\mathrm{NH}_{4} \mathrm{OH}$, 80: 36: $2(\mathrm{v} / \mathrm{v})$, according to the method of Skipsky and Barclay (1969). Results are depicted in Figure 9. Again only one spot corresponding to the phosphatidylethanolamine. standard was observed.

A general lịpid class separation solvent was used to determine whether sodium carbonate extraction of free fatty acids from the neutral lipid fraction was complete. Results are shown in Figure 10 and 11. It can be seen that complete separation of free fatty acids from the neutral lipid fraction was achieved. Free fatty acids were then methylated as described by Fales et al. (1973) and neutral lipid, phospholipid and total lipid fractions were methylated by the method of Nichols, Harris and James (1965) and used for gas-chromatographic analysis.

Thin-Layer Chromatography of ${ }^{14} \mathrm{C}$-Labelled Lipids

Thin-layer chromatographic analysis was also performed on ${ }^{14} \mathrm{C}$-1abelled lipids extracted from cells grown in media containing small amounts of 
Figure 10. Thin layer chromatogram of neutral lipid minus free fatty acid (NLMF) fractions obtained from A. chroococcum cells grown under varying oxygen tensions. A general lipid class separation solvent was used. Procedures are described in "Methods".

Column (1) $5 \% \mathrm{O}_{2}$ NLMF $50 \mu \mathrm{g}$

(2) $5 \% \mathrm{O}_{2}$ neutral lipid $50 \mathrm{\mu g}$

(3) $20 \% \mathrm{O}_{2}$ NLMF $50 \mathrm{\mu g}$

(4) $20 \% \mathrm{O}_{2}$ neutral lipid $50 \mu \mathrm{g}$

(5) TLC standards (1) + (3) $50 \mu \mathrm{g}$ each

(6) $30 \% \mathrm{O}_{2}$ NLMF $50 \mu \mathrm{g}$

(7) $30 \% \mathrm{O}_{2}$ neutral lipid $50 \mu \mathrm{g}$

(8) $40 \% \mathrm{O}_{2}$ NLMF $50 \mu \mathrm{g}$

(9) $40 \% \mathrm{O}_{2}$ neutral lipid $50 \mu \mathrm{g}$

Spots: in ascending order: (0) origin (A) unknown (B) cholesterol (C) unknown (D) fatty acids (E) triglyceride (F) methyl oleate (G) cholestery1 oleate. 


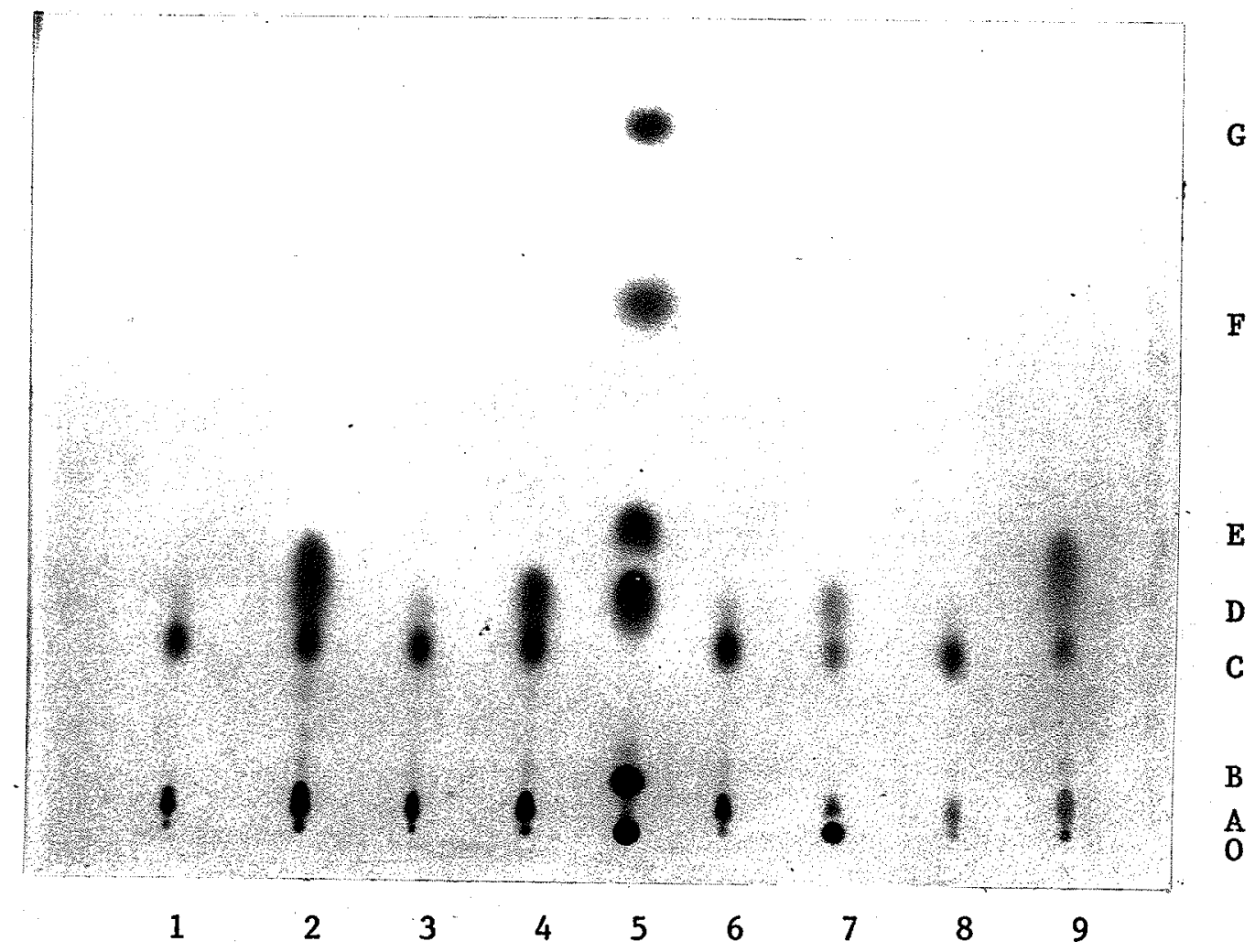


Figure 11. Thin layer chromatogram of sodium carbonate extract of neutral lipids of $\mathrm{A}$. chroococcum cells grown under different oxygen tensions. A solvent system for general lipid class separation was used.

Column (1) $40 \mu \mathrm{l}$ sodium carbonate extract $5 \% \mathrm{O}_{2}$

(2) $25 \mu 1$ neutral 1ipid fraction $5 \% \mathrm{O}_{2}$

(3) $40 \mu 1$ sodium carbonate extract $20 \% \mathrm{O}_{2}$

(4) 25 ul neutral lipid fraction $20 \% \mathrm{O}_{2}$

(5) $25 \mu 1$ TLC standards (1) + (3)

(6) $40 \mu 1$ sodium carbonate extract $30 \% \mathrm{O}_{2}$

(7) $25 \mathrm{HI}$ neutral lipid fraction $30 \% \mathrm{O}_{2}$

(8) $40 \mu 1$ sodium carbonate extract $40 \% \mathrm{O}_{2}$

(9) 25 HI neutral lipid fraction $40 \% \mathrm{O}_{2}$

Spots: in ascending order: (O) origin (A) unknown

(B) cholesterol (C) unknown (D) fatty acids

(E) triglyceride (F) methyl oleate (G)

cholesteryl oleate. 


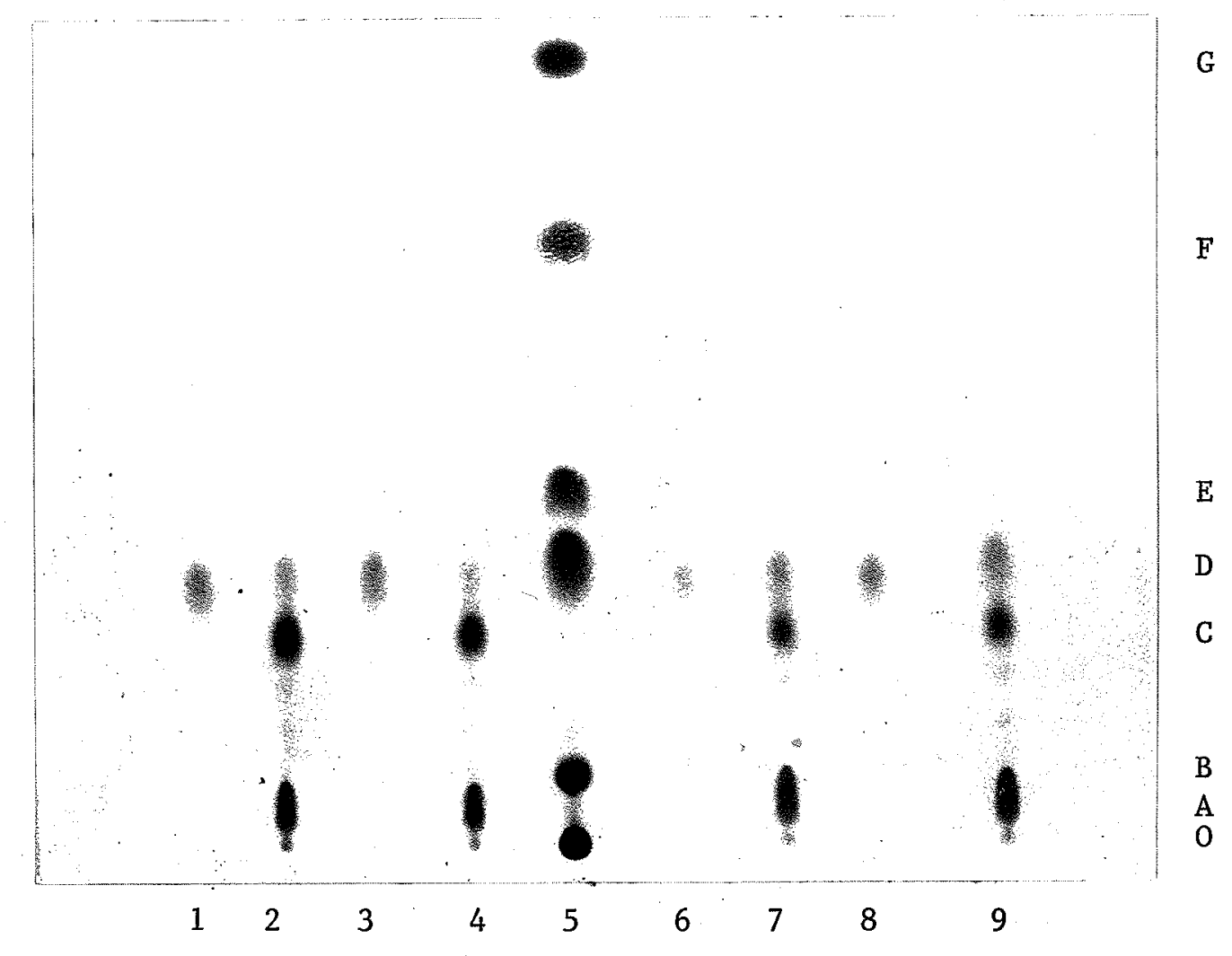


U- ${ }^{14}$ C-Acetate (Figs 12 and 13). Details of this experiment are described in "Methods". Figure 12 shows an autoradiogram which depicts the distribution of label on a plate spotted with various neutral lipid fractions obtained from labelled cells. The autoradiogram may be compared with results obtained from charring of the plate containing labelled neutral lipid samples and unlabelled standards. Free fatty acids from $20 \% \mathrm{O}_{2}$ neutral lipid did not appear to take up appreciable label whereas at $40 \% \mathrm{O}_{2}$, free fatty acids were labelled. The unknown component (C in Fig. 12) which is more polar than free fatty acids also became labelled although to a lesser extent than the second unknown compound (A in Fig. 12), which lies closest to the origin. This component was seen to account for the greatest amounts of label and gave dark, distinct spots on the autoradiogram. Figure 13 shows an autoradiogram depicting the distribution of label on a plate spotted with various labelled phospholipid fractions. Results of charring are exactly as seen in Figures 8 and 9. Clearly label was incorporated into the phospholipid fraction readily and only one component-phosphatdylethanolamine - was labelled.

\section{Fatty Acid Composition of Azotobacter Lipids}

Free fatty acids (FFA) were extracted from the neutral lipid fraction with sodium carbonate and together with fatty acids from neutral 1ipid fraction minus free fatty acids, phospholipid fraction and total 1ipid fraction, were methylated and subjected to gas chromatographic analysis as described in "Methods". Methylated fatty acid standards of various 
Figure 12.

Autoradiogram of thin layer chromatogram of neutral lipid fraction extracted from cells grown in $\mathrm{U}-{ }^{14} \mathrm{C}$-acetate. Lower figure shows the thin layer plate after charring to visualize the 1ipid. Procedures are described in "Methods".

(1) neutral 1ipid ${ }^{14} \mathrm{C} 3 \min 20 \% \mathrm{O}_{2}$

(2) neutral 1ipid ${ }^{14} \mathrm{C} 6 \min 20 \% \mathrm{o}_{2}$

(3) TLC standards (1) + (3) $100 \mu g$ of each

(4) neutral lipid ${ }^{14} \mathrm{C} 3 \min 40 \% \mathrm{O}_{2}$

(5) neutral 1ipid ${ }^{14} \mathrm{C} 6$ min $40 \% \mathrm{O}_{2}$

Spots: in ascending order: (0) origin (A) unknown

(B) cholesterol (C) unknown (D) fatty acids (E) methyl oleate. 


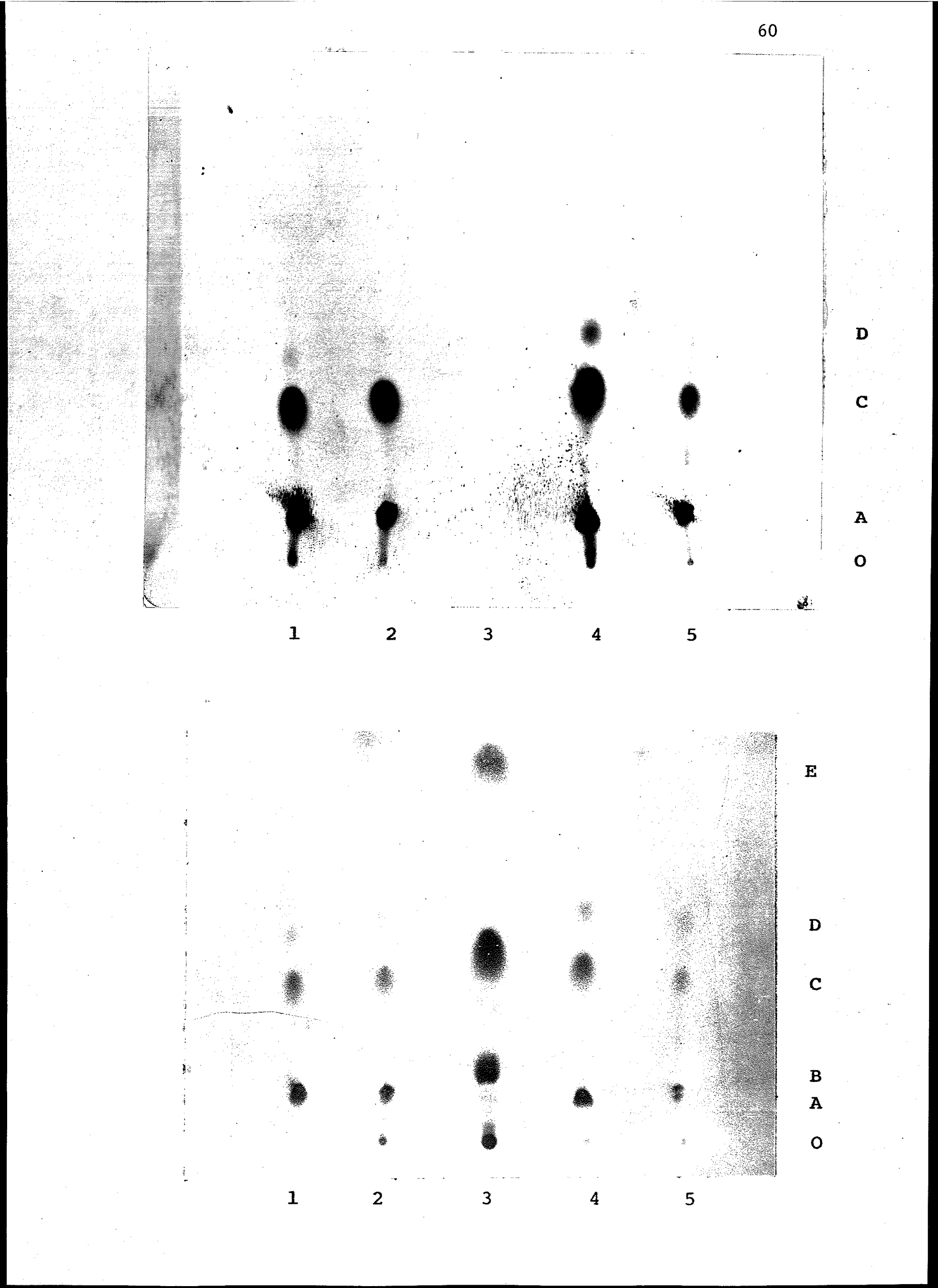


Figure 13.

Autoradiogram of thin layer chromatogram

of phospholipid fraction extracted from cells grown in $\mathrm{U}-{ }^{14} \mathrm{C}$-acetate. Procedures are described in "Methods". Refer to Figure 8 for explanation of the spots.

(1) phospholipid ${ }^{14} \mathrm{C} 3 \min 20 \% \cdot \mathrm{O}_{2}$

(2) phospholipid ${ }^{14} \mathrm{C} 6$ min $20 \% \mathrm{O}_{2}$

(3) TĹ standard (3)

(4) phospholipid ${ }^{14} \mathrm{C} 3 \min 40 \% \mathrm{O}_{2}$

(5) phospholipid ${ }^{14} \mathrm{C} 6$ min $40 \% 0_{2}$ 


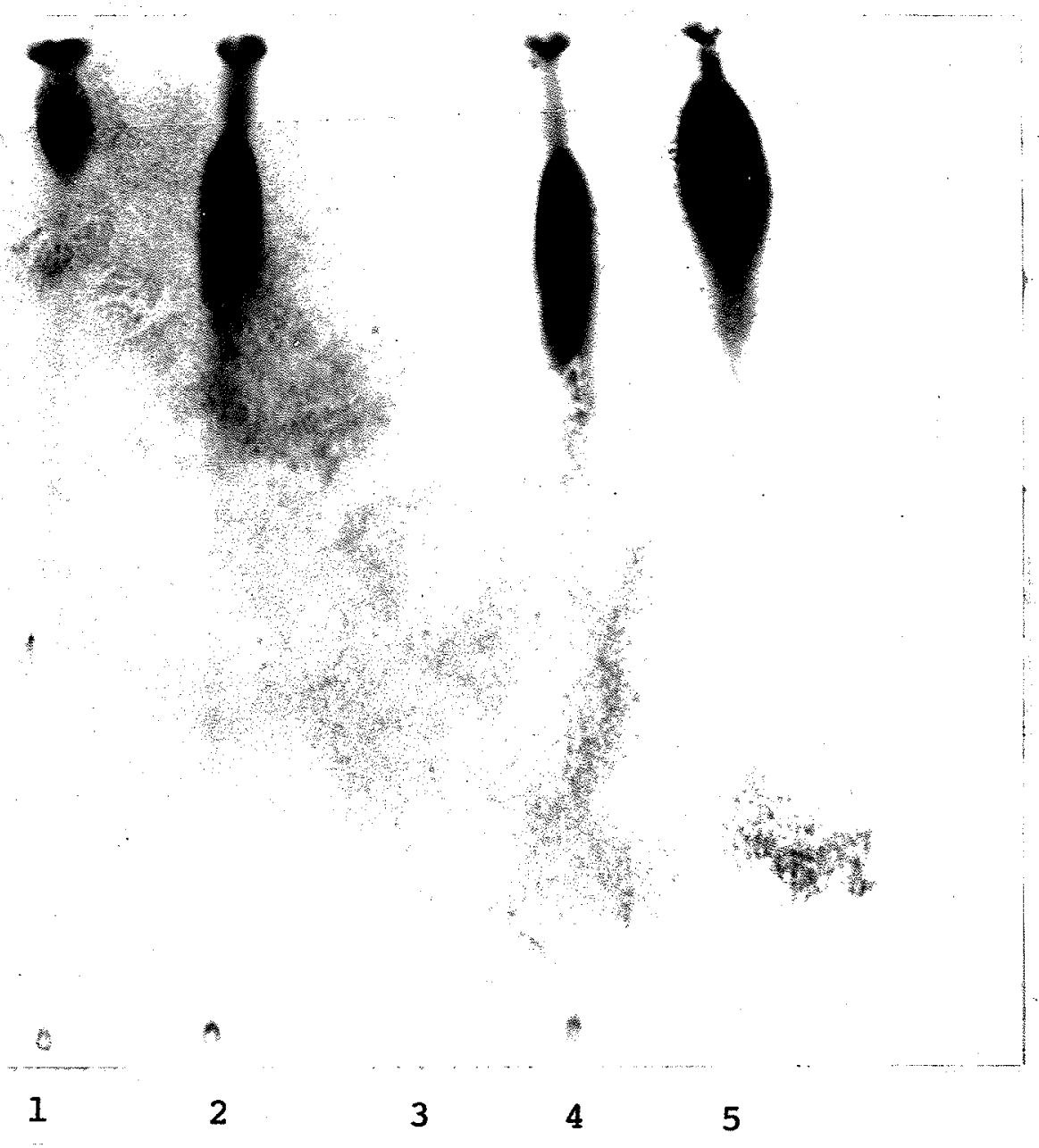


types were used to obtain standard curves (Fig. 14). The identities of all fatty acids were obtained by comparing their retention times relative to palmitic $\left(\mathrm{C}_{16: 0}\right)$ acid. Tables II and III show the comparisons of fatty acid compositions of these fractions extracted from cells grown under varying oxygen tensions. In all instances, excepting phospholipid fractions and free fatty acid fractions, a total of nine different fatty acids were detected. In the case of the phospholipid fractions, only eight different fatty acids were seen' the fatty acid which is absent is of unknown identity and was present in the other fractions in only trace amounts. The free fatty acid fraction, on the other hand, lacked myrisitc $\left(\mathrm{C}_{14: 0}\right)$ acid and the branched chain fatty acid $\underline{i s o-}_{15: 0}$ (13-methyltetradecanoic acid). In all fractions three major components were present. These were palmitic $\left(C_{16: 0}\right)$, hexadecenoic $\left(C_{16: 1}\right)$ and octadecenoic $\left(C_{18: 1}\right)$ acids. In all but the free fatty acids extracted from neutral lipid of cells grown under $40 \% \mathrm{O}_{2}$, there were present in trace amounts only, the iso-and anteiso-types of monobranched saturated isomers of stearic acid $\left(\mathrm{C}_{18: 0}\right)$. In this fraction however, iso- $\mathrm{C}_{18: 0}$ comprised $27 \%$ of the total fatty acids while anteiso $C_{18: 0}$ comprised $5.6 \%$ of the total fatty acids. A graphical representation of the changes in quantities of the major fatty acid components is given in Figures 16-19. In the free fatty acid fraction, short chain fatty acids myristic $\left(C_{14: 0}\right)$ and iso- $_{15: 0}$ were absent altogether. As oxygen tension was raised, the trend in the free fatty acid fraction was toward a lowering in the amount of $\mathrm{C}_{16: 1}$ whereas the 
Figure 14.

Plot of $\log$ of relative retention time for

various fatty acid methyl esters versus chain

length. Conditions for gas chromatographic

analyses are described in "Methods". Fatty acids

were identified by their retention time relative

to palmitic acid $\mathrm{C}_{16: 0}$ as 1.00 .

$\mathrm{x} \longrightarrow \mathrm{x}$ saturated fatty acids

$\Delta$ iso saturated fatty acids

- anteiso saturated fatty acids

- mono-unsaturated fatty acids. 


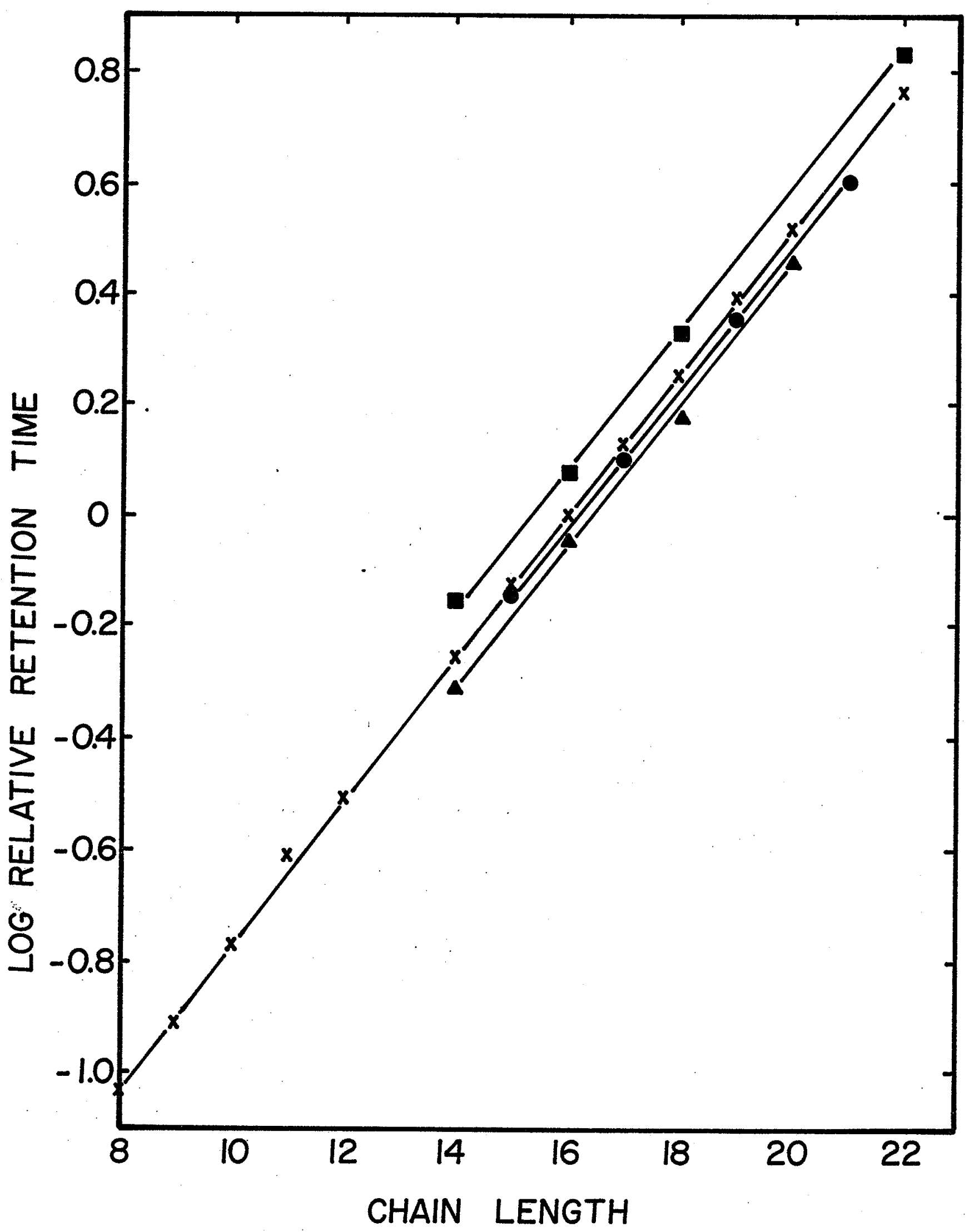


Figure 15. Gas chromatographic identification of total

fatty acids obtained from total lipid fraction

extracted from cells grown under $40 \%$ oxygen.

Experimental procedures were outlined in the

"Methods" section. 


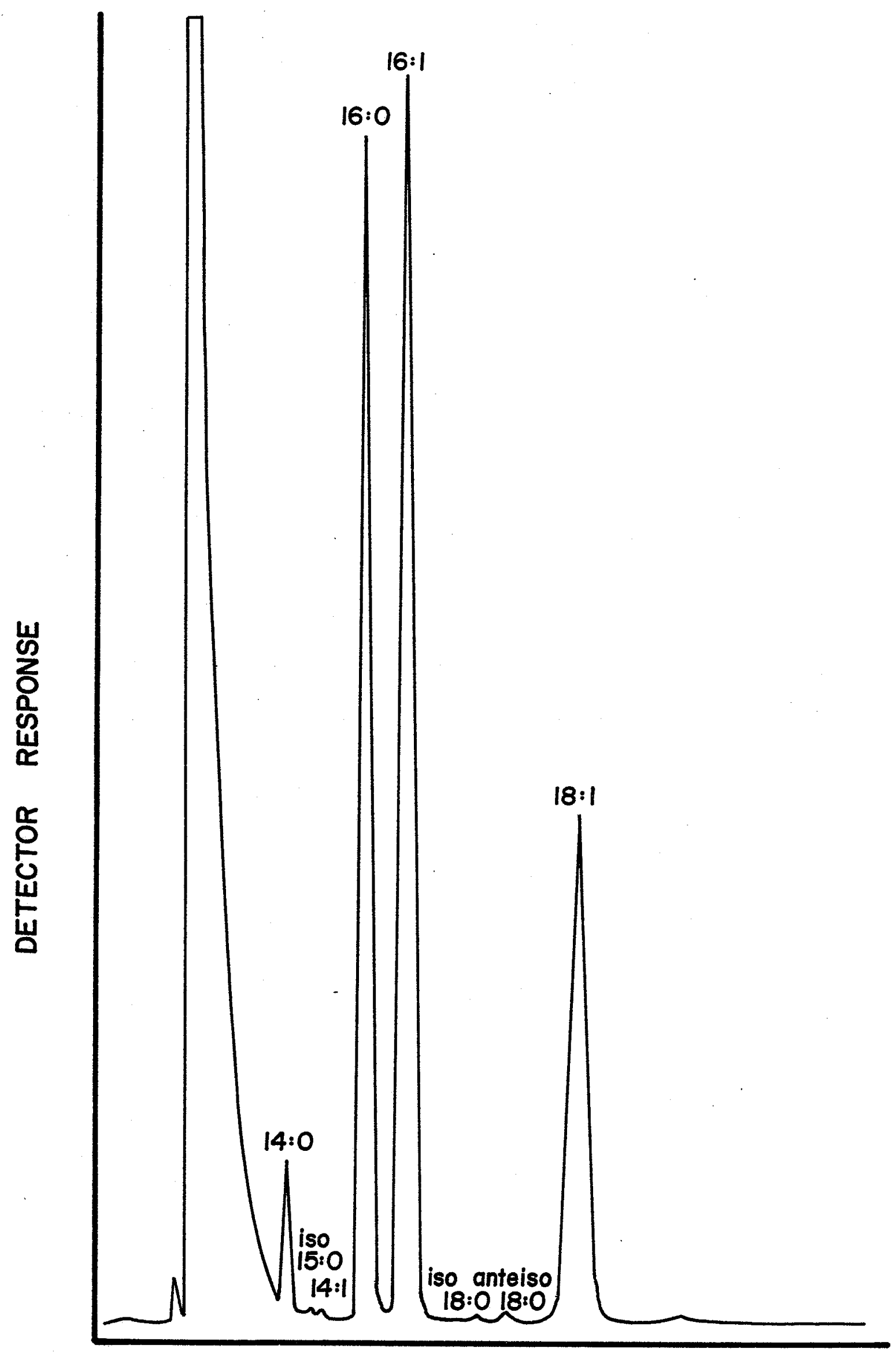


TABLE II

Fatty acid composition of lipid classes obtained from $\underline{A}$. chroococcum during growth under different oxygen tensions. ${ }^{1}$

\begin{tabular}{|c|c|c|c|c|c|c|c|c|}
\hline \multirow[t]{2}{*}{ Peak } & \multicolumn{4}{|c|}{ Free Fatty Acids } & \multicolumn{4}{|c|}{$\begin{array}{l}\text { Neutral Lipid Minus } \\
\text { Free Eatty Acids }\end{array}$} \\
\hline & $5 \%$ & $20 \%$ & $30 \%$ & $40 \%$ & $5 \%$ & $20 \%$ & $30 \%$ & $40 \%$ \\
\hline $\mathrm{C}_{14: 0}$ & - & - & - & - & 4.2 & 1.7 & 1.6 & 2.2 \\
\hline Iso $C_{15: 0}$ & - & - & - & - & trace & trace & trace & trace \\
\hline$c_{14: 1}$ & trace & trace & trace & trace & trace & trace & trace & trace \\
\hline$c_{16: 0}$ & 20.2 & 19.8 & 14.2 & 19.4 & 25.8 & 26.5 & 28.1 & 32.3 \\
\hline $\mathrm{c}_{16: 1}$ & 42.8 & 48.5 & 35.6 & 18.1 & 49.7 & 47.6 & 44.8 & 41.4 \\
\hline Iso $C_{18: 0}$ & trace & trace & trace & 2.7 & trace & trace & trace & trace \\
\hline anteiso $C_{18: 0}$ & trace & trace & trace & 5.6 & trace & trace & trace & trace \\
\hline$c_{18: 1}$ & 37.0 & 31.6 & 50.2 & 54.2 & 20.3 & 41.1 & 25.5 & 24.0 \\
\hline unknown & trace & trace & trace & trace & trace & trace & trace & trace \\
\hline & & & & $\therefore$ & & & & \\
\hline $\begin{array}{l}{ }^{1} \text { Fatty acid } \\
\text { fraction as } \\
\text { of the total }\end{array}$ & st & $\begin{array}{l}\text { ers we } \\
\text { in "N } \\
\text { ids de }\end{array}$ & lods". & $\begin{array}{l}\text { d from } \\
\text { igures }\end{array}$ & quote & & $\begin{array}{l}\text { pid } \\
\text { ages }\end{array}$ & \\
\hline
\end{tabular}


TABLE III

Fatty acid composition of lipid classes obtained from $\underline{A}$. chroococcum during growth under different oxygen tensions. ${ }^{1}$

\begin{tabular}{|c|c|c|c|c|c|c|c|c|}
\hline \multirow[t]{2}{*}{ Peak } & \multicolumn{4}{|c|}{ Phospholipid } & \multicolumn{4}{|c|}{ Total Lipid } \\
\hline & $5 \%$ & $20 \%$ & $30 \%$ & $40 \%$ & $5 \%$ & $20 \%$ & $30 \%$ & $40 \%$ \\
\hline$c_{14: 0}$ & 3.6 & 2.1 & 1.7 & 3.2 & 3.1 & 2.9 & 1.9 & 2.8 \\
\hline iso $C_{15: 0}$. & trace & trace & trace & trace & trace & trace & trace & trace \\
\hline$c_{14: 1}$ & trace & trace & trace & trace & trace & trace & trace & trace \\
\hline $\mathrm{C}_{16: 0}$ & 28.1 & 28.0 & 34.8 & 29.9 & 27.9 & 27.4 & 28.7 & 29.6 \\
\hline$c_{16: 1}$ & 45.0 & 51.9 & 38.0 & 41.6 & 47.8 & 51.9 & 44.0 & 41.1 \\
\hline iso: $C_{18: 0}$ & trace & trace & trace & trace & trace & trace & trace & trace \\
\hline anteiso $C_{18: 0}$ & trace & trace & trace & trace & trace & trace & trace & trace \\
\hline $\mathrm{C}_{18: 1}$ & 23.2 & 18.0 & 25.5 & 25.3 & 21.2 & 17.8 & 25.4 & 26.5 \\
\hline unknown & - & - & - & - & trace & trace & trace & trace \\
\hline
\end{tabular}

${ }^{1}$ Fatty acid methyl esters were prepared from the appropriate lipid fraction as described in "Methods". Figures quoted are percentages of the total fatty acids detected. 
amount of longer chain monounsaturated fatty acid $e_{18: 1}$ was seen to increase. Similarly, a rise in the amounts of iso- $_{18: 0}$ and anteiso$\mathrm{C}_{18: 0}$ types of branched chain fatty acids was observed as they increased from barely detectable amounts to $2.7 \%$ and $5.6 \%$ of total fatty acids respectively. Changes in bound fatty acids from the neutral lipid fraction may be seen in Figure 17. Here, both short chain saturates, $C_{14: 0}$ and iso- $_{15: 0}$ are present and levels of the former remained fairly constant throughout changes in oxygen tension. Levels of the other major fatty acid classes also remained fairly constant. Slight increases occurred in the amounts of palmitic acid $\left(\mathrm{C}_{16: 0}\right)$ which increased $6.5 \%$ and octadecenoic $\left(C_{18: 1}\right)$ which increased $3.7 \%$ over the range of oxygen tensions investigated. On the other hand, levels of hexadecenoic $\left(C_{16: 1}\right)$ acid were seen to fall $8.3 \%$ as oxygen tensions were increased from $5 \% \mathrm{O}_{2}$ to $40 \% \mathrm{O}_{2} \cdot$ Figures 18 and 19 show the changes which occur in the fatty acid content of the phospholipid and total lipid fractions. Slight changes may be noticed in both fractions in the amounts of hexadecenoic $\left(C_{16: 1}\right)$ and octadecenoic $\left(C_{18: 1}\right)$ acids: the former is seen to decrease slightly as oxygen tension is . increased while the latter tends to increase by a small amount as the oxygen tension is increased from $5 \% \mathrm{O}_{2}$ to $40 \% \mathrm{O}_{2}$. Compositions of the total lipid, phospholipid and NLMF fractions were all quite similar - it is the free fatty acid fraction which differed from the others - chiefly in the absence of short chain saturates and in the increased amounts of octadecenoic acid present. 
Figure 16. Changes in major constituents of free fatty acid fraction during growth under different oxygen tensions. Free fatty acids were extracted from neutral 1ipid fraction with sodium carbonate and methylated as described in "Methods".

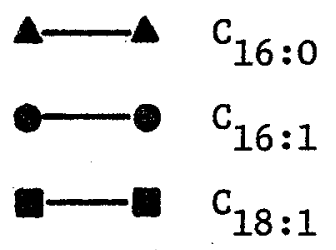




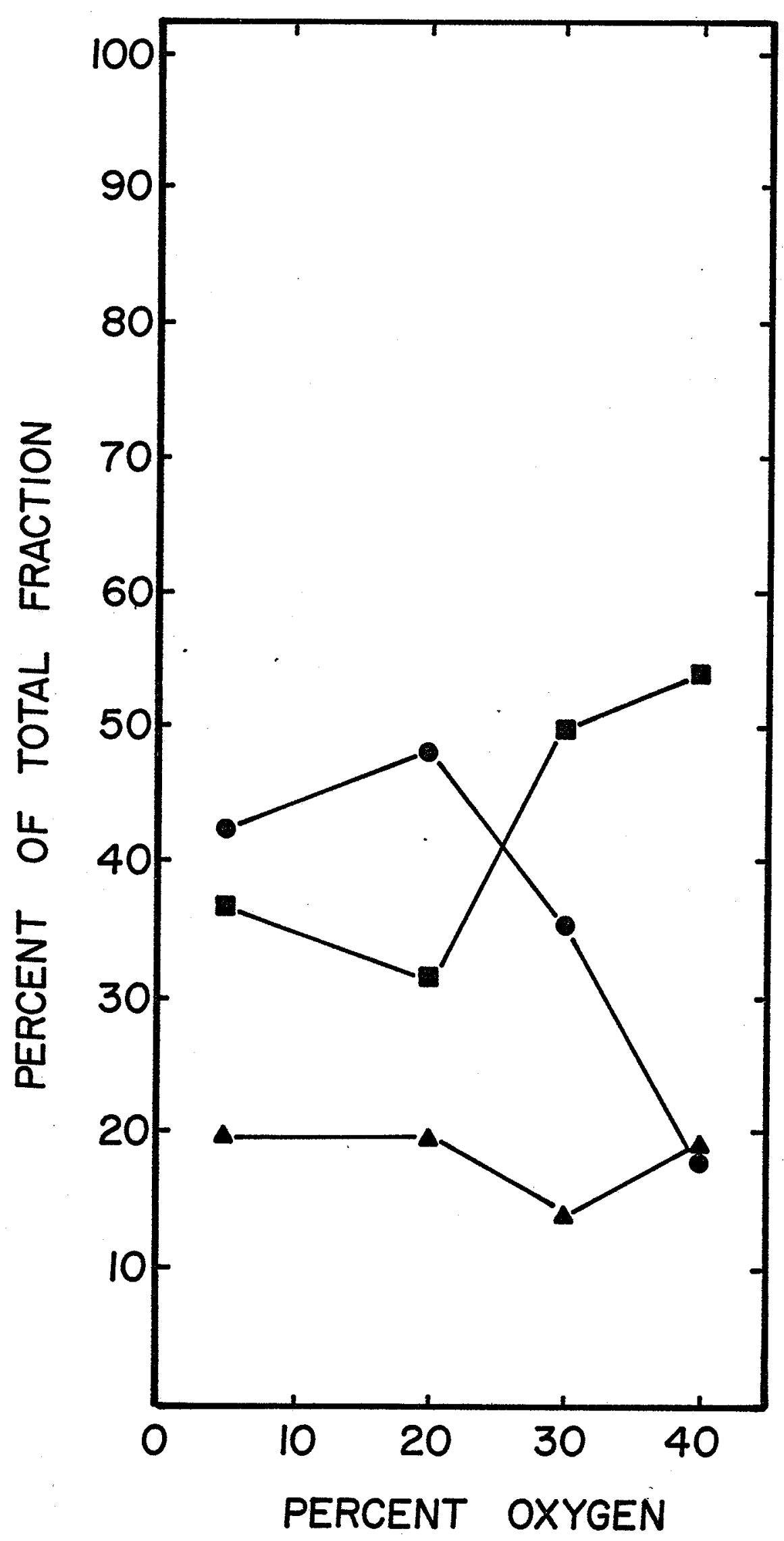


Figure 17. Changes in major constituents of neutral

lipid minus free fatty acid fraction during

growth under different oxygen tensions. Free

fatty acids were extracted with sodium carbonate and methylated as described in "Methods".

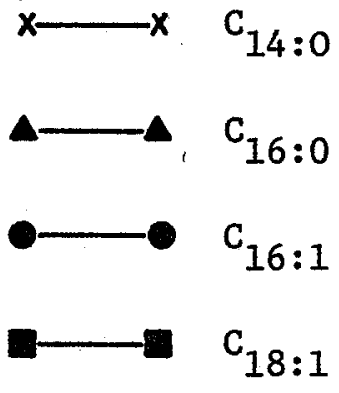




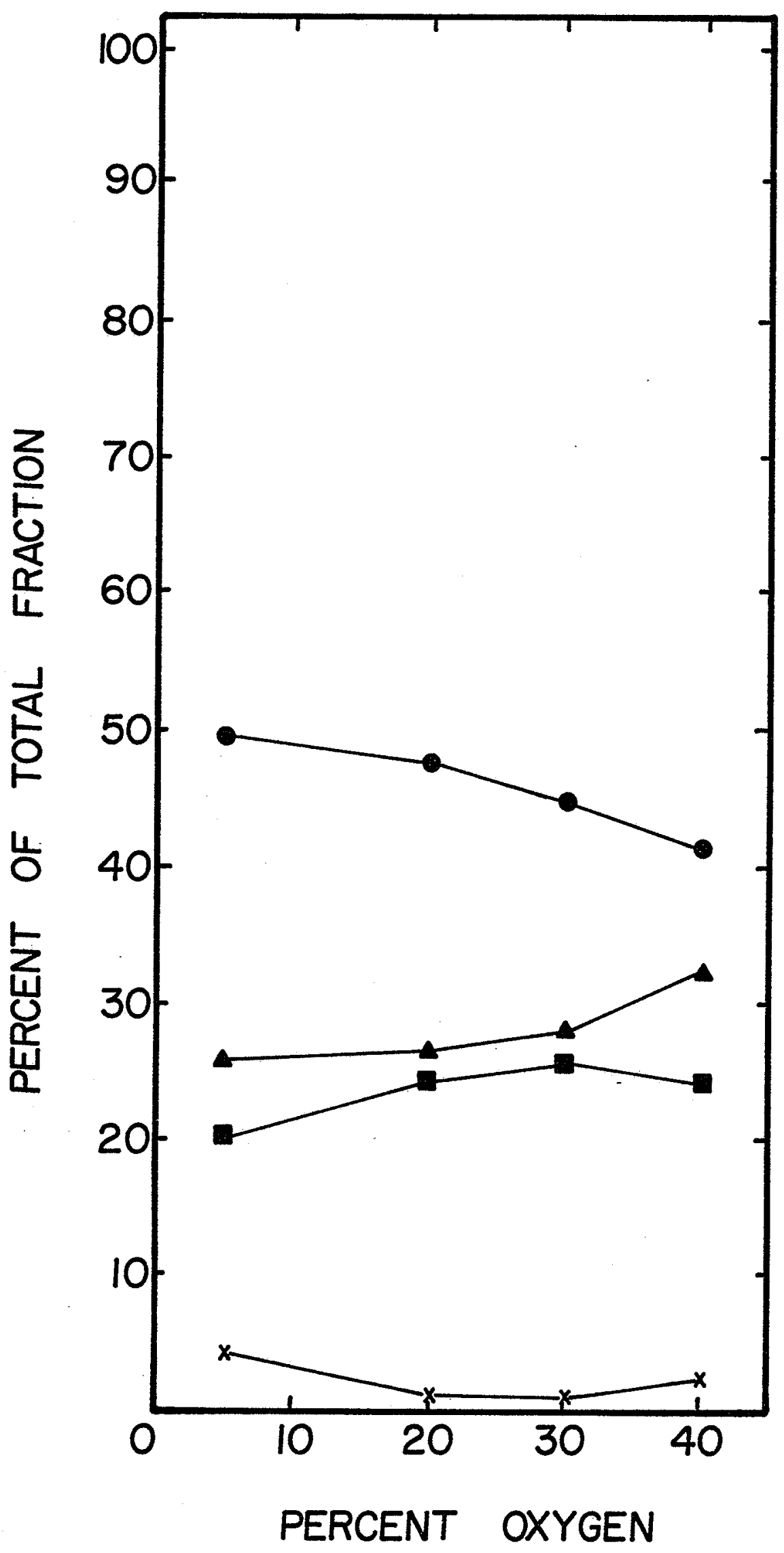


Figure 18. Changes in major constituents of phospholipid fraction during growth under different oxygen tensions. Fractions were separated on silicic acid columns and methylated as described in "Methods".

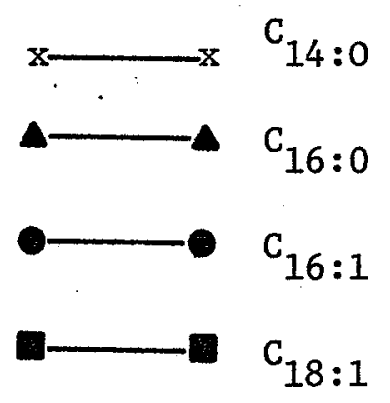




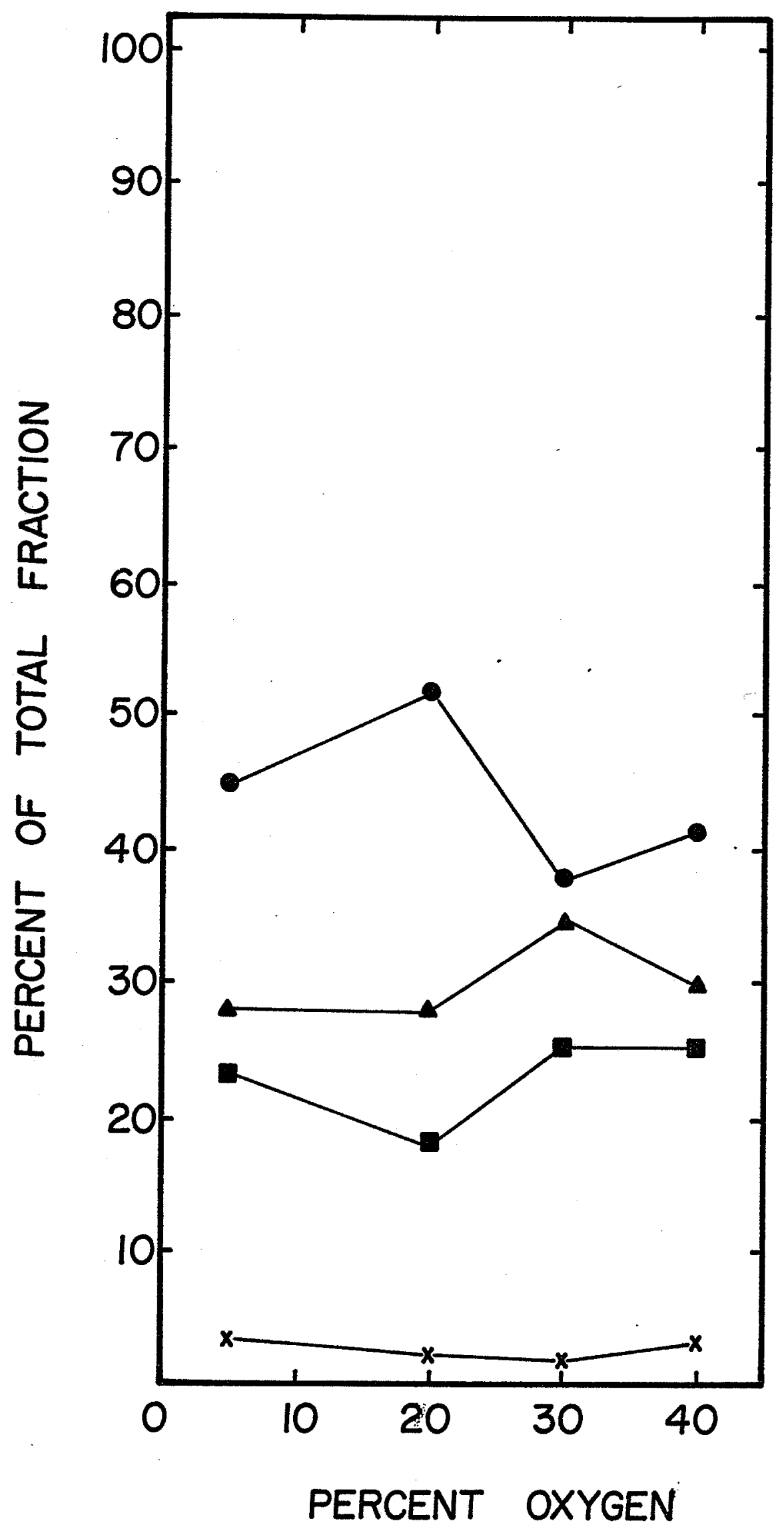


Figure 19. Changes in major constituents of total lipid extract obtained from A. chroococcum during growth under different oxygen tensions. Lipid was extracted and methy 1 esters were formed as described in "Methods".

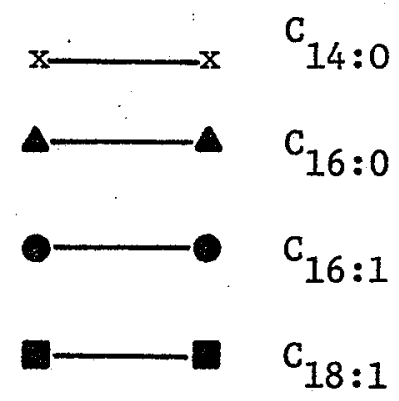




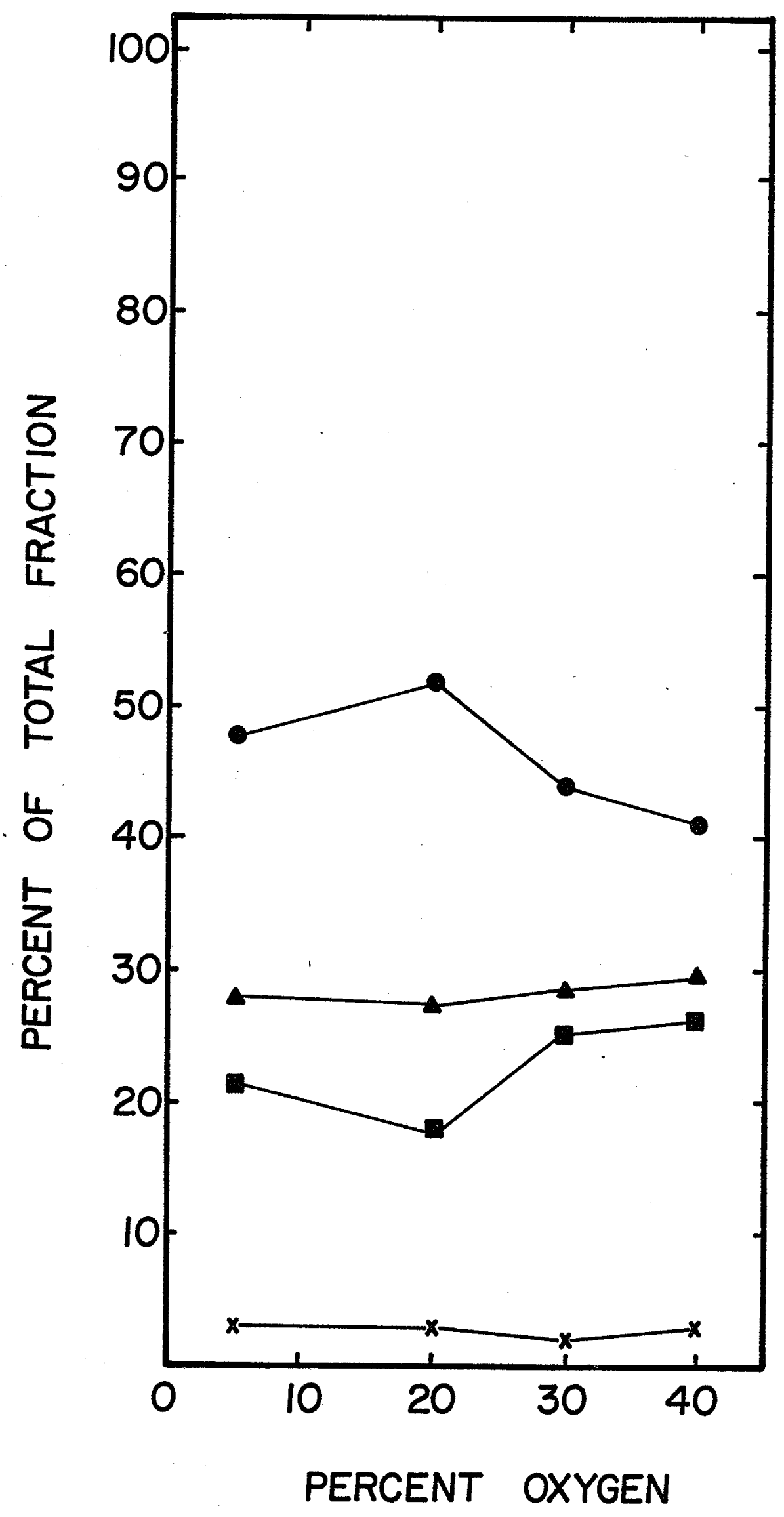


Incorporation of $1-{ }^{14} \mathrm{C}$-Acetate into Lipid by $\mathrm{A}$. chroococcum During Growth Under Different Oxygen Tensions

It would be desirable, not only to undertake investigation of the types of lipid present in $\underline{A}$. chroococcum under varying oxygen tensions, but also to compare the turnover rates at these oxygen tensions. Figure 20 shows the incorporation of ${ }^{14} \mathrm{C}$-acetate into $\underline{A}$. chroococcum lipid after addition to the growth medium. Details of the experiment are given in "Methods" section. In spite of the fact that exactly the same amount of label was added to both those cultures growing at $20 \% \mathrm{O}_{2}$ and those growing at $40 \% \mathrm{O}_{2}$, more label was finally incorporated into the lipid of cells grown under $20 \%$ oxygen. Moreover, the initial rate at which acetate was incorporated into lipid was higher for cells grown under the lower oxygen tension, indicating a higher rate of 1ipid turnover at these oxygen tensions.

In order to determine if labelled acetate was incorporated into a specific lipid component within each of the three major 1ipid classes, and if so what this component was, total lipid extracted from A. chroococcum was subjected to silicic acid column chromatography as described in "Methods". Results may be seen in Figures 21 and 22. During growth at both oxygen tensions, the greatest amounts of label were initially incorporated into the neutral lipid fraction. Between one and three minutes, the amount of label in the phospholipid fractions then rose, reaching a maximum value at six minutes. From three to six minutes, the amount of label in the neutral lipid fraction fell. 
Figure 20. Uptake of $\mathrm{U}^{14} \mathrm{C}$-acetate into total lipid

fraction of $A$. chroococcum grown under varying oxygen tensions. Cells were incubated with $\mathrm{U}-{ }^{14} \mathrm{C}$-acetate (sp. act. $5.80 \mu \mathrm{Ci} / \mu \mathrm{mole}$ ) and at regular intervals, samples were removed. Details of the experiment were given in the "Methọs" section.

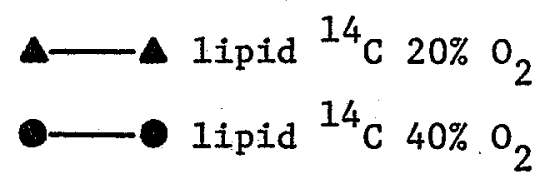




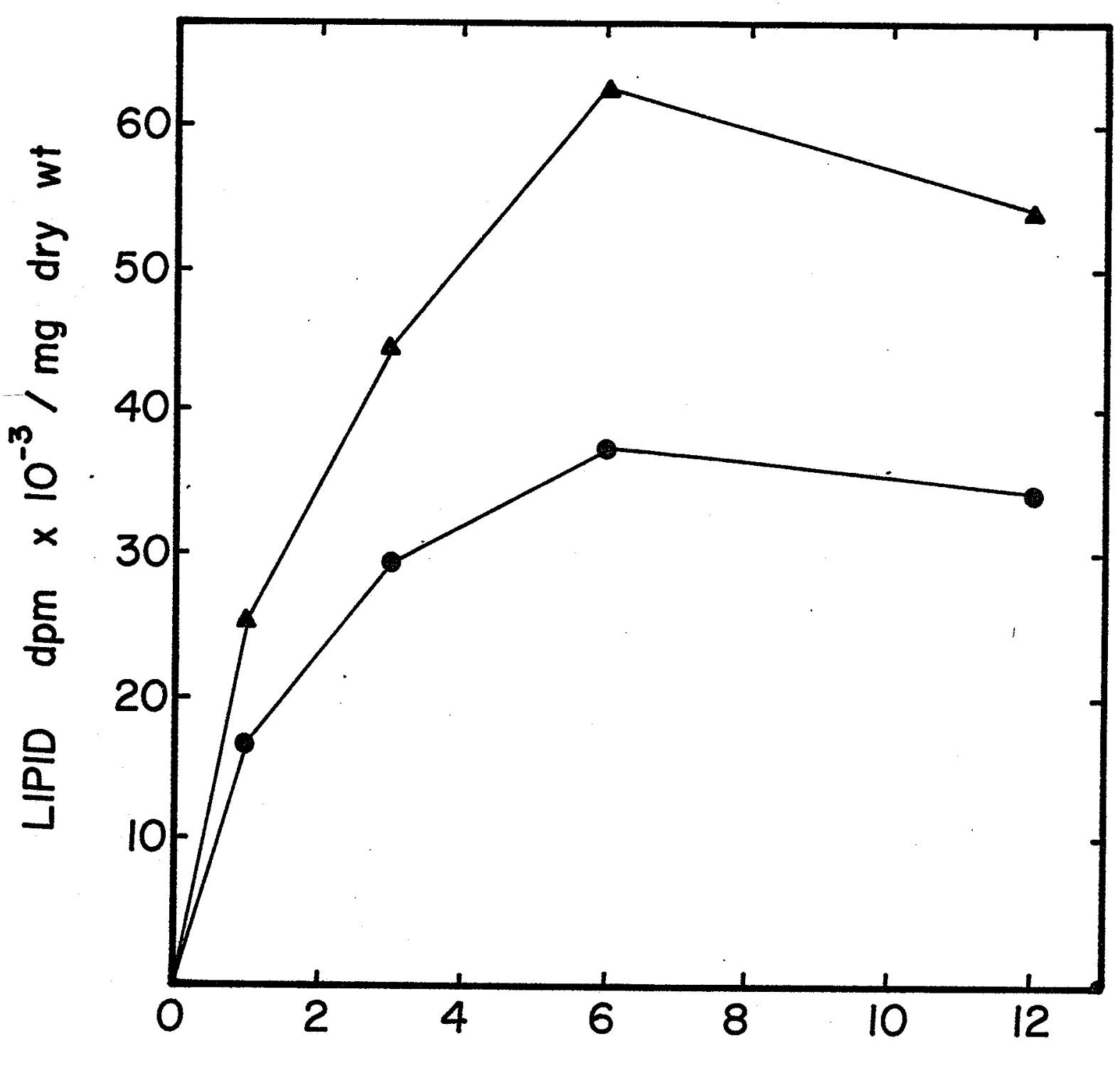

TIME (min) 
Figure 21. Uptake of $\mathrm{U}-{ }^{14} \mathrm{C}$-acetate into individual

lipid classes of $A$. chroococcum during growth under $20 \% \mathrm{O}_{2}$. Details of the experiment were given in the "Methods" section.

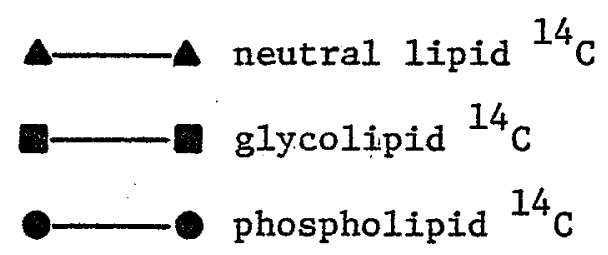




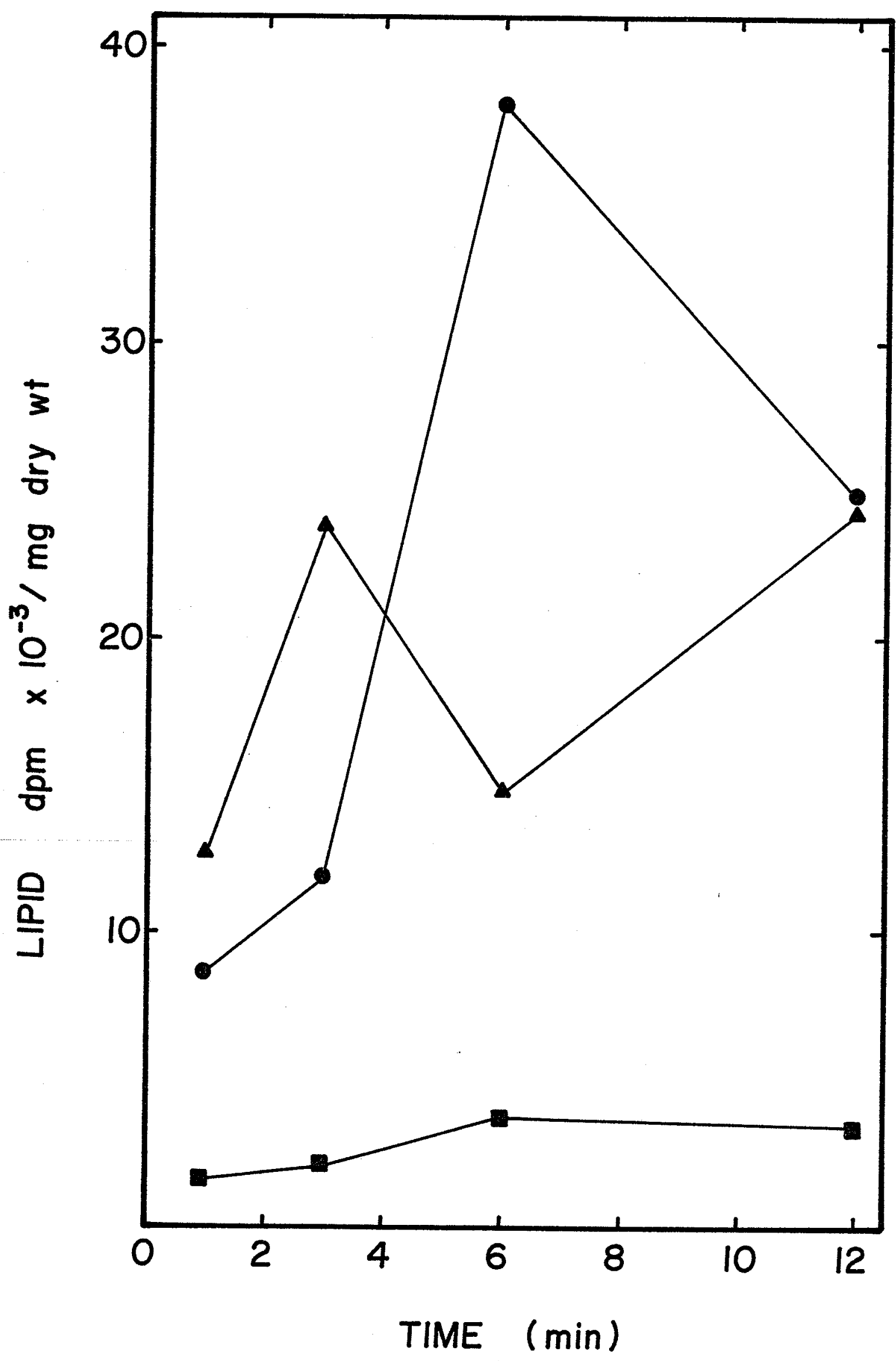


Figure 22. Uptake of $\mathrm{U}^{14} \mathrm{C}$-acetate into individual lipid classes of $\underline{A}$. chroococcum during growth under $40 \% \mathrm{O}_{2}$. Details of the experiment were given in the "Methods" section.

$$
\begin{aligned}
& \Delta \longrightarrow \Delta \text { neutral Iipid }{ }^{14} \mathrm{C} \\
& \square-\square \text { glycolipid }{ }^{14} \mathrm{C} \\
& 0 \longrightarrow 0 \text { phospholipid }{ }^{14} \mathrm{C}
\end{aligned}
$$




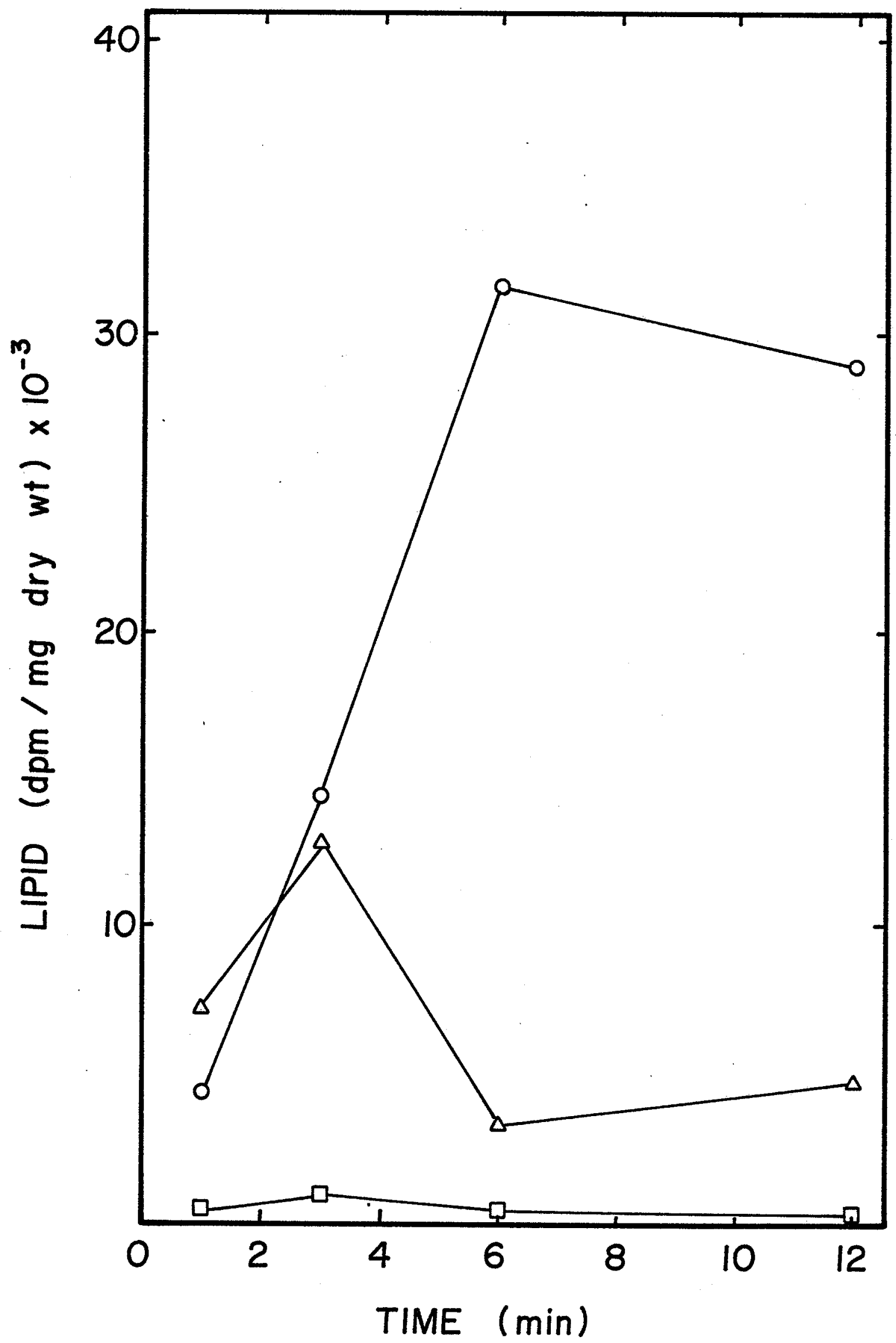


Following the six minute time point, the amount of label in the phospholipid fractions fell while an increase occurred in the neutral

lipid fractions. At both oxygen tensions, throughout the course of the investigations, the levels of label incorporated into the glycolipid fractions remained small and did not change appreciably. 
DISCUSSION 
DISCUSSION

Study of the membrane 1ipids of Azotobacter is of interest for two reasons. Firstly, membrane composition has been examined in relation to early events in encystment. The addition of the inducer for encystment $\beta$-hydroxybutyrate (BHB) to cultures of Azotobacter causes an immediate reduction in nitrogen fixation (total loss occurs within 1 hour after addition) (Sadoff, 1975). Because nitrogen-fixation occurs via a membrane-bound complex, membrane modifications were studied as related to events during encystment.

The formation of membrane vesicles during the growth of Azotobacter has been outlined by previous authors (Oppenheim and Marcus, 1970, Pate et a1., 1973, Hill et al., 1972). Confusion exists as to the conditions necessary for the existence of the vesicles and as to whether or not they are concerned with nitrogen fixation. Recently Dawson (1977) has outlined the effects of various oxygen tensions and ammonium ion concentrations upon the ultrastructure of $\underline{A}$. chroococcum grown under vortex conditions. The number of vesicles and the regularity of their spacing changed in response to the concentration of oxygen that the nitrogen-fixing cells were exposed to. These changes in ultrastructure also made it of interest to undertake a study of membrane Iipids of Azotobacter. 
Drozd, Tubb and Postgate (1972) attributed a $70 \%$ increase in phospholipid under $\mathrm{N}_{2}$-fixing conditions found earlier (Hill et al., 1972) to experimental error. Marcus and Kaneshiro (1972) reported a 30\% increase in phospholipid and an $80 \%$ reduction and a $50 \%$ reduction in neutral lipid and anionic phospholipid (phosphatidylglycerol) respectively with the induction of an internal membranous network during $\mathrm{N}_{2}$-fixing conditions. Our data demonstrate an appreciable difference in both phospholipid and neutral lipid contents over a range of oxygen tensions. Phospholipid was seen to increase slightly until $20 \%$ oxygen was reached; thereafter the amount of phospholipid decreased as oxygen tension was raised. Neutral lipid behaved in an exactly opposite manner it decreased from $5 \%$ to $20 \%$ oxygen, then increased as oxygen tension was raised to $40 \%$. Reductions in phospholipid were almost exactly equal in value to increases in neutral lipid and glycolipid. Marcus and Kaneshiro (1972) observed that cells grown in the presence of fixed nitrogen contained more neutral lipid than cells grown in air $\left(\mathrm{N}_{2}-\right.$ fixing conditions). It was pointed out by Dawson (1977) that cells grown at such concentrations of $\mathrm{NH}_{4}^{+}$(approximately $38 \mathrm{mM}$ ) are not "normal" and exhibit varied morphology. However, differences in methods of growth and growth conditions such as aeration make meaningful comparisons difficult.

A lack of agreement exists between the cell yield data we obtained and that obtained by Hine and Lees (1976). This may be accounted for by the fact that while our cell yield is expressed as wet weight of 
cells, that of Hine and Lees (1976) represents a dry weight measurement of biomass. Another factor to be considred is the fact that we chose to remove the layer of polysaccharide and cell debris which remained above the pellet obtained after harvesting and washing the collected cells. Further, Dalton and Postgate (1969 b) found that alteration of the concentration of any soluble component of the medium, or changes in the detectable amounts of dissolved oxygen between the limits of 15 to $30 \mu \mathrm{M}$ did not influence the biomass produced.

The present work shows that some changes in lipid composition during changes in oxygen tension do occur. Yet, overal1, the amount of lipid in a given dry weight of cells and the amounts of the different components of each of the neutral lipid and phospholipid fractions all remain quite constant. The average value for total lipid of $8.9 \%$ of the cell weight is quite close to that quoted by Sadoff (1975) for A. vinelandii $(9.2 \%)$ even though our value was obtained by nitrogen drying while other published values were obtained by drying under vacuum over $\mathrm{CaSO}_{4}$. This 1atter method has been shown to give rather widely fluctuating values, whereas nitrogen drying gave highly reproducible results (Heefner and Claus, 1976). The lack of increase in cellular lipid suggests that the lipid found in the increasingly greater numbers of vesicles present as the oxygen tension is raised, comes from lipid already present in the cell or alternately that the newly formed membranes contain an amount of the total cellular lipid which is negligibly small and cannot be measured by techniques used here. 
The development of intracytoplasmic membranes in gram-negative cells and their effect on the amount of cellular lipid has been the subject of a few recent studies. Steiner et al. (1970) showed there was no increase in extractable lipid from a strain of Chromatium after development of chromatophores and they suggested that it was the phospholipids of the membrane which may undergo reorganization upon exposure of the cells to high intensity light. Heefner and Claus (1976) found increased amounts of "free lipid" occurred upon the formation of intracytoplasmic membranes of Gluconobacter oxydans.

When separated on thin-layer plates, neutral lipid fractions yielded 3 major spots (possibly 4 had better resolution of the spot nearest the origin been obtained). Marcus and Kaneshiro (1972) obtained 4 spots upon the applicaton of their "neutral fractions" to silica gel G thin layer plates. However, the solvent which they used for separation (1ight petroleum-methanol-water, 70/30/10, v/v) was much more polar than the general lipid class separation solvent mixture used in this work, making comparisons difficult. Migration of the uppermost two pigmented spots corresponded closely to that of a reference coenzyme. $Q$ isolated from Azotobacter (Marcus and Kaneshiro, 1972). Spectral analysis and other tests performed on our unknown lying below the free fatty acid spot, indicate it is not related to coenzyme $Q$ as the unknown does not exhibit a peak at $275 \mathrm{~nm}$ which may be reduced with $\mathrm{NaBH}_{4} \cdot$ Marcus and Kaneshiro (1972) found phosphatidylserine, phosphatidylglycerol and cardiolipin, in addition to phosphatidylethanolamine, to be present in the polar lipid fractions obtained from A. vinelandii 
grown in air. Sadoff (1975) found phosphatidylethanolamine to represent $70 \%$ of the membrane phospholipid, phosphatidylglycerol, $21 \%$ and diphosphatidylglycero1, 6\%. The phospholipid fraction isolated from A. chroococcum consisted entirely of phosphatidylethanolamine. The results of these studies clearly indicate that a drop in the amount of phospholipid and an increase in the amount of neutral lipid contained in the total lipid both occurred at oxygen tensions greater than $20 \% \mathrm{O}_{2}$. Hine and Lees (1976) noted that the respiratory index of a culture of $\underline{A}$. chroococcum levels off at about 0.11 when the gas phase is $20 \% \mathrm{O}_{2}$. At oxygen tensions higher than $20 \% \mathrm{O}_{2}$, the respiratory index increases dramatically. It may be significant that the oxygen tension at which the membrane composition begins to change markedly should correspond to the oxygen tension at which the respiratory index also begins to change markedly. In the presence of $\mathrm{NH}_{4}^{+}$, the amount of oxygen used to supply the energy for nitrogen fixation would decrease or be eliminated (since the need for nitrogen fixation would be reduced or eliminated) and the amount of oxygen wasted to keep the interior of the cell free from oxygen and its reduction products $\left(\mathrm{O}_{2}^{-}, \mathrm{H}_{2} \mathrm{O}_{2}\right)$ would of necessity increase (Dawson, 1977). Thus, cultures supplied with increasing amounts of ammonia would be expected to become sensitive to oxygen at increasingly lower oxygen tensions once the amount of oxygen wasted reached a maximum value. The rapid increase in respiratory index would be expected to occur at lower oxygen tensions in cultures subjected to increasingly higher concentrations of ammonia. It would therefore be of interest to 
determine the effect of addition of increasing amounts of $\mathrm{NH}_{4}^{+}$ on the composition of the total Iipid of $\underline{A}$. chroococcum i.e.

whether the change in the relative amounts of phospholipid and neutral lipid would occur at an oxygen tension lower than $20 \% \mathrm{O}_{2}$ as was demonstrated in this study.

It was also of interest to investigate the fatty acid contents of the various fractions obtained from cells grown under different oxygen tensions. Major fatty.acids detected were $C_{14: 0}, C_{16: 1}$ and $C_{18: 1}$. Sadoff et al. (1975) state that these are the normal fatty acids of the vegetative cell state. However Marcus and Kaneshiro (1972) detected significant amounts of $\mathrm{C}_{18: 0}$ in the fatty acids of the neutral lipid fraction obtained from cells grown in air. In $\underline{A}$. chroococcum, as the oxygen tension was raised, a reduction was seen in the amount of $\mathrm{C}_{16: 1}$ which was coupled to an increase in the amount of the longer chain unsaturate $C_{18: 1}$ in all four fractions (although most notably in the free fatty acid fraction) and to a small increase in the amount of the shorter chain saturate $C_{16: 0}$ in the neutral lipid minus free fatty acid, phospholipid and total 1ipid fractions. Such changes in the relative amounts of $C_{16: 1}$ and $C_{18: 1}$ may be important in the regulation of membrane fluidity which may ultimately serve to regulate transport of metabolites or of oxygen into the cell.

No unique fatty acids are present in the membranes of the vegetative cells. Within 6 hours after the induction of encystment, Azotobacter membranes contain $\mathrm{C}_{17}$ and $\mathrm{C}_{19}$ cyclopropane fatty acids which are formed at the expense of $C_{16: 1}$ and $C_{18: 1}$ (Sadoff, 1975). However, the presence of a relatively stable set of membrane fatty acids under varying oxygen tensions may only serve as evidence for astable membrane condition 
being needed to ensure the maintenance of a functioning nitrogenase. A modification of the condition of the membrane may lead to a change in the "conformational protection" of the nitrogenase leading to exposure of oxygen sensitive sites which are now able to interact with oxygen. This would lead to the inactivation of the enzyme-precisely what is seen with the onset of encystment.

Labelled acetate is seen to be incorporated to a greater extent and at a greater initial rate, into lipid of cells grown at $20 \%$ oxygen then when grown at $40 \% \mathrm{O}_{2}$. Incorporation is initially greatest into the neutral lipid fraction, especially that of cells grown at $20 \%$ oxygen. This may indicate the existence of a precursor-product relationship between the neutral lipid and phospholipid fractions. Presumably it is the free fatty acids which contain most of the label initially seen in the neutral lipid fraction. Within six minutes, the majority of the label became incorporated into the phospholipid fraction, indicating the formation of phospholipid containing fatty acids derived from the neutral lipid fraction. These phosopholipids are probably broken down to their constituent fatty acids as indicated by the loss of label from the phospholipid fraction and the increase in the amount of label present in the neutral lipid fraction. Such a "turnover" of fatty acids bound to the lipids of the membrane would make possible the rapid regulation of membrane fluidity by the substitution of $\mathrm{C}_{16: 1}$ fatty acids by $\mathrm{C}_{18: 1}$ fatty acids as oxygen tension is increased. While these experiments do not indicate the rate of turnover of lipids, 
they quite clearly show the rates of uptake of labelled acetate are different in cells grown at different oxygen tensions. Whether uptake is limited by hindered passage of acetate into the cell or by a low rate of incorporation into lipid is not clear.

The stability of the membrane lipid composition of $\mathrm{A}$. chroococcum during changes in oxygen tension can be seen from the results of this investigation. The membrane of Azotobacter during nitrogen fixation may represent a single functional state necessary for efficient operation of membrane-bound nitrogenase enzyme. Deviation from this state results in the cessation of nitrogen fixation as during the onset of encystment, possibly through the loss of "conformational protection" provided for the nitrogenase. The changes in the proportions of $\mathrm{C}_{16: 1}$ and $\mathrm{C}_{18: 1}$ mentioned above, could reflect changes in membrane properties necessary to maintain conformational protection as $\mathrm{O}_{2}$ tension changes. A great deal of energy must be expended by the cell for the formation and organization of these membranes which would probably not be carried out if it did not ultimately serve some purpose in the cell. It seems reasonable that these membranes serve to protect the cell and the nitrogenase enzyme from oxygen.

It has been shown that a correlation exists between the intracellular accumulation of guanosine tetraphosphate (ppGpp) and the inhibition of phospholipid synthesis in E. coli (Merlie and Pizer, 1973). The requirements for the synthesis of ppGpp in E. coli have been shown (Haseltine and Block, 1973 and Pederson, et al., 1973). Nunn and Cronan (1976) demonstrated a quantitative relationship between the intracellular. 
levels of ppGpp and the rate of membrane phospholipid synthesis in E. coli. Guanosine tetraphosphate inhibits two enzymes specifically in the phospholipid biosynthesis pathway in E. coli, namely glycerol-3phosphate acyltransferase and glycerol-3-phosphate phosphatidy1 transferase (Merlie and Pizer, 1973). It was felt that the increase in ppGpp levels which might have occurred in $\underline{A}$. chroococcum as judged by the decrease in the quantity of phospholipids present as oxygen tension was raised from $5 \%$ to $40 \%$, would not be sufficient to warrant investigation at this time. However, a difference in the levels of phospholipid and therefore presumably in the levels of ppGpp also, may exist when cells of A. chroococcum are grown in media containing fixed nitrogen as ammonium ion. This is another area where future studies may prove interesting. 
REFERENCES 


\section{REFERENCES}

AckrelI, B.A.C. and C.W. Jones. 1971 a. The respiratory system of Azotobacter vinelandii. 1. Properties of the phosphorylating respiratory enzymes. Eur. J. Biochem. 201:22-28.

Ackre11, B.A.C. and C.W. Jones. 1971 b. The respiratory system of Azotobacter vinelandii. 2. Oxygen effects. Eur. J. Biochem. $\underline{20}: 29-35$.

Aeration and agitation. In: Biochemical Engineering, Ed. S. Aiba, A.E. Humphrey and N.F. Mills. Academic Press, New York, 1973.

Baker, K. 1968. Low cost continuous culture apparatus. Lab. Pract. $17: 817-824$.

Bangham, A.D. 1972. Lipid bilayers and biomembranes. Ann. Rev. Biochem. $41: 753-766$.

Bayer, M.E. and C.C. Remsen. 1970. Structure of Escherichia coli after freeze-etching. J. Bact. 101:304-313.

Bergey's manual of determinative bacteriology. 1974. 8 Ed., Williams and Wilkins Co.

Birchmeier, W., C.E. Kohler and G. Schatz. 1976. Interaction of integral and peripheral membrane proteins: affinity labelling of yeast cytochrome oxidase by modified yeast cytochrome C. Proc. Nat. Acad. Sci. U.S.A. 23:4334-4338. 
Bligh, E.G. and W.J. Dyer. 1959. A rapid method of total lipid extraction and purification. Can. J. Biochem. Physiol. 37: $911-917$.

Bui, P.T. and L.E. Mortenson. 1968. Mechanism of the enzymic reduction of $\mathrm{N}_{2}$ : the binding of adenosine $5^{\prime}$ triphosphate and cyanide to the $\mathrm{N}_{2}$-reducing system. Proc. Nat. Acad. Sci. U.S.A. 61:1021-1027.

Bui, P.T. and L.E. Mortenson. 1969. The hydrolysis of adenosine triphosphate by purified components of nitrogenase. Biochemistry. $\underline{8}: 2462-2465$.

Bulen, W.A. and J.R. LeComte. Nitrogenase complex and its components. In: Methods in enzymology. Ed. A. San Pietro. 24:456-470. Academic Press, New York.

Bulen, W.A., R.C. Burns and J.R. LeComte. 1964. Nitrogen Fixation: cell free system with extracts of Azotobacter. Biochim. Biophys. Res. Comm. 17:265-271.

Bulen, W.A. and J.R. LeComte. 1966. The nitrogenase system from Azotobacter: two enzyme requirement for $\mathrm{N}_{2}$ reduction, ATPdependent $\mathrm{H}_{2}$ evolution and ATP hydrylysis. Proc. Nat. Acad. Sci. U.S.A. 56:979-986. 
Burns, R.C., R.D. Holsten and R.W.F. Hardy. 1970. Isolation by crystallization of the Mo-Fe protein of Azotobacter nitrogenase. Biochem. Biophys. Res. Comm. 39:90-99.

Carnahan, J.E., L.E. Mortenson, H.F. Mower and J.E. Castle. 1960. Nitrogen fixation in cell-free extracts of Clostridium pasteurianum. Biochim. Biophys. Acta. 44:520-535.

Carro11, K.K. 1961. Quantitative estimation of peak areas in gas1iquid chromatography. Nature. 191:377-378.

Chen, J.S., J.S. Multani and L.E. Mortenson. 1973. Structural investigation of nitrogenase components from Clostridium pasteurianum and comparison with similar components of other organisms. Biochim. Biophys. Acta. 310:51-59.

Cook, G.M.W. 1971. Membrane structure and function. Ann. Rev. Plant. Phys. 22:

Cronan, J.E. Jr. and P.R. Vagelos. 1972. Metabolism and function of the membrane phospholipids of Escherichia coli. Biochim. Biophys. Acta. 265:25-60.

Cronan, J.E. and E.P. Gelman. 1975. Physical properties of membrane lipids: biological relevance and regulation. Bact. Rev. $\underline{39}$ : 232-256. 
Dalton, H. and J.R. Postgate. 1969 a. Effect of oxygen on growth of Azotobacter chroococcum in batch and continuous culture. J. Gen. Microbiol. 54:463-473.

Dalton, H. and J.R. Postgate. 1969 b. Growth and physiology of Azotobacter chroococcum in continuous culture. J. Gen Microbiol. 56:307-319.

Dalton, H. and L.E. Mortenson. 1972. Dinitrogen $\left(\mathrm{N}_{2}\right)$ fixation (with a biochemical emphasis). Bacteriol. Rev. 36:231-260.

Danielli, J.F. and H. Davson. 1935. A contribution to the theory of permeability of thin films. J. Cell. Comp. Phys. $\underline{5}, 495-508$.

Dawson, D. 1977. M.Sc. Thesis. University of Manitoba.

Dillworth, M.J. 1966. Acetylene reduction by nitrogen-fixing preparations from Clostridium pasteurianum. Biochim. Biophys. Acta. 127: 285-294.

Dittmer, J.C. and M.A. Wells. 1969. Quantitative and qualitative analysis of lipids and lipid components. In: Methods in enzymology. Ed. J.M. Lowenstein. 14:482-530. Academic Press, New York.

Drozd, J. and J.R. Postgate. 1970. Effects of oxygen on acetylene reduction, cytochrome content and respiratory activity of Azotobacter chroococcum. J. Gen. Microbiol. 63:63-73. 
Drozd, J.W., R.S. Tubb and J.R. Postgate. 1972. A chemostat study of the effect of fixed nitrogen sources on nitrogen fixation, membranes and free amino acids in Azotobacter chroococcum. J. Gen. Microbiol. 73:221-232.

Eady, R.R., K.A. Smith, K.A. Cook and J.R. Postgate. 1972. Nitrogen of Klebsiella pneumoniae. Purification and Properties of the component proteins. Biochem. J. 128:655-675.

Eady, R.R. and J.R. Postgate. 1974. Nitrogenase. Nature 249:805-810.

Eytan, G.D., M.J. Matheson and E. Racker. 1976. Incorporation of mitochondrial membrane proteins into liposomes containing acidic phospholipids. J. Biol. Chem. 251:6831-6837.

Fales, H.M., T.M. Jaomi and J.R. Bahashak. 1973. Simple device for preparing ethereal diazomethane without resorting to codistillation. Analy. \&: Chem. 45:2302-2303.

Finean, J.B. 1972. The development of ideas on membrane structure. Sub-Ce11. Biochem. 1:363-373.

Gel'man, N.S., M.A. Lukoyanova and D.N. Ostrovskii. 1975. Bacterial membranes and the respiratory chain. In: Biomembranes. Ed. L.A. Manson. vol. 6. Ch. 4. Plenum Press, New York.

Gorter, E. and F. Grendel. 1925. Bimolecular layers of lipids on chromatocytes of blood. J. Exper. Med. 41:439-443.

Gulik-Krzywicki, T. 1975. Structural studies of the associations between biological membrane components. Biochim. Biophys. Acta. 415: 1-28. 
Gumaa, K.A., P. McLean and A.L. Greenbaum. 1971. Compartmentation in relation to metabolic control in liver. In: Essays in Biochemistry. Ed. P.N. Campbe11 and F. Dickens. Vol. 7. p. 39-86. Academic Press, London.

Hadfie1d, K.L. and W.A. Bulen (1969). Adenosine triphosphate requirement of nitrogenase from Azotobacter vinelandii. Biochemistry. $\underline{8}: 5103-5108$.

Hardy, R.W.F. and E. Knight. 1966. Reductant-dependent adenosine triphosphatase of nitrogen-fixing extracts of Azotobacter vinelandii. Biochim. Biophys. Acta. 132:520-531.

Hardy, R.W.F. and R.C. Burns. 1968. Biological nitrogen fixation. Ann. Rev. Biochem. 37:331-358.

Hardy, R.W.F., R.C. Burns, J.T. Stasny and G.W. Parsha11. 1975. The nitrogenase reaction. In: Nitrogen fixation by free-living micro-organisms. Ed. W.D.P. Steward. Ch. 24. Cambridge University Press, Cambridge.

Haseltine, W.A. and R. Block. 1973. Synthesis of guanosine tetraand pentaphosphate requires the presence of a codon-specific uncharged transfer ribonucleic acid in the acceptor site of ribosomes. Proc. Nat. Acad. Sci. U.S.A. 70:1564-1568. 
Heefner, D.L. and G.W. Claus. 1976. Change in quantity of lipids and cell size during intracytoplasmic membrane formation in Gluconobacter oxydans. J. Bacteriol. 125:1163-1171.

Herbert, D. 1958. Some principles of continuous culture. In: Recent progress in microbiology. Ed. G. Tuneval1. p 381-396. Stockholm.

Herbert, D., R. Elsworth and R.C. Telling. 1956. The continuous culture of bacteria, a theoretical and experimental study. J. Gen. Microbiol. 14:601-622.

Hi11, S., J.W. Drozd and J.R. Postgate. 1972. Environmental effects on the growth of nitrogen-fixing bacteria. J. Appl. Chem. Biotechno1. 22:541-558.

Hine, P.W. 1975. M.Sc. Thesis. University of Manitoba.

Hine, P.W. and H. Lees. 1976. The growth of nitrogen-fixing Azotobacter chroococcum in continuous culture under intense aeration. Can. J. Microbio1. 22:

Huang, T.C., W.G. Zumft and L.E. Mortenson. 1973. Structure of the molybdoferredoxin complex from Clostridium pasteurianum and isolation of its subunits. J. Bacteriol. 113:884-890.

Jones, C.W., J.M. Brice, V. Wright and B.A.C. Ackre11. 1973. Respiratory protection of nitrogenase in Azotobacter vinelandii. FEBS letters. $29: 77-81$. 
Kates, M. 1972. Techniques of lipidology. Ch. 5. Ed. T.S. Work and E. Work. North-Holland Publishing Co,, Amsterdam, London.

Kleiner, D. and C.H. Chen. 1974. Physical and chemical properties of the ritrogenase proteins from Azotobacter vinelandii. Arch. Microbio1. 98:93-100.

Law, S.W.T. 1975. Ph.D. Thesis. University of Manitoba.

Li, J.K-K. and F. Fox. 1975. Ultrastructural studies on the inner and outer membranes of an unsaturated fatty acid auxotroph of Escherichia coli. J. Ultrastruc. Res. 2: 120-133.

Lin, L.P. and H.L. Sadoff. 1968. Encystment and polymer production by Azotobacter vinelandii in the presence of $\beta$-hydroxybutyrate. J. Bacterio1. 95:2336-2343.

Linden, C.D., K.L. Wright, H.M. McConnell and C.F. Fox. 1973. Lateral phase separations in membrane lipids and the mechanism of sugar transport in Escherichia coli. Proc. Nat. Acad. Sci. U.S.A. $\underline{70}: 2271-2275$.

Marcus, L. and T. Kaneshiro. 1972. Lipid composition of Azotobacter vinelandii in which the internal membrane network is induced or repressed. Biochim. Biophys. Acta. 288:296-303. 
Meyerhoff, O. and D. Burk. 1928. Uber die fixation des luftstickstoffs durch Azotobacter. 2. Physik. Chem. Leipzig. A 139, 117 (cited from Dalton and Postgate, 1969 a)..

Monod, J. 1942. Recherches sur la croissance bacterienne. Masson, Paris. (cited from Tempest, 1970).

Monod, J. 1950. La technique de culture continue; théorie et applications. Ann. Inst. Pastēur. 79:390-410. (cited from Tempest, 1970).

Morrisett, J.D., H.J. Pownall, R.T. Plumlee, L.C. Smith, Z.E. Zehner, M. Esfahani and S.J. Wakil, 1975. Multiple thermotropic phase transitions in Escherichia coli membranes and membrane lipids. J. Biol. Chem. 250:6969-6976.

Muinck, E., H. Rhodes, W.H. Orme-Johnson, L.C. Davis, W.V. Brill and V.K. Shah. 1975. Nitrogenase VIII. Mossbauer and EPR spectroscopy. The Mo-Fe protein component from Azotobacter vinelandii OP. Biochim. Biophys. Acta. 400:32-53.

Nichols, B.W., R.V. Harris and A.T. James. 1965. The 1ipid metabolism of blue-gree algae. Biochim. Biophys. Res. Comm. 20:256-262.

Nunn, W.D. and J.E. Cronan, Jr. 1976. Regulation of membrane phospholipid synthesis by the rel A gene: dependence on ppGpp levels. Biochemistry. 15:2546-2550. 
Oppenheim, J. and L. Marcus. 1970. Correlation of ultrastructure in Azotobacter vinelandii with nitrogen source for growth. J. Bacteriol. 101, 286-291.

Oppenheim, J., R.J. Fisher, P.W. Wilson and L. Marcus. 1970. Properties of a soluble nitrogenase in Azotobacter. J. Bacteriol. 101: 292-296.

Overath, P. and H. Trauble. 1973. Phase transitions in cells, membranes, and lipids of Escherichia coli. Detection by flourescent probes, light scattering and dilatometry. Biochem. 12:2625-2634.

Pangborn, J., A.G. Marr and S.A. Robrish. 1962. Localization of respiratony enzymes in intracytoplasmic membranes of Azotobacter agilis. J. Bacteriol. 84:669-678.

Pate, J., V.K. Shah and W.J. Bri11. 1973. Internal membrane control in Azotobacter vinelandii. J. Bacteriol. 114:1346-1350.

Pederson, F.S., E. Lund and N.O. Kjeldgaad. 1973. Codon specific tRNA dependent in vitro synthesis of ppGpp and PppGpp. Nature. 243: 13-15.

Phillips, D.H. and M.J. Johnson. 1961. Measurement of dissolved oxygen in fermentations. J. Biochem. Microbiol. Technol. Engen. 3: $277-309$. 
Puchwein, G., T. Pfeuffer and E.J.M. Helmreich. 1974. Uncoupling of catecholamine activation of pigeon erythrocyte membrane adenylate cyclase by filipin. J. Biol. Chem. 249:3232-3240.

Quinn, P.J. 1976. The molecular biology of cell membranes. University Park Press, Ltd. Baltimore, Maryland.

Raveed, D., D.W. Reed and R.E. Toia. 1973. Localization of the nitrogenase by antibody binding to membranes from Azotobacter vinelandii. J. Ce11. Biol. 59:292 a.

Razin, S. 1972. Reconstitution of biological membranes. Biochim. Biophys. Acta. 265:241-296.

Reed, D.W., R.E. Toia and D. Raveed. 1974. Purification of azotophore membranes containing the nitrogenase from Azotobacter vinelandii. Biochem. Biophys. Res. Comm. 58:20-25.

Robertson, J.D. 1959. The ultrastructure of cell membranes and their derivatives. Biochem. Soc. Symp. Vol. 16 p. 3-43. Cambridge University Press, London.

Rouser, G., G. Kritchevsky and A. Yamamato. 1967. Lipid chromatographic Analysis. Vol. 1. p.99-162. Dekker Inc., New York.

Sadoff, H.L. 1975. Encystment and germination in Azotobacter vinelandii. Bacteriol. Rev.. 39:516-539. 
Sadoff, H.L., W.V. Page and R.N. Reusch. 1975. The cyst of Azotobacter vinelandii: comparative view of morphogenesis. In: Spores VI. Ed. P. Gerhardt, R.N. Costilow and H.L. Sadoff. P. 52-60. American Society for Microbiology, Washington, D.C.

Salton, M.R.J. and P. Owen. 1976. Bacterial membrane structure. Ann. Rev. Microbio1. 30:451-482.

Schmidt-Lorenz, W. and A. Rippel-Baldes. 1957. Wirkung des sauerstoff-partialdrucks auf wachstum: und stickstoff bindung von Azotobacter chroococcum. Beijj. Arch. Microbiol. 28:45 (cited from Dalton and Mortenson, 1972.

Schollhorn, R. and R.H. Burris. 1967. Acetylene as a competitive inhibitor of $\mathrm{N}_{2}$ fixation. Proc. Nat. Acad. Sci. U.S.A. 58:213-216.

Segrest, J.P., T. Gulik-Krzywicki and C. Sardet. 1974. Association of the membrane-penetrating polypeptide segment of the human erythrocyte MN-glycoprotein with phospholipid bilayers. I. Formation of the freeze-etch intramembranous particles. Proc. Nat. Acad. Sci. U.S.A. 71:3294-3298.

Seto, B. and L.E. Mortenson. 1973. Effect of carbamyl phosphate on the regulation of nitrogenase in clostridium pasteurianum. Biochim. Biophys. Res. Comm. 53:419-423. 
Seto, B.L. and L.E. Mortenson. 1974. Mechanism of carbamyl phosphate inhibition of nitrogenase of Clostridium pasteurianum. J. Bacteriol. 117:805-812.

Shah, V.K., L.C. Davis and W.J. Bril1. 1972. Nitrogenase I. Repression and depression of the iron-molybdenum and iron proteins of nitrogenase in Azotobacter vinelandii. Biochim. Biophys. Acta. 256:498-511.

Shah, V.K. and W.J. Brill. 1973. Nitrogenase IV. Simple method of purification to homogeneity of nitrogenase components from Azotobacter vinelandii. Biochim. Biophys. Acta. 305:445-454.

Shah, V.K. J.L. Pate and W.J. Brill. 1973. Protection of nitrogenase in Azotobacter vinelandii. J. Bacteriol. 115:15-17.

Shimshick, E.J. and H.M. McConne11. 1973. Lateral phase separations in binary mixtures of cholesterol and phospholipids. Biochem. Biophys. Res. Comm. 53:446-451.

Singer, S.J. 1971. The molecular organization of biological membranes. In: Structure and function of biological membranes. Ed. L.J. Rothfield. Academic Press, New York.

Singer, S.J. 1974. The molecular organization of membranes. Ann. Rev. Biochem. 43:805-833.

Singer, S.V. and G.I. Nicolson. 1972. The fluid mosaic model of the structure of cell membranes. Science 175:720-731. 
Skipsky, V.P. and M. Barclay. 1969. Thin Layer Chromatography of Lipids. In: Methods in enzymology. Ed. J.M. Lowenstein. 14:530-598. Academic Press, New York.

Strandberg, G.W. and P.W. Wilson. 1968. Formation of the nitrogenfixing enzyme system in Azotobacter vinelandii. Can. J. Microbiol. $14: 25-31$

Stasny, J.T., R.C. Burns, and R.W.F. Hardy. 1973. The immuno-electron microscopic localization of the Mo-Fe protein component of nitrogenase in cells of Azotobacter vinelandii. In: 31st Ann. Proc. Electron - Microsc. Soc. Amer. Ed. C.J. Arceneaus. New Orleans, La.

Streicher, S.L., R.A. Bender and B. Magasanik. 1975. Genetic contro1 of glutamine synthetase in Klebsiella aerogenes. J. Bacteriol. 121:320-331.

Steiner, S., J.C. Burnham, S.F. Conti and R.L. Lester. 1970. Polar lipids of Chromatium strain D grown at different light intensities. J. Bacteriol. 103:500-503.

Tempest, D.W. 1970. The continuous cultivation of micro-organisms. I. Theory of the chemostat. In: Methods in microbiology. Ed. J.R. Norris and D.W. Ribbons. 2:259-276. Academic Press, London and New York. 
Torres-Pereira, J., R. Melhorn, A.D. Keith and L. Packer. 1974. Changes in membrane lipid structure of illuminated chloroplasts studies with spin-labelled and freeze-fractured membranes. Arch. Biochem. Biophys. 160:90-99.

Tschapek, M. and N. Grambiagi. 1955. Nitrogen fixation of Azotobacter in soil - its inhibition by oxygen. Arch. Mikrobio1. 21:376-390.

Tsim, A.C-H. 1976. M.Sc. Thesis. University of Manitoba.

Tso, M.Y.W. 1974. Some properties of the nitrogenase proteins from Clostridium pasteurianum, molecular weight, subunit structure, isolelectric point and EPR spectra. Arch Microbio1. 99:71-80.

Tso, M.Y.W. and R.H. Burris. 1973. The binding of ATP and ADP by nitrogenase components from Clostridium pasteurianum. Biochim. Biophys. Acta. 309:263-270.

Tubb, R.S. 1974. Glutamine synthetase and ammonium regulation of nitrogenase synthesis in Klebsiella. Nature. 251:481-485.

Tubb, R.S. and J.R. Postgate. 1973. Control of nitrogenase synthesis in Klebsiella pneumoniae. J. Gen. Microbio1. 79:103-117.

Tyrrell, D.A., T.D. Heath, C.M. Colley and B.E. Ryman. 1976. New aspects of 1iposomes. Biochim. Biophys. Acta. 457:259-302. 
Vail, W.V., D. Papahadjopoulos and M.A. Moscarello. 1974. Interaction of a hydrophobic protein with liposomes - evidence for particles seen in freeze fracture as being proteins. Biochim. Biophys. Acta. $345: 463-467$.

Van Deenen, L.L.M. and G.H. DeHaas. 1964. The synthesis of phosphoglycerides and some biochemical applications. In: Advances in lipid research. Ed. R. Paoletti and D. Kritchevsky. Vo1. 2. p.167-234. Academic Press, New York.

Vandecasteele, J.-P. and R.H. Burris. 1970. Purification and properties of the constituents of the nitrogenase complex from clostridium pasteurianum. J. Bacteriol. 101:794-801.

Watt, G.D. and A. Burns. 1977. Kinetics of dithionite ion utilization and ATP hydrolysis for reactions catalyzed by the nitrogenase complex from Azotobacter vinelandii. Biochemistry. 16:264-270.

Wilson, G., S.P. Rose and C.F. Fox. 1970. The effect of membrane lipid unsaturation of glycoside transport. Biochim. Biophys. Acta. 38: $617-623$.

Wunderlich, F., R. Müller and V. Speth. 1973. Direct evidence for a colchicine-induced impairment in the mobility of membrane components. Science 182:1136-1138. 
Wyss, O., M.G. Neumann and M.D. Sokolofsky. 1961. Development and germination of the Azotobacter cyst. J. Biophys. Biochem. Cyto1. 10: 555-565.

Yates, M.G. 1970. Effect of non-haem iron proteins and cytochrome C from Azotobacter upon the activity and oxygen sensitivity of

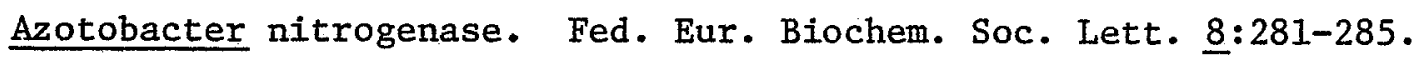

Yates, M.G. and K. Planqué. 1975. Nitrogenase from Azotobacter chroococcum. Eur. J. Biochem. 60:467-476.

Yates, M.G. and R.M. Danie1. 1970. Acetylene reduction with physiological electron donors by extracts and particulate fractions from nitrogen-fixing Azotobacter chroococcum. Biochim. Biophys. Acta. 197:161-169.

Zumft, W.G., G. Palmer and L.E. Mortenson. 1973. Electron paramagnetic resonance studies on nitrogenase. II. Interaction of adenosine $5^{\prime}$-triphosphate with azoferredoxin. Biochim. Biophys. Acta. 292:413-421.

Zumft, W.G. and L.E. Mortenson. 1975. The nitrogen fixing complex of bacteria. Biochim. Biophys. Acta. 416:1-52.

Zumft. W.G., L.E. Mortenson and G. Palmer. 1974. Electron paramagnetic resonance studies on nitrogenase. Investigation of the oxidationreduction behavior of azoferredoxin and molybdoferredoxin with potentiometric and rapid-freeze techniques. Eur. J. Biochem. $46: 525-535$ 